\title{
MODELO HÍBRIDO PARA LA SEGMENTACIÓN DE IMÁGENES CEREBRALES MULTIESPECTRALES DE RESONANCIA MAGNÉTICA
}

\author{
Tesis para obtener el grado de \\ Doctora en Ciencias \\ (Ingenieria Biomédica) \\ que presenta: \\ Raquel Valdés Cristerna
}

Asesora: Dra. Verónica Medina Bañuelos

Sinodales:

Dra. María Elena Algorri

Dr. Ernesto Bribiesca

Dra. Verónica Medina

Dr. Christian Roux

Dra. Patricia Saavedra 
Caminante, son tus huellas el camino y nada más; caminante, no hay camino, Se hace camino al andar. al andar se hace camino, y al volver la vista atrás se ve la senda que nunca se ha de volver a pisar. Caminante no hay camino sino estelas en la mar.

Hay dos modos de conciencia: una es luz, y otra paciencia. una estriba en alumbrar un poquito el hondo mar, otra, en hacer penitencia con caña o red, y esperar el pez, como pescador.

Dime tú: ¿cuál es mejor? ¿conciencia de visionario que mira en el hondo acuario peces vivos, fugitivos que no se pueden pescar, - esa maldita faena de ir arrojando a la arena, muertos los peces del mar?

Antonio Machado Proverbios y Cantares, 1914

\section{A mis padres, con todo mi cariño}




\section{AGRADECIMIENTOS}

A andar por este camino me han ayudado diferentes actores en diversos espacios y momentos de colaboración que deseo reconocer:

Agradezco al Consejo Nacional de Ciencia y Tecnología (CONACyT) por su apoyo financiero. En nuestra Casa Abierta al Tiempo, agradezco a la División de Ciencias Básicas e Ingeniería por apoyarme con una beca para realizar mis estudios de posgrado. Agradezco al Departamento de Ingeniería Eléctrica por su solidaridad en este esfuerzo académico. Agradezco al área de Procesamiento Digital de Señales e Imágenes Biomédicas, por facilitarme los recursos materiales para la elaboración de este trabajo. Agradezco al Laboratorio de Neuroimagenología por mantener el espíritu crítico en nuestro trabajo académico.

Agradezco al Dr. Alfredo Rodríguez, al Dr. Fernando Barrios y al servicio de Resonancia Magnética del Hospital ABC de México por proporcionamos las primeras imágenes cerebrales multiespectrales. Agradezco al Dr. Louis Collins del Instituto Neurológico de Montréal, por proporcionarnos volúmenes de imágenes cerebrales multiespectrales, de acuerdo al protocolo ICBM.

Agradezco también a la Dra. María Elena Algorri Guzmán, al Dr. Ernesto Bribiesca, al Dr. Christian Roux y a la Dra. Patricia Saavedra por la revisión de este documento y sus aportaciones en la discusión de este trabajo de tesis.

Agradezco a mi asesora, Dra. Verónica Medina Bañuelos por todo su apoyo y dirección de tesis. Agradezco al M. en I. Oscar Yáñez Suárez por su apoyo y asesoría a lo largo de este trabajo. De ambos aprecio un tesoro aún mayor, nuestra entrañable amistad.

Mi respeto y profunda gratitud a todos mis profesores por su empeño en compartir su experiencia conmigo.

Agradezco a mi familia por su apoyo y enorme tolerancia a mis largas ausencias. 


\title{
MODELO HIBBRIDO PARA LA SEGMENTACIÓN DE IMÁGENES CEREBRALES MULTIESPECTRALES DE RESONANCIA MAGNÉTICA
}

\author{
Tesis para obtener el grado de \\ Doctora en Ciencias \\ (Ingeniería Biomédica) \\ que presenta: \\ Raquel Valdés Cristerna
}

Asesora: Dra. Verónica Medina Bañuelos

Sinodales:

Dra. María Elena Algorri

Dr. Ernesto Bribiesca

Dra. Verónica Medina

Dr. Christian Roux

Dra. Patricia Saavedra 
Caminante, son tus huellas el camino y nada más; caminante, no hay camino, Se hace camino al andar. al andar se hace camino, y al volver la vista atrás se ve la senda que nunca se ha de volver a piser. Caminante no hay camino sino estelas en la mar.

Hay dos modos de conciencia: una es luz, y otra paciencia. una estriba en alumbrar un poquito el hondo mar; otra, en hacer penitencia con caña o red, y esperar el pez, como pescador. Dime tư: ¿cuál es mejor? ¿conciencia de visionario que mira en el hondo acuario peces vivos, fugitivos que no se pueden pescar, o esa maldita faena de ir arrojando a la arena, muertos los peces del mar?

Antonio Machado Proverbios y Cantares, 1914

\section{A mis padres, con todo mi cariño}




\section{AGRADECIMIENTOS}

A andar por este camino me han ayudado diferentes actores en diversos espacios y momentos de colaboración que deseo reconocer:

Agradezco al Consejo Nacional de Ciencia y Tecnología (CONACyT) por su apoyo financiero. En nuestra Casa Abierta al Tiempo, agradezco a la División de Ciencias Básicas e Ingeniería por apoyarme con una beca para realizar mis estudios de posgrado. Agradezco al Departamento de Ingeniería Eléctrica por su solidaridad en este esfuerzo académico. Agradezco al área de Procesamiento Digital de Señales e Imágenes Biomédicas, por facilitarme los recursos materiales para la elaboración de este trabajo. Agradezco al Laboratorio de Neuroimagenología por mantener el espíritu crítico en nuestro trabajo académico.

Agradezco al Dr. Alfredo Rodríguez, al Dr. Fernando Barrios y al servicio de Resonancia Magnética del Hospital ABC de México por proporcionarnos las primeras imágenes cerebrales multiespectrales. Agradezco al Dr. Louis Collins del Instituto Neurológico de Montréal, por proporcionamos volúmenes de imágenes cerebrales multiespectrales, de acuerdo al protocolo ICBM.

Agradezco también a la Dra. María Elena Algorri Guzmán, al Dr. Ernesto Bribiesca, al Dr. Christian Roux y a la Dra. Patricia Saavedra por la revisión de este documento y sus aportaciones en la discusión de este trabajo de tesis.

Agradezco a mi asesora, Dra. Verónica Medina Bañuelos por todo su apoyo y dirección de tesis. Agradezco al M. en I. Oscar Yáñez Suárez por su apoyo y asesoria a lo largo de este trabajo. De ambos aprecio un tesoro aún mayor, nuestra entrañable amistad.

Mi respeto y profunda gratitud a todos mis profesores por su empeño en compartir su experiencia conmigo.

Agradezco a mi familia por su apoyo y enorme tolerancia a mis largas ausencias. 


\section{Resumen}

La segmentación de imágenes cerebrales, es un procedimiento necesario en aplicaciones médicas tales como, el análisis cuantitativo de la morfologia de estructuras neurológicas para diagnóstico diferencial; o bien para la planeación de neurocinugías; o el estudio de la evolución temporal de un padecimiento o tratamiento específicos; los resultados de la segmentación de imágenes cerebrales también pueden coadyuvar a la generación de atlas neurológicos poblacionales. El estudio clínico de referencia es el de Resonancia Magnética, dada su capacidad para generar imágenes con una alta resolución espacial y la posibilidad de caracterizar diferentes tejidos neurológicos en un espacio multidimensional.

Existen diversas propuestas para resolver el problema de la segmentación de imágenes cerebrales de Resonancia Magnética, tanto en una aproximación de segmentación por regiones como en la segmentación por contomos, sin embargo, aún se considera un problema abierto. Se han propuesto técnicas de segmentación basadas en clasificadores bayesianos o modelos de estimación no paramétrica, que en términos generales presentan problemas de definición en los bordes de las estructuras a segmentar, por otro lado se han propuesto técnicas de segmentación por contornos activos que resaltan por su desempeño en la localización del borde, sin embargo presentan problemas de convergencia. Las propuestas hibridas han arrojado mejores resultados.

En este trabajo de investigación se propuso un modelo híbrido de segmentación de imágenes cerebrales multiespectrales de Resonancia Magnética que acopla, un modelo de clasificación supervisada, basado en una red neuronal con funciones de activación con base radial, con un modelo de contornos activos basado en una interpolación con splines cúbicos.

La hibridación del modelo se planteó en dos momentos, el primero de ellos consistió en que la red neuronal hiciera la función de presegmentador y proporcionara un contorno inicial para el modelo de contornos activos; el segundo momento consistió en integrar en el término de energía del contorno activo un componente de restricción que se deriva directamente de los mapas de probabilidad posterior generados por la red; la combinación de este término de restricción con el término de energía de la imagen, coadyuvan en la convergencia del contorno final hacia el borde deseado, que en este trabajo fue el borde materia gris-materia blanca.

Se probaron diferentes términos de energía derivados de la imagen, entre ellos el promedio de magnitudes de los gradientes para cada banda de intensidad, la magnitud del gradiente sobre la imagen multiespectral y el flujo de vector gradiente. El mejor resultado se obtuvo para un término compuesto por una 
operación no lineal sobre el promedio de magnitudes de gradientes monoespectrales.

Se valoraron dos tipos de acoplamiento entre la Red con Funciones de Base Radial y el modelo de contorno activo. El primero de ellos se denominó acoplamiento estático, debido a que la incorporación de la fuerza de restricción en el término de energía del contorno activo permanece sin cambio a lo largo del proceso de búsqueda del contorno final. En el acoplamiento dinámico se propone un lazo de retroalimentación, que liga la salida del contorno activo en cada iteración, con un ajuste de los parámetros de la red. Se presume que en cada iteración, la búsqueda del contorno deseado mejora, con esta información es posible actualizar los parámetros de la red que influyen en la región limitada por el contorno. Este ajuste a su vez, mejora la calidad del término de restricción que es empleado por el modelo de los contornos activos para realizar la siguiente iteración en la búsqueda del contomo óptimo.

Como parte del pre-procesamiento de las imágenes, se planteó una normalización del espacio de intensidades. Las variaciones en los protocolos de generación de las imágenes multiespectrales, producen imágenes cuya estadística es diferente al conjunto de aquellas empleadas para entrenar la red neuronal, sin embargo, la estructura de la distribución de las clases de tejido de interés se conserva, por lo que se empleó la transformación de Karhunen-Loeve para normalizar los espacios de intensidad.

Para la depuración de la estructura inicial de la red, se empleó un conjunto de imágenes reales provistas por el Hospital ABC. Para las pruebas del modelo híbrido propuesto, se emplearon imágenes cerebrales multiespectrales de RM, provistas por el simulador del Instituto Neurológico de Montréal (INM); el mismo Instituto provee el volumen etiquetado de referencia para validación de algoritmos de segmentación. Finalmente se aplicó el modelo a dos conjuntos de imágenes reales, generados bajo el protocolo ICBM y provistos también por el INM.

Se realizó una comparación de los resultados obtenidos con el modelo propuesto y otros paradigmas de segmentación. De acuerdo al parámetro de evaluación del desempeño usado, el modelo propuesto obtuvo resultados muy favorables.

Como resultado de la pre-segmentación con la red neuronal se obtuvo un Indice de Tanimoto medio de 0.72 , cabe señalar que para otros métodos de segmentación de imágenes cerebrales, este índice representa una mejora entre el $4 \%$ al $6 \%$. El Índice de Tanimoto medio para el modelo híbrido fue de 0.74 .

En conclusión, se confirmó la hipótesis de trabajo referente a que la segmentación de las imágenes de RM, se ve favorecida si se considera información multiespectral en lugar de sólo considerar información monoespectral. Se confirma también la hipótesis de que, el modelo híbrido mejora los resultados que pueden obtener individualmente cada uno de los modelos acoplados. 
Contenido

\section{Presentación}

I Segmentación de Imágenes Cerebrales Multiespectrales de Resonancia Magnética

I.1 Imágenes Cerebrales

I.2 Estudios Clínicos de Imagen Cerebral Multiespectral de Resonancia Magnética

1.2.1 Resonancia Magnética ............................................................. 3

1.2.2 Estudios clínicos .......................................................................... 5

I.3 Segmentación de Imágenes Cerebrales ....................................... 6

I.4 Planteamiento del problema ......................................................... 10

II Modelo Híbrido de Segmentación

II.1 Imágenes Cerebrales Multiespectrales

II.2 Preprocesamiento de los Volúmenes de

Resonancia Magnética

II.2.1 Registro de Imágenes ................................................................. 15

II.2.2 Normalización del Espacio de Intensidades ............................. 17

II.3 Red de Funciones de Base Radial Modificada ......................... 20

II.3.1 Fundamentos ............................................................................. 21

II.3.2 Entrenamiento ...................................................................... 22

II.3.3 Propiedades ............................................................................... 24

II.4 Contornos y superficies activas con splines cúbicos ................ 25

II.5 Acoplamiento RFBRcc-CASC ............................................. 27

II.5.1 Inicialización ............................................................................. 27

II.5.2 Muestreo de Puntos de Control para el Contorno Inicial ......... 28

II.5.3 Acoplamiento Estático ............................................................. 30

II.5.4 Acoplamiento Dinámico .......................................................... 34

II.6 Evaluación de Desempeño ............................................................ 36 


\section{Resultados y Discusión}

III.1 Variaciones del modelo híbrido ..................................................... 40

III.1.1 Registro de Imágenes Reales .................................................. 40

III.1.2 Normalización del Espacio de Intensidades ................................ 42

III.1.3 Red de Funciones de Base Radial Modificada ........................... 43

III.1.4 Análisis del desempeño de la RFBRcc en diferentes condiciones de ruido ........................................................................... 48

III.1.5 Imágenes de Prueba ......................................................................... 49

III.1.6 Contomo Inicial .............................................................................. 51

III.1.7 Contorno Activo basado en Splines Cúbicos ............................. 52

III.1.8 Muestreo de Puntos de Control .................................................. 56

III.1.9 Modelo Híbrido Adaptable ............................................................ 59

III.1.10 Desempeño del Modelo Híbrido de Segmentación de Imágenes con Ruido ..............................................................61

III.1.11 Segmentación de otras estructuras ............................................ 62

III.2 Segmentación de Volúmenes Reales ............................................ 64

III.2.1 Normalización del Espacio de Intensidades ............................... 65

III.3 Comparación con otros métodos ..................................................... 70

III.4 Îndice de Desempeño .............................................................. 71

Conclusiones

Referencias

\section{Índice de Figuras}

Indice de Tablas

Apéndice A. Parámetros del Modelo Híbrido

Apéndice B. Publicaciones 


\section{Presentación}

Una de las principales aplicaciones del procesamiento digital de imágenes (PDI) es el análisis de las mismas, donde se persigue descomponer una imagen en elementos de información básicos, bien identificados o clasificados que permitan hacer aseveraciones sobre el fenómeno completo estudiado que en su todo no proporciona información clara o suficiente. En el caso de imágenes médicas un objetivo particular del PDI es proveer mayor calidad de información al especialista para apoyar al diagnóstico ylo pronóstico de algún padecimiento. La primera fase del análisis de imágenes es precisamente la segmentación, esto es, un proceso que permite dividir a la imagen en regiones homogéneas disjuntas atendiendo a un criterio o propiedad preestablecida. Si este criterio o propiedad es seleccionada sin intervención del experto, el método de segmentación es considerado automático; si alguno o algunos de los parámetros de la segmentación requieren de la experiencia del especialista, se clasifica al método de segmentación como semiautomático o supervisado. Otra clasificación de los métodos de segmentación puede abordarse según la clase de resultado esperado, esto es, si se desea obtener las regiones completas que pertenecen a una clase determinada, o bien, si se desea obtener sólo las fronteras entre clases específicas.

En particular la segmentación de imágenes cerebrales, es un procedimiento necesario en aplicaciones médicas tales como, el análisis cuantitativo de la morfología de estructuras neurológicas para diagnóstico diferencial; o bien para la planeación de neurocirugías; o el estudio de la evolución temporal de un padecimiento o tratamiento especificos; los resultados de la segmentación de imágenes cerebrales también pueden coadyuvar a la generación de atlas neurológicos poblacionales.

El estudio de imagen de referencia en la clínica es el de Resonancia Magnética (RM), dada su sensibilidad para diferenciar diversos tejidos neurológicos, así como, su capacidad para generar imágenes con una alta resolución espacial. La mayoria de los métodos de segmentación sobre imágenes de RM, consideran únicamente una caracteristica espectral y desaprovechan información complementaria de las otras bandas.

Se han generado diversas propuestas para resolver el problema de la segmentación de imágenes cerebrales, tanto en una aproximación de segmentación por regiones como en la segmentación por contornos, sin embargo, aún se considera un problema abierto.

Por un lado se han propuesto técnicas de segmentación basadas en clasificadores bayesianos, que en términos generales presentan problemas de definición en los bordes de las estructuras a segmentar, por otro lado se han propuesto técnicas de segmentación por contomos activos que resaltan por su desempeño en la 
localización del borde, sin embargo presentan problemas de convergencia. Las propuestas híbridas sugieren mejores resultados.

En esta tesis se aborda el problema de la segmentación por contomos de imágenes cerebrales multiespectrales por Resonancia Magnética (RM). El enfoque con que se abordó el problema, consistió en la combinación de un modelo de clasificación bayesiana, basado en una Red Neuronal con Funciones de Base Radial (RFBRcc) y un modelo de Contornos Activos basado en una interpolación con splines cúbicos. El modelo híbrido de segmentación fue valorado en imágenes simuladas y reales.

Este documento se organiza de la siguiente forma, en el primer capitulo se incluye un revisión breve de aspectos generales en la generación de imágenes cerebrales multiespectrales de RM, así como los antecedentes en la segmentación de dichas imágenes. Al final de este capítulo, se hace el planteamiento del problema de investigación y las hipótesis de trabajo. En el segundo capítulo, se describen los datos y las diferentes etapas de la metodología empleada, tales como el preprocesamiento de las imágenes, cada uno de los elementos del modelo híbrido de segmentación y el parámetro para evaluación de calidad de segmentación. En el tercer capítulo se presentan y discuten los resultados obtenidos en cada etapa de la metodologia propuesta en el segundo capítulo, empleando imágenes simuladas; igualmente se presentan resultados obtenidos en la segmentación de imágenes reales y la comparación del desempeño del modelo propuesto respecto a otros métodos de segmentación de imágenes cerebrales. Finaliza el documento, un capitulo con conclusiones sobre el trabajo realizado y los resultados obtenidos; se hacen también planteamientos sobre trabajo futuro en esta línea de investigación.

Se anexa un apéndice con los valores de los parámetros del modelo híbrido, empleados para la obtención de los resultados discutidos. Un segundo apéndice contiene las publicaciones derivadas de este trabajo de investigación. 


\section{Segmentación de Imágenes Cerebrales Multiespectrales de Resonancia Magnética}

En el ámbito clínico, la neuroimagen más empleada es precisamente la derivada de los estudios de Resonancia Magnética (RM), pues posee técnicamente las mejores cualidades para el especialista, y que son: su sensibilidad para diferenciar tejido neurológico y su alta resolución espacial. En aplicaciones como el análisis morfológico y morfométrico de estructuras neurológicas para diagnóstico diferencial, la planeación de neurocirugias, seguimiento de un tratamiento, seguimiento de la evolución de un padecimiento particular o la construcción de atlas poblacionales, el procesamiento digital de las imágenes cerebrales comienza con un procedimiento de segmentación guiado por el problema. Esto significa que cada aplicación determina si la segmentación debe ser orientada a regiones o bien, realizar una segmentación por contornos. Igualmente se define también si es necesaria la incorporación de conocimiento a priori que el usuario proporciona, o bien si toda la información necesaria está contenida a nivel de los datos. A continuación se describen las características de las imágenes cerebrales generadas por RM, algunas aplicaciones clínicas sobre el análisis de imágenes multiespectrales y por último se describen los trabajos más relevantes en la segmentación de estas imágenes.

\section{I.1 Imágenes Cerebrales}

El cerebro, como la médula espinal, es una estructura semisólida muy delicada que requiere de soporte fisico y protección. El organismo satisface estos requerimientos al cubrir el cerebro con varias membranas (meninges) y hacerlo flotar en líquido cefalorraquídeo (Icr), además de alojarlo en la cavidad craneana. El cerebro humano es una estructura relativamente pequeña, con un peso aproximado de $1.5 \mathrm{~kg}$, un porcentaje minimo del peso total corporal.

El cerebro se divide en dos hemisferios cerebrales que son estructuras duplicadas en espejo, que están formados por una corteza con circonvoluciones profundas y una capa inferior o interna considerable de materia blanca, así como una colección de masas neuronales profundas, conocidas como los ganglios basales. Los hemisferios cerebrales están parcialmente separados por la fisura longitudinal, en la porción central se localiza el cuerpo calloso, que consiste en un conjunto de fibras que interconectan ambos hemisferios. A su vez, cada hemisferio está dividido en varios lóbulos (frontal, parietal, temporal y occipital) acotados por grandes fisuras o circunvoluciones profundas, que típicamente se emplean como referencias espaciales por los neuroanatomistas.

El líquido cefalorraquídeo es un líquido incoloro que contiene pequeñas cantidades de proteina, glucosa y potasio; en mayor proporción contiene cloruro de sodio y agua. La flotación del cerebro en lcr reduce a un $4 \%$ el efecto del peso 
del cerebro en comparación a la medida hecha en el aire. La mayor área de contacto del Icr, se tiene con la superficie de la corteza cerebral y en la zona ventricular.

La materia blanca forma el corazón de las circunvoluciones corticales y contiene básicamente tres tipos de fibras neurales: fibras de proyección, fibras de asociación y fibras comisurales. El nombre de esta estructura se debe a que las fibras que la forman están cubiertas por mielina que se caracteriza precisamente por ese color.

La corteza cerebral tiene un área aproximada de $2200 \mathrm{~cm}^{2}$, su espesor varía desde $4.5 \mathrm{~mm}$ en el giro pre-central hasta $1.5 \mathrm{~mm}$ en las profundidades de la cisura calcarina. La corteza es siempre gruesa en la cresta de la circunvolución y delgada en la profundidad de las cisuras. En la Figura I.1 (a) se pueden observar estas características; se resaltan sólo algunas estructuras. La corteza está formada por fibras neurales aferentes y terminales, fibras de asociación y comisurales, así como fibras neurales de proyección en su capa más profunda; en las capas mas superficiales se concentran más fibras de asociación.

Es un hecho que la materia blanca, la materia gris y el lcr, mantienen una configuración espacial característica: la materia blanca subyace a la materia gris, la porción más superficial de la corteza cerebral está permanentemente en contacto con Icr. En una vista horizontal, la materia blanca ocupa la porción más cercana al centro del cerebro, y alejándose de él se encuentra la materia gris y alejándose aún mas se encuentra el lcr, con excepción del lcr ventricular.

El estudio de las funciones cognitivas superiores y su correlación con la localización de zonas especializadas en la corteza cerebral ha permitido la elaboración de mapas de la superficie de la corteza cerebral en donde es posible ubicar zonas predominantemente sensitivas o motoras, visuales, auditivas etc., y generar atlas anatomo-funcionales que han apoyado a diversas subespecialidades de la Neurología, tales como neurofisiología o la neurocirugía. En la Figura 1.1 (b) y (c) se muestran algunos ejemplos de estos mapas funcionales. Se ha definido el Espacio de Talairach como un sistema de referencia espacial para poder ubicar las mismas estructuras en diferentes cerebros y hacer comparaciones y descripciones poblacionales [2]. 


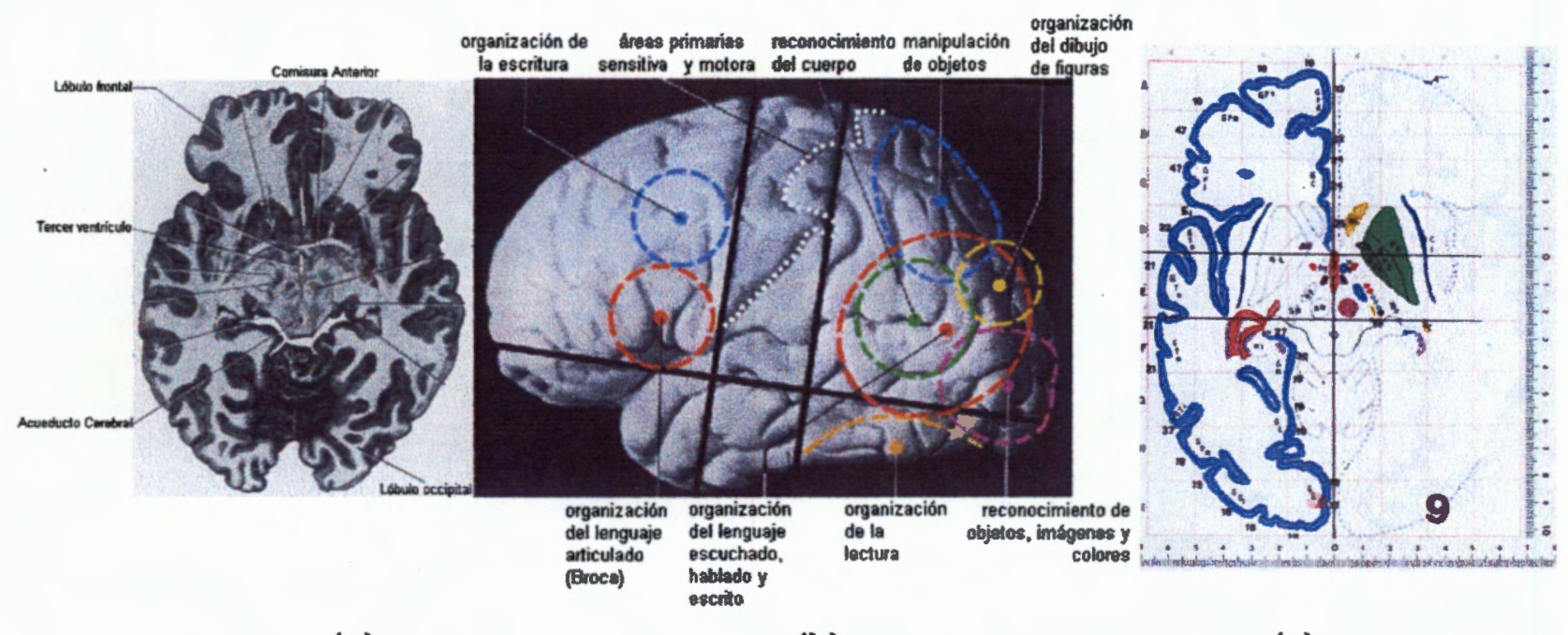

(a)

(b)

(c)

Figura I.1. (a) Sección horizontal de los hemisferios cerebrales pasando a través de la comisura anterior y el crus cerebri (Adaptado de [8], pp. 31) (b) Mapa funcional según el atlas de Tailarach (c) Lámina 121 que corresponde al corte mostrado en (a) (Adaptado de [40], pag. 15, 101)

\subsection{Estudios Clínicos de Imagen Cerebral Multiespectral de Resonancia Magnética}

\section{I.2.1 Resonancia Magnética}

El campo de la imagenología médica sufrió una revolución cuando fue posible la reconstrucción tomográfica de una imagen, empleando los principios de la Resonancia Magnética. Las cualidades de esta técnica son básicamente que, permite generar imágenes con excelente resolución espacial y de amplio rango dinámico, ademas permite obtener reconstrucciones en diversos planos. Desde un punto de vista clínico, una cualidad relevante es que se considera una técnica diagnóstica no invasiva.

El principio general de generación de imágenes por RM consiste en lo siguiente: el objeto de estudio es colocado bajo la influencia de un campo magnético de gran intensidad; este campo magnético obliga a alinearse respecto a él a los vectores de magnetización de los protones, definiendo un estado basal, posteriormente este estado del vector de magnetización puede ser alterado al perturbar el medio con un nuevo campo magnético diferencial, generado con bobinas cuya influencia es bastante focalizada. El efecto del retorno del vector de magnetización neto hacia el estado basal, cuando ha desaparecido la perturbación local, es registrado por antenas de radiofrecuencia. La señal registrada por las antenas, refleja características particulares del material que forma al objeto en estudio $[4,53]$. 
El objetivo de la imagenología por RM es entonces, producir un contraste entre diferentes tipos de tejidos, con base en la respuesta diferencial a manipulaciones sobre el vector de magnetización neto en una región anatómica de interés; estas manipulaciones son sistematizadas como una secuencia de pulsos que activan/desactivan diferentes elementos del resonador (bobinas o antenas).

Definir la secuencia apropiada es la parte crítica de la adquisición de la imagen. Existen diversos diseños de secuencias que producen diferentes clases de contraste entre tejido, por ejemplo la secuencia Spin-Echo (SE), la secuencia Inversion Recovery Spin-Echo (IR) o la secuencia Gradient-Echo (GE).

El efecto final del contraste se obtiene al controlar, con una secuencia en particular, el registro de parámetros intrínsecos del tejido, como son las constantes de relajación T1 y T2, la densidad de protones (DP) o el flujo a través de un tejido. Los parámetros extemos más importantes por controlar son: el tiempo de repetición en la secuencia (TR), el tiempo del eco (TE) y el ángulo de retorno o flip angle.

Por lo tanto, la variación de estos parámetros externos, permite la generación de diversos tipos de imágenes que resaltan alguna de las caracteristicas intrinsecas del tejido mencionadas con anterioridad. Se dice que estas imágenes son pesadas en T1, T2, DP , T2*, etc. , todas ellas adquiridas sobre el mismo objeto de estudio, lo que permite hacer una descripción multiespectral de la estructura anatómica en cuestión [4,53].

Entre los tipos de IRM cerebral frecuentemente empleados se encuentran:

a) Imágenes pesadas en T1. Imagen elemental en un estudio clínico de RM, provee buen detalle anatómico, generan un buen contraste entre materia blanca y materia gris. Es una técnica apropiada para detectar displasias corticales.

b) Imágenes pesadas en T2. Son imágenes altamente sensibles para la detección de padecimientos intracraneales, junto con estas imágenes pueden generarse también imágenes de densidad de protones (DP) que permiten hacer una buena diferenciación de lesiones en el parénquima cerebral. Las imágenes T2 proveen también un buen contraste entre materia blanca y materia gris.

c) Imágenes FLAIR (Flow Attenuation Inverse Recovery). Imágenes ideales para la detección de padecimientos en las regiones contenedoras de líquido cefalorraquídeo, como son la superficie cerebral y los ventrículos. La hemorragia subaracnoide puede visualizarse mejor con imágenes FLAIR que con imágenes de Tomografia Axial Computada (TAC).

d) Imágenes de difusión. Estas imágenes reflejan la cantidad y dirección del movimiento browniano de protones libres. Este movimiento está influenciado por la organización estructural y la integridad de los tejidos, por lo que puede considerarse como una imagen que provee información anatómico-funcional. 
Permite la detección de infartos cerebrales, diferenciar entre edemas citotóxicos o vasogenéticos, permite valorar cambios isquémicos, entre otras aplicaciones clínicas [49].

En casos de esclerosis múltiple, donde se requiere analizar las dimensiones de las lesiones y su distribución espacial, o bien en el análisis de los ventrículos cerebrales en casos de esquizofrenia, se requiere de la evaluación clínica centrada en regiones de interés, sin embargo en estudios de alcoholismo o enfermedad de Alzheimer, la región de interés es el cerebro completo [2].

\subsubsection{Estudios clínicos}

El desarrollo reciente de nuevos protocolos o secuencias para la generación de imágenes de RM, ha permitido la obtención de imágenes con alto valor diagnóstico y cuya interpretación requiere del análisis conjunto de tales imágenes. Por ejemplo, en el análisis de la integridad de los nervios periféricos es necesaria la comparación entre imágenes pesadas en T1 y T2. Para el diagnóstico y seguimiento de ciertos tipos de epilepsia, es necesario el análisis conjunto de imágenes T1, T2 y FLAIR $[29,36,51]$. En algunas patologías congénitas o que aparecen durante el desarrollo, tales como el síndrome Dabdy-Walker, anormalidades ventriculares, perturbación en la proliferación neuronal, o bien para el diagnóstico de enfermedades adquiridas tales como tumores, infecciones infartos cerebrales, enfermedades desmielinizantes, enfermedades neurodegenerativas, se seleccionan al menos dos modalidades de imagen anatómica de RM para establecer el diagnóstico, típicamente imágenes pesadas en T1, T2 y eventualmente DP o FLAIR [19].

Valk y van der Knaap [48] han sistematizado el análisis de imágenes anatómicas de RM y estudios de espectroscopia, para el estudio de enfermedades de materia blanca en niños. Han propuesto una clasificación de padecimientos de la materia blanca en términos de los signos y síntomas del paciente y se apoyan en un sistema de reconocimiento de patrones, asistido por computadora, para identificar cada caso con su correspondiente categoria. Parte del análisis sobre las imágenes DP, T2 y FLAIR consiste en evaluar si la materia blanca se encuentra agrandada o encogida, si existe simetría en los cambios, qué regiones de la materia blanca están afectadas, si la materia gris también presenta anormalidades y si aparecen en las imágenes otras anormalidades como calcificaciones o hemorragias. El reconocimiento de patrones puede ser empleado no sólo para categorizar el conjunto de signos y síntomas, sino para ayudar al análisis o segmentación de las imágenes mismas.

En este mismo sentido, las imágenes cerebrales multiespectrales presentan diversas características no deseables, algunas de ellas son: los artefactos debidos al movimiento del paciente 0 a las inhomogeneidades del campo magnético principal o por las antenas, el efecto del volumen parcial, marcos de referencia 
espacial sin registrar y un fuerte traslape en la distribución de intensidades para cada tejido cerebral.

Las propuestas de solución que se han planteado, intentan resolver algunos de estos problemas; los mejores resultados se han observado en propuestas que combinan algoritmos convencionales de procesamiento de imágenes con técnicas de clasificación robusta o reconocimiento de patrones.

\section{l.3 Segmentación de Imágenes Cerebrales}

Diversos métodos, orientados a segmentación por regiones o por contornos, se han propuesto para la segmentación de imágenes cerebrales. Se han propuesto métodos basados en clasificación bayesiana o de estimación robusta no paramétrica, que presentan problemas en la localización de bordes entre pares de tejidos $[1,2,4,11,17,22,26,52]$. Otros métodos basados en modelos de contornos activos, resuelven el problema de localización del borde, sin embargo presentan problemas de convergencia [12-14,18,27]. Comparativamente, las propuestas híbridas han mostrado mejores resultados [9,23,27,50,57]. Aún ahora la segmentación de estas imágenes se considera un problema abierto.

Como se ha mencionado antes, el estudio de Resonacia Magnética ofrece la posibilidad de exploración de diferentes características de un mismo objeto, cuando se definen protocolos distintos para la generación de las imágenes. De esta manera es posible generar imágenes pesadas en T1 o T2, imágenes FLAIR o de DP. Lo anterior implica que los tejidos pueden ser mejor diferenciados cuando se considera la información multiespectral de cada voxel. La mayor parte de los métodos de segmentación usados en IRM consideran imágenes monoespectrales, descartando información complementaria de las otras bandas.

El procesamiento digital de imágenes multiespectrales ha confirmado que los componentes particulares o bandas pueden no revelar toda la información útil, sin embargo, una combinación apropiada de la información multiespectral puede mejorar ya sea una interpretación clínica o la determinación de regiones estratégicas en imágenes satelitales [20]. Especialmente, la segmentación de imágenes cerebrales multiespectrales o multimodalidad ha sido implementada con diversos métodos, los más frecuentemente usados son: la segmentación por regiones usando estimadores de máxima verosimilitud o de máxima probabilidad a posteriori (MAP) en modelos de campos aleatorios Markovianos, clasificadores de distancia mínima, algoritmos de agrupamiento tales como $k$-means o c-means, estimadores estadisticos robustos, etc [1, 11, 27]. En [2] puede encontrarse una revisión exhaustiva de estos métodos.

Ozkan et al [37] obtuvieron su mejor resultado usando una red neuronal multicapa en comparación con un clasificador de máxima verosimilitud, en donde la función de densidad de probabilidad para cada tejido, la modelaron con una gaussiana 
multivariada. Collins et al [11] reportaron los mejores resultados en segmentación de imágenes cerebrales multiespectrales, de acuerdo a la opinión de neuroanatomistas, usando un clasificador con red neuronal en comparación con un clasificador de distancia minima. Reddick et al [39] desarrollaron un algoritmo basado en un esquema combinado de redes neuronales, que consistió primero de un mapa auto-organizado para una segmentación gruesa, seguido de una red multicapa que finalmente clasifica la imagen en siete diferentes estructuras cerebrales (materia blanca, materia blanca/gris, materia gris, materia gris/lcr, $\mathrm{lcr}$, fondo y otra).

La distribución de intensidades para diferentes clases de tejido de las imágenes cerebrales multiespectrales reflejan un problema de separabilidad no-lineal, por lo que el empleo de métodos de clasificación de distancia mínima, resulta inapropiado. Esta misma distribución de clases presenta también una geometría compleja, difícil de aproximar por un modelo simple de función de densidad de probabilidad, como por ejemplo, una gaussiana multivariada; en este sentido, se explica por qué se han obtenido mejores resultados con modelos de clasificación no-lineal que definen regiones de pertenencia a una clase, con geometria compleja.

En la propuesta de Yañez et al [56] se considera la segmentación de imágenes multiespectrales (T1,T2, FLAIR) como un caso de clasificación supervisada, se emplea una red neuronal con funciones de base radial. La entrada a la capa de estimación, se forma con los valores de intensidad de cada banda para un voxel. Esta capa oculta está formada por cinco unidades con funciones gaussianas de activación; los parámetros de estas funciones fueron estimados mediante el algoritmo EM para mezclas de gaussianas. La entrada de la capa de clasificación se forma por la salida de las cinco unidades de procesamiento de la capa oculta y dos entradas más que corresponden a las coordenadas cilíndricas del voxel a clasificar. Los pesos de esta capa fueron estimados con la solución de la pseudoinversa para la función de error de la suma de los cuadrados (LS, sus siglas en inglés). La capa de clasificación cuenta con tres unidades con función de activación lineal, cada unidad corresponde a cada clase deseada: materia blanca, fondo y materia gris. Como método de registro de imágenes se empleó un procedimiento de maximización de la información mutua mediante una variación del algoritmo del recocido simulado. Los resultados obtenidos apuntan hacia la pertinencia de estimar la función de densidad de probabilidad posterior con el tipo de red neuronal empleado en este trabajo.

Por otro lado, los modelos de contornos y superficies activas ofrecen una poderosa herramienta para el análisis médico, ya que son capaces de incorporar y combinar restricciones geométricas y fisicas al comportamiento del contorno deseado [34]. En el caso de las imágenes cerebrales, diversos modelos de contornos activos o snakes han sido propuestos. Algunos de ellos, recuperan la idea original propuesta por Kass et al [24] y agregan algunos elementos como términos de restricción o términos de imagen mas sofisticados que permiten mejorar el desempeño del modelo $[12-14,18,55]$. Modelos de contornos activos 
geométricos también han sido propuestos, en donde la naturaleza discreta de la imagen y la geometría del contorno deseado se explotan al máximo $[28,57]$.

Valdes y Yañez [46] proponen una reformulación del modelo de contomo activo propuesto por Kass et al [24], para incluir la expresión analítica de las derivadas del contorno, representadas por una interpolación con splines cúbicos, en el término de energía interna. El término de energía externa se definió como la magnitud del gradiente de la imagen, obtenida mediante el operador de la derivada de una gaussiana (operador de Canny) [8]. El modelo fue probado en la segmentación de tráquea en imágenes de Tomografia Axial Computada (TAC) y en la segmentación del ventrículo izquierdo en imágenes cardiacas por RM [35, 43-44]. El modelo demostró robustez ante errores en la definición del contorno inicial. La imposición de la interpolación con splines cúbicos permitió conservar el orden de los puntos de control a través de las iteraciones.

Mclnerney y Terzopolous [33] en su revisión sobre la aplicación de los modelos deformables en el análisis de imágenes médicas, señalan que el desarrollo de nuevos métodos apunta hacia la incorporación de conocimiento a priori e inteligencia artificial o mecanismos de reconocimiento basado en redes neuronales.

Con anterioridad la segmentación se ha presentado como un problema dual, ya que es posible etiquetar a la imagen en regiones que contienen una característica común, o bien, es posible etiquetar regiones disjuntas definidas por la frontera entre ellas. En términos generales los métodos de segmentación por regiones tienen un bajo desempeño en la frontera entre clases, mientras que las técnicas de segmentación por contornos tienen dificultad para resolver la heterogeneidad entre regiones vecinas. Trabajos recientes apuntan hacia modelos híbridos de segmentación, en donde las ventajas de cada una de las aproximaciones puede ser aprovechada, superando el desempeño individual de la técnica [2].

En lo que respecta a esta posible combinación de modelos de snakes con técnicas bayesianas, algunas propuestas consisten en pre-segmentar las imágenes (clasificador bayesiano) para proveer de un buen contorno inicial al proceso de los contomos activos $[18,47]$. Otros métodos reportados, incorporan un descriptor de comportamiento probabilistico al modelo de la snake, con el objetivo de mejorar la convergencia del modelo y hacerlo más robusto en condiciones de ruido $[27,38$, 50].

Kapur et al [23] proponen una combinación de clasificadores basados en la intensidad de los pixeles, operadores morfológicos y un modelo de balón para obtener la superficie de la corteza cerebral en volúmenes de RM. Valizadeh y Soltanian [47] han reportado una combinación de una segmentación con $k$-means y un modelo discreto de contornos activos, propuesto previamente por Lobregt y Viergever [25]. 
Usar un presegmentador robusto para inicializar un modelo de snake, resuelve un problema recurrente en los contornos activos y que es, la definición de un contorno inicial de buena calidad. Sin embargo, la interacción entre ambos modelos puede resultar más enriquecedora si se aprovecha el conocimiento generado por el presegmentador, para ayudar en el proceso de búsqueda del contorno óptimo.

Lundervold y Storvik [27] proponen un procedimiento que integra conocimiento a priori para segmentar el parénquima cerebral y líquido cefalorraquídeo. En esta propuesta, la función de densidad de probabilidad de las imágenes se modeló como una mezcla de gaussianas, cuyos parámetros fueron estimados con el algoritmo Expectation-Maximization (EM) inicializado con un $k$-means para un conjunto de entrenamiento. El conocimiento a priori consiste en la defínición de cuatro regiones anatómicas en un corte axial, que pueden separarse mediante tres contornos cerrados que no se intersectan entre ellos. En esta propuesta se imponen restricciones en la forma y suavidad de los contornos. La búsqueda del contorno óptimo se realiza mediante un estimador de máxima probabilidad a posteriori (MAP) y el método de recocido simulado. Chiou y Hwang [9] proponen el acoplamiento entre una red neuronal multicapa y un contorno activo, para robustecer el término de energía externa.

En el trabajo de Xu et al [54], las imágenes son pre-procesadas para remover piel, grasa y tejido meningeo en un proceso interactivo con el usuario. Posteriormente se hace una segmentación difusa de la imagen incluyendo un procedimiento de corrección de inhomogeneidades del campo magnético. El resultado consiste en una estimación inicial de una superficie activa cuyo modelo incorpora también un término de restricción derivado de la pre-segmentación. En el modelo de $\mathrm{Xu}$ et al, el término de energía externa de la superficie activa está basado en el cálculo del flujo del vector gradiente (FVG), este campo direccional de fuerzas obliga a la superficie activa, a adherirse a los bordes de las estructuras por segmentar. En su propuesta también se incorpora un procedimiento de ajuste adaptable para los parámetros de la energía interna de la superficie.

Xu et al deciden abordar el problema de la pre-segmentación con un enfoque de conglomerados, esto es muy interesante puesto que evitan hacer consideraciones - supuestos sobre la función de densidad de probabilidad de los datos; sin embargo la construcción de este modelo de distribución de la pertenencia de clase, que radica en los datos mismos, es altamente demandante de recursos de cómputo, puesto que cada volumen de imágenes requiere de la construcción del modelo propio. Lo anterior explica la existencia del proceso manual para remover piel, grasa y tejido meníngeo, con esto se reduce el espacio de búsqueda de prototipos de clase en el análisis de conglomerados. 


\section{I.4 Planteamiento del problema}

Como lo muestra la sección anterior, la segmentación de imágenes cerebrales ha sido abordada desde diversos enfoques; se han hecho contribuciones al conocimiento en este campo, sin embargo las características de las imágenes cerebrales multiespectrales de RM (intensidades no normalizadas, artefactos debidos al paciente y a los elementos del resonador, traslape de intensidades en diferentes clases, etc), no han permitido resolver el problema de su segmentación.

En este trabajo se abordó este problema de la segmentación de imágenes cerebrales multiespectrales de Resonancia Magnética. El objetivo particular fue, localizar el borde entre materia gris y materia blanca.

La solución se planteó como un modelo híbrido de segmentación, en donde se combina un segmentador por regiones, bajo un esquema de clasificación supervisada, definido en principio para hacer segmentación volumétrica si es necesario; con un modelo de contornos activos, basado en una interpolación con splines cúbicos en una representación bidimensional.

Se consideraron las siguientes hipótesis de trabajo:

a) Las imágenes cerebrales multiespectrales proveen de mejor información para su segmentación que una imagen cerebral monoespectral.

b) La combinación de modelos de segmentación por regiones y contornos mejora la localización del borde deseado. 


\section{Modelo Híbrido de Segmentación.}

El uso de los contornos activos o snakes para la segmentación de imágenes presenta hasta el momento problemas por resolver; el primero de ellos es la dependencia del desempeño del modelo respecto a las condiciones de inicialización del mismo. Ligado a esta primera característica de los contornos activos se aúna el hecho de que su convergencia al resultado deseado está en función de una gran cantidad de parámetros, por lo que el problema de optimización para encontrar el contomo de mínima energía, requiere salvar la situación de quedar atrapado en mínimos locales. Una solución que se ha dado para resolver este par de problemas es la de proveer al modelo de un contorno inicial muy cercano al contorno deseado. Sin embargo, esta propuesta no es posible generarla siempre, debido a que la imagen original tiene niveles de ruido elevados, o bien, no se cuenta con información completa para estimar el contorno inicial. Es necesario entonces, dotar al modelo de elementos que le permitan mostrar un desempeño robusto para contender con imágenes ruidosas, por un lado y por otro, contender con la falta de información. Una alternativa para resolver el problema de falta de información a bajo nivel suele sustituirse con información provista por los expertos (información de alto nivel), sin embargo dicha información no está siempre disponible y en cierta medida hace depender al método de la intervención y calidad de un experto.

Las imágenes cerebrales de Resonancia Magnética, presentan las siguientes características que deben ser consideradas en un proceso de segmentación:

- Presencia de información espuria debido a:

Artefactos de movimiento

Inhomogeneidades del campo magnético

- Efecto de volumen parcial, debido a la resolución del volumen explorado, existe superposición de estructuras en un mismo voxel que enmascara zonas de transición.

- En las imágenes multiespectrales, se presentan diferentes marcos de referencia espacial en cada banda, por lo que se requiere hacer registro intermodalidad.

- La distribución de intensidades de la imagen para cada una de las bandas, muestra zonas de traslape entre diferentes clases de tejido, por ejemplo materia blanca y materia gris.

- En imágenes bidimensionales, se presentan problemas de discontinuidad entre regiones con la misma clase de tejido, por lo que es difícil generar un único contorno para un tejido específico. 
En vista de los problemas descritos y de la literatura revisada, en esta tesis se propone una metodología de segmentación híbrida basada en información de bajo nivel contenida en la imagen. En la Figura II.1 se plantea un diagrama general de la metodología empleada; cada una de la etapas propuestas se describen en este capitulo.

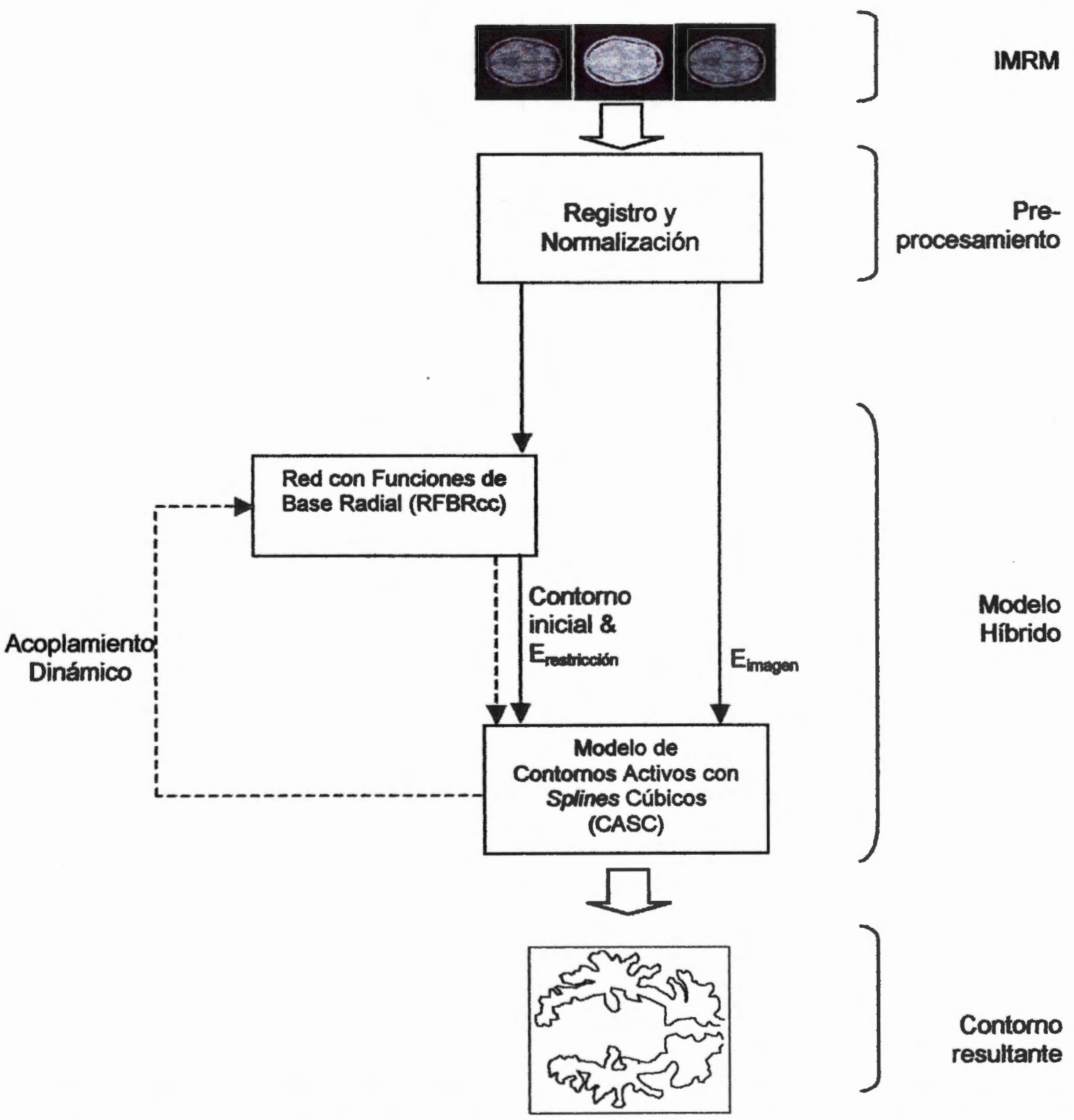

Figura II.1. Esquema general de la metodología propuesta para la segmentación híbrida de imágenes cerebrales multiespectrales de Resonancia Magnética (IMRM). 
En términos generales, la solución propuesta se ha planteado como el acoplamiento entre un clasificador supervisado (red con funciones de base radial), que se encarga de realizar una pre-segmentación de las imágenes multiespectrales, y un modelo de contornos activos (con interpolación spline cúbica) que localice el borde entre regiones de diferente clase de tejido. El vector de características empleado por el pre-segmentador está formado por la intensidad del voxel en cada una de las bandas T1, T2 y DP, además de las coordenadas cilíndricas $\rho$ y z, que definen su localización espacial. El modelo de contornos activos incorpora a su término de energía, información sobre gradiente espacial de la imagen multiespectral y términos de restricción obtenidos del presegmentador. 


\section{II.1 Imágenes Cerebrales Multiespectrales}

Se contó con tres conjuntos de imágenes cerebrales multiespectrales de Resonancia Magnética:

a) Conjunto de imágenes simuladas provistas por el Instituto Neurológico de Montreal de la Universidad de McGill, Canadá. Este conjunto de imágenes está formado por un volumen de 181 imágenes de $217 \times 181$ pixeles cada una en las bandas T1, T2 y PD (densidad de protones), con una resolución espacial de: $1 \mathrm{~mm}^{3} /$ voxel [7]. El mismo laboratorio proporciona el volumen segmentado y validado por expertos, que puede ser utilizado como patrón de referencia (VR) para validación del método [11]. Se han empleado cuatro volúmenes simulados con los parámetros señalados en la Tabla II-1. El primero de ellos (Estudio I) fue utilizado para la definición del conjunto de entrenamiento de la Red Neuronal con Funciones de Base Radial; el resto se empleó para realizar pruebas de diferentes etapas de la metodología propuesta.

\begin{tabular}{|r|r|r|r|r|}
\hline & \multicolumn{4}{|c|}{ Estudio } \\
\hline Parámetro & \multicolumn{1}{|c|}{ I } & \multicolumn{1}{|c|}{ II } & \multicolumn{1}{c|}{ III } & \multicolumn{1}{c|}{ IV } \\
\hline Secuencia & Spin-Echo & Spin-Echo & Spin-Echo & Spin-Echo \\
\hline TR (ms) & & & & \\
T1 & 400 & 500 & 800 & 460 \\
T2 & 3000 & 3500 & 1000 & 2200 \\
DP & 400 & 450 & 800 & 2200 \\
\hline TE (ms) & & & & \\
T1, & 10 & 10, & 50 & 20 \\
T2, & 30 & 30, & 150 & 10 \\
DP & 10 & 10 & 50 & 25 \\
\hline
\end{tabular}

Tabla II-1. Parámetros para la generación de Volúmenes de Imágenes Multiespectrales de Resonancia Magnética según el simulador del Instituto de Neurología de Montréal, Universidad de McGill [7].

b) Conjunto de imágenes reales, provistas por el Servicio de Resonancia Magnética del Hospital American British Cowdray (ABC) de la Ciudad de México, que consiste en cinco volúmenes de 12 imágenes de 256×256 pixeles cada una. Las imágenes multiespectrales se forman con estudios de T1, T2 y FLAIR [53]. Estos volúmenes se emplearon en la valoración del modelo de pre-segmentación.

c) Conjunto de imágenes reales de sujetos sanos adultos, varones, provistas por el Instituto Neurológico de Montréal de la Universidad de McGill, Canadá. Este conjunto de imágenes está formado por volúmenes de 181 imágenes de $217 \times 181$ pixeles cada una en las bandas T1, T2 y PD, con una resolución espacial de: $1 \mathrm{~mm}^{3} /$ voxel, registrados al espacio de Talairach. La generación de estos 
volúmenes se hizo de acuerdo al protocolo del International Consortium for Brain Mapping (ICBM) [21], cuyos parámetros se resumen en la Tabla II-2.

En el resto del documento se hará referencia a los volúmenes reales como RI y RII, para distinguir entre el primero, que se empleó para hacer pruebas y definir parámetros, y el segundo, que fue procesado por el modelo híbrido propuesto.

\begin{tabular}{|c|c|}
\hline Parámetro & Descripción \\
\hline 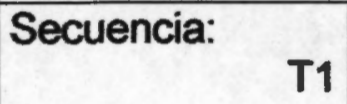 & Flow-compensated $3 D$ RF Spoiled GRE \\
\hline T2/DP & 2D multiple slice dual-echo fast spin-echo (FSE) \\
\hline TR/TE/Flip angle: & \\
\hline T1 & $18 \mathrm{~ms} / 10 \mathrm{~ms} / 30^{\circ}$ \\
\hline T2/DP & $3300 \mathrm{~ms} / 35$ y $120 \mathrm{~ms} /$ - \\
\hline Voxel & $1 \mathrm{~mm}^{3}$ \\
\hline
\end{tabular}

Tabla II-2. Parametros de adquisición de estudios reales bajo el protocolo ICBM [21]

\section{II.2 Pre-procesamiento de los Volúmenes de Resonancia Magnética}

Como se ha descrito anteriormente, la calidad de las imágenes multiespectrales depende por supuesto de las condiciones de adquisición, tales como propiedades del resonador, parámetros del estudio y características propias del sujeto de estudio. Bajo la perspectiva de una segmentación supervisada, tales diferencias obligan a preprocesar las imágenes con el objetivo de trasladar todos los estudios hacia un mismo marco de referencia, no sólo espacial sino en la distribución de intensidades, en donde se cumplan los supuestos estadísticos del clasificador.

\section{II.2.1 Registro de Imágenes}

Las coordenadas cilindricas incluidas en los vectores de características, no son del todo útiles por si mismas para la clasificación, considerando que existen diferencias anatómicas inter-individuos. Sin embargo, definidas en el marco de referencia del paciente, estas características son capaces de proveer de mayor información al clasificador para mejorar la segmentación, por lo que se ha asumido que existe un marco de referencia espacial definido por el estudio de base, al que deben ser trasladados el resto de los estudios. 
Dado que el problema del registro consiste en determinar los parámetros de una transformación $T_{\theta}$ sobre las coordenadas de los pixeles de una imagen destino (I), que la convierta en imagen similar a una imagen de referencia (R), como se describe en Ec. II-1; en esta propuesta, se consideró una transformación lineal global no-rígida para llevar a cabo el registro de las imágenes; esto es, para una imagen I en el volumen destino, $T_{\theta}(I)$ denota la transformación lineal sobre I, que modifica las posiciones de los pixeles de I, sin alterar su valor de intensidad. Eventualmente el proceso requiere de una interpolación para reducir los efectos de discretización del espacio.

$$
\left[\begin{array}{c}
x_{T} \\
y_{T} \\
1
\end{array}\right]=\underbrace{\left.\left.\left[\begin{array}{ccc}
S_{x} & 0 & 0 \\
0 & S_{y} & 0 \\
0 & 0 & 1
\end{array}\right] \begin{array}{ccc}
\cos (\alpha) & -\operatorname{sen}(\alpha) & 0 \\
\operatorname{sen}(\alpha) & \cos (\alpha) & 0 \\
0 & 0 & 1
\end{array}\right] \begin{array}{ccc}
0 & 0 & D_{x} \\
0 & 0 & D_{y} \\
0 & 0 & 1
\end{array}\right]}_{T_{\theta}}\left[\begin{array}{c}
x_{I} \\
y_{I} \\
1
\end{array}\right]
$$

donde:

$\boldsymbol{x}_{\boldsymbol{b}} \boldsymbol{y}_{\boldsymbol{I}} \quad$ coordenadas de un pixel en la imagen destino

$x_{T,} y_{T}$ coordenadas transformadas

$S_{\infty} S_{y}$ escalamientos

$\alpha \quad$ Ángulo de rotación en el plano xy

$D_{D_{0}} D_{\text {y }}$ desplazamientos

$\theta$ conjunto de parámetros de la transformación $\left\{S_{x}, S_{y}, \alpha, D_{x}, D_{y}\right\}$

Los parámetros de la transformación se optimizan en función de la medida de similitud empleada, en este caso se ha empleado la Información Mutua normalizada (IM) [2], entre la imagen de referencia $R$ y la imagen destino transformada $T_{\theta}(I)$, que se describe a continuación:

$$
I M\left(R, T_{\theta}(I)\right)=\frac{H(R)+H\left(T_{\theta}(I)\right)-H\left(R, T_{\theta}(I)\right)}{H(R)+H\left(T_{\theta}(I)\right)}
$$

donde:

$\boldsymbol{R} \quad$ imagen de referencia

I imagen destino

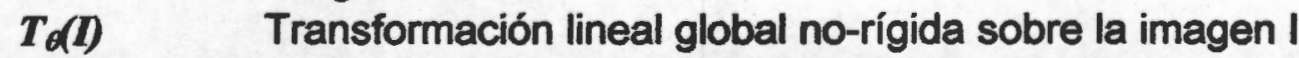

$\operatorname{IM}\left(\boldsymbol{R}, \boldsymbol{T}_{\theta}(D)\right)$ Información Mutua entre la imagen de referencia y la imagen destino transformada

$\boldsymbol{H}(\boldsymbol{R}), \quad$ denota la entropía de la función de densidad de la imagen $\boldsymbol{R}$ ó $\boldsymbol{T}_{\theta}(\boldsymbol{I})$ $H\left(T_{\theta}(I)\right)$

$\boldsymbol{H}\left(\boldsymbol{R}, \boldsymbol{T}_{\theta}(\boldsymbol{I})\right)$ denota la entropia de la función de densidad conjunta entre las Imágenes $R$ y $T_{\theta}(\boldsymbol{I})$ 
El planteamiento del problema de optimización es el siguiente:

$$
\theta^{*}=\underset{\theta}{\arg \max }\left(I M\left(R, T_{\theta}(I)\right)\right.
$$

El comportamiento de la IM respecto a los cinco parámetros de la transformación, es altamente cambiante, por lo que existe una gran colección de mínimos locales cercanos entre sí que podrian atrapar al proceso de optimización. Por esta razón, abordamos este problema por medio de una versión simplificada del algoritmo del recocido simulado $[32,56]$ que permite guiar la búsqueda del óptimo global.

\section{II.2.2 Normalización del Espacio de Intensidades}

Como se ha mencionado anteriormente, la estadística de la distribución de clases de tejido cerebral respecto a la intensidad reflejada en la imagen se modifica de acuerdo a las características del resonador y protocolo con que se obtienen las imágenes, por lo que resulta indispensable para un esquema de clasificación basado en el análisis estadístico de las imágenes definir un procedimiento de normalización del espacio de intensidades. En este trabajo, se propone una normalización automática del espacio de características guiada por los datos, para acoplarse al pre-segmentador basado en una red con funciones de base radial, que consiste en transformar el espacio de intensidades de cada estudio, en un espacio normalizado que fue pre-definido por el estudio de referencia y en donde fue entrenado el pre-segmentador.

Esta metodología se basa en la hipótesis de que la estructura de la distribución de clases de tejido se conserva entre estudios distintos. En la Figura II.2a se muestran imágenes multiespectrales adquiridas con diferentes parámetros; en el inciso (b) se muestra la distribución de características de una muestra de vectores, que corresponden a materia blanca, materia gris y liquido cefalorraquídeo, para el conjunto de referencia en negro (estudio I) y para otro conjunto de prueba en gris (estudio III).

Se propuso la transformación de Karhunen-Loeve (KL) para mapear el espacio de intensidades hacia los ejes de mayor varianza de los datos, como se describe en la siguiente ecuación (Ec. III-1). Dado que los volúmenes de estudio se encuentran registrados en el espacio de Talairach, es posible extraer automáticamente una muestra de vectores que correspondan a materia gris, materia blanca o líquido cefalorraquídeo, para estimar la matriz de autocorrelación y su media. Cada vector de la muestra está definido por una terna de valores que corresponden a la intensidad de cada una de las bandas de los estudios multiespectrales (T1,T2 y DP). La normalización consta de dos pasos, el primero en la descomposición en valores y vectores propios de la matriz de autocorrelación y el segundo, en la determinación de la mejor orientación de tales vectores propios. 


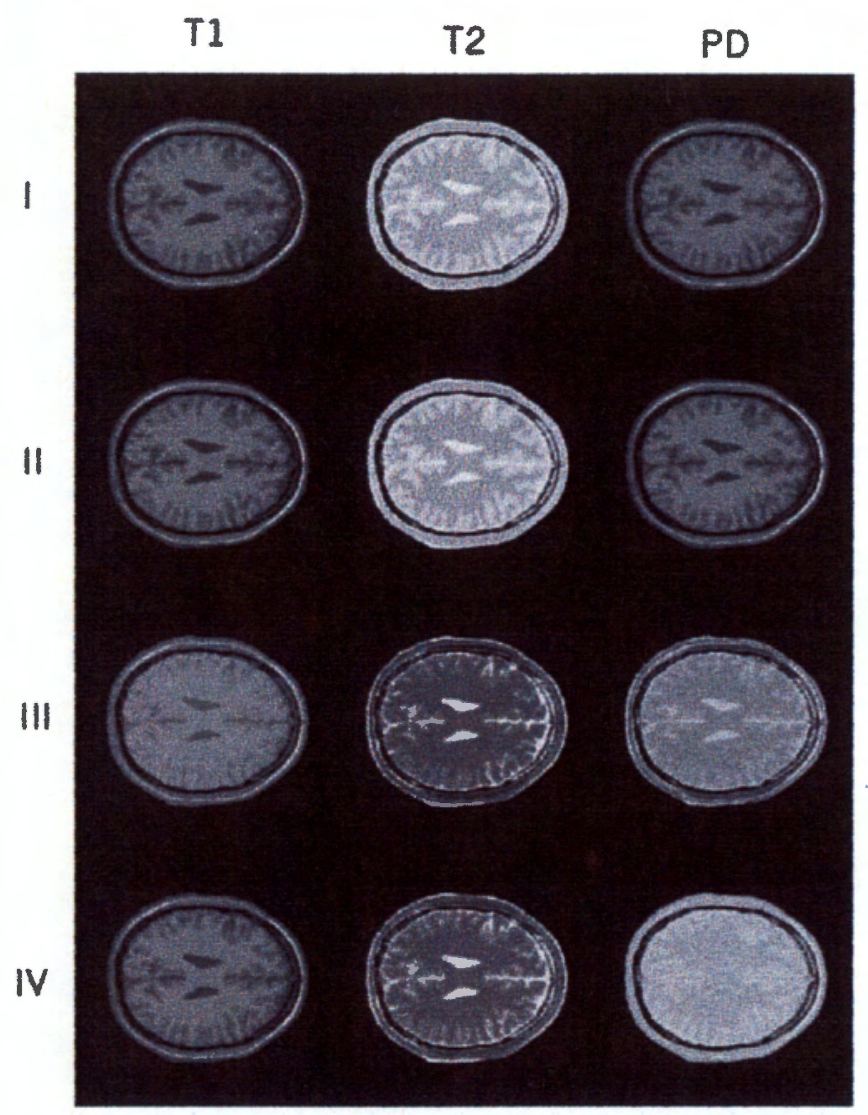

(a)

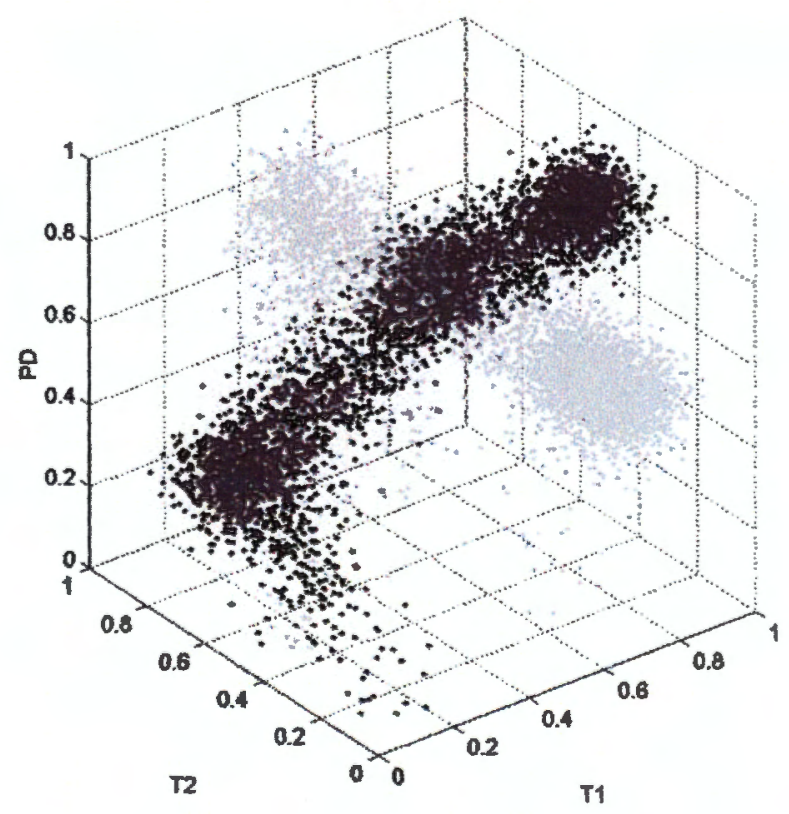

(b)

Figura II.2 Normalización de intensidades: (a) muestra de imágenes multiespectrales de los cuatro estudios simulados, (b) distribución de intensidades en estudios multiespectrales de RM. Se muestran vectores de materia gris, materia blanca y Icr. En negro el estudio de referencia, en gris claro un estudio de prueba. 
1) La descomposición en valores y vectores propios de la matriz de autocorrelación de la muestra $\left(\mathbf{R}_{3 \times 3}\right)$, consiste en:

$$
\mathbf{D}=\mathbf{V}^{\boldsymbol{T}} \mathbf{R V}
$$

donde:

R matriz de autocorrelación de la muestra de vectores

D es la matriz diagonal que contiene los valores propios de $\mathbf{R}$

$\mathbf{V}$ matriz de vectores propios de $\mathbf{R}$, arreglados en columnas

La transformación $\mathrm{KL}$ de los vectores, se muestra a continuación:

$$
q=\mathbf{V}^{T}(\mathbf{x}-\overline{\mathbf{x}})
$$

donde:

x vector de características en el espacio original de intensidades

x vector media de la muestra

q vector de características en el espacio normalizado de intensidades

2) La descomposición en valores propios de la matriz de autocorrelación, permite la definición de $2^{3}$ posibles transformaciones sobre los datos, al considerar para cada vector propio un sentido de orientación directo o inverso, por lo que es necesario realizar una prueba sobre la calidad de la transformación. Puesto que los datos normalizados serán evaluados por el pre-segmentador para su clasificación, se decidió que la calidad de la transformación KL en sus ocho combinaciones fuera evaluada de acuerdo a la verosimilitud (likelihood) de la muestra [16] para el modelo definido de la siguiente manera:

$$
\begin{aligned}
& f\left(\mathbf{q}_{j} \mid \Phi\right)=\sum_{j=1}^{13} P_{j} p\left(\mathbf{q}_{i}, \mu_{j}, \Sigma_{j}\right) \\
& L(\mathbf{q})=\prod_{i=1}^{N} f\left(\mathbf{q}_{i} \mid \Phi\right)
\end{aligned}
$$

donde:

$f\left(q_{i} \mid \Phi\right) \quad$ función de densidad de probabilidad de los datos con parámetros definidos por $\Phi(\mu, \Sigma$ y P). Representa una mezcla de 13 gaussianas multivariadas $p\left(\mathbf{q}, \boldsymbol{\mu}_{j}, \Sigma_{j}\right)$. Este modelo es consistente con la estructura del pre-segmentador. (Sección II.3)

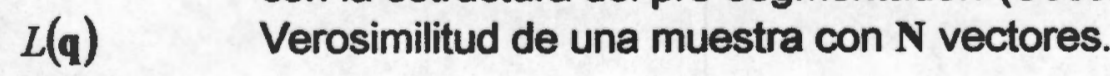


El conjunto de parámetros $\Phi$ ya está definido de acuerdo a los datos del estudio multiespectral de resonancia magnética de referencia.

Sea $L^{\prime}(\mathbf{q})=-\frac{1}{N} \log (L(\mathbf{q}))$, por lo tanto

$L^{\prime}(\mathbf{q})=-\frac{1}{N} \sum_{i=1}^{N} \log \left(f\left(\mathbf{q}_{i} \mid \Phi\right)\right)$

La selección de la orientación de los vectores propios para la transformación KL, se hace de tal forma que se minimice el negativo del logaritmo medio de la verosimilitud (loglikelihood) descrito en la (Ec. II-6).

\section{II.3 Red de Funciones de Base Radial Modificada (RFBRcc)}

De la observación de la distribución de las intensidades de las diferentes clases de tejido en las imágenes cerebrales multiespectrales (Figura II.3) resulta evidente que la segmentación de estas imágenes es un problema no-separable linealmente. Aún mas, las clases se distribuyen con cierta geometría radial, al menos para un eje de simetría. En este trabajo se propuso emplear una variación de una Red de Funciones de Base Radial para la pre-segmentación de las imágenes de RM.

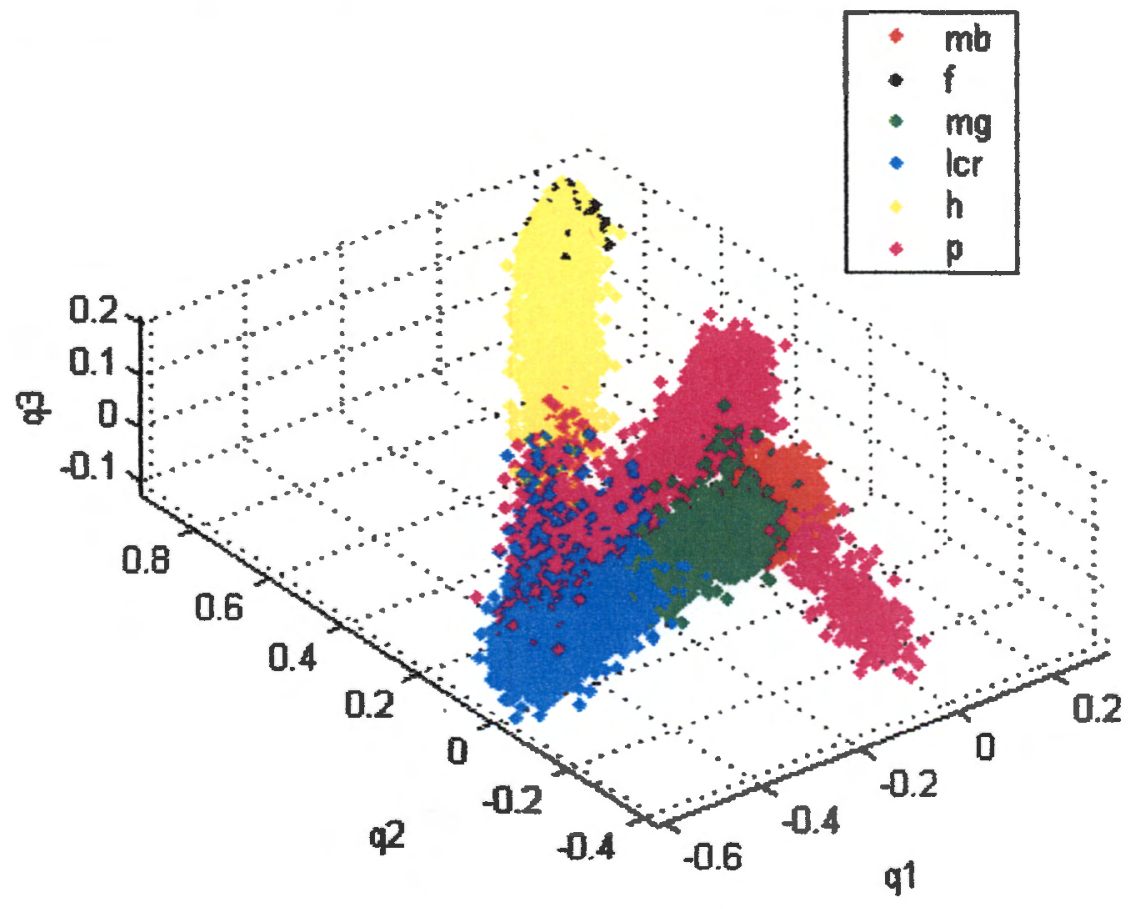

Figura II.3. Distribución de intensidades normalizadas para las clases materia blanca (mb), fondo (f), materia gris (mg), liquido cefalorraquideo (lcr), hueso (h) y piel-grasa (p) del estudio $\mathrm{II}$, en un espacio normalizado de intensidades. 


\section{II.3.1 Fundamentos}

Dentro de la variedad de Redes Neuronales empleadas en el reconocimiento de patrones, la Red de Funciones de Base Radial se ubica en la taxonomía de clasificadores bayesianos supervisados no lineales. Fundamentalmente en la capa oculta, hacen una transformación no-lineal con geometría radial del espacio de características y esto se complementa con una capa de salida formada por unidades básicas perceptrón [16]. La estructura general de una red de este tipo se muestra en la Figura II.4.

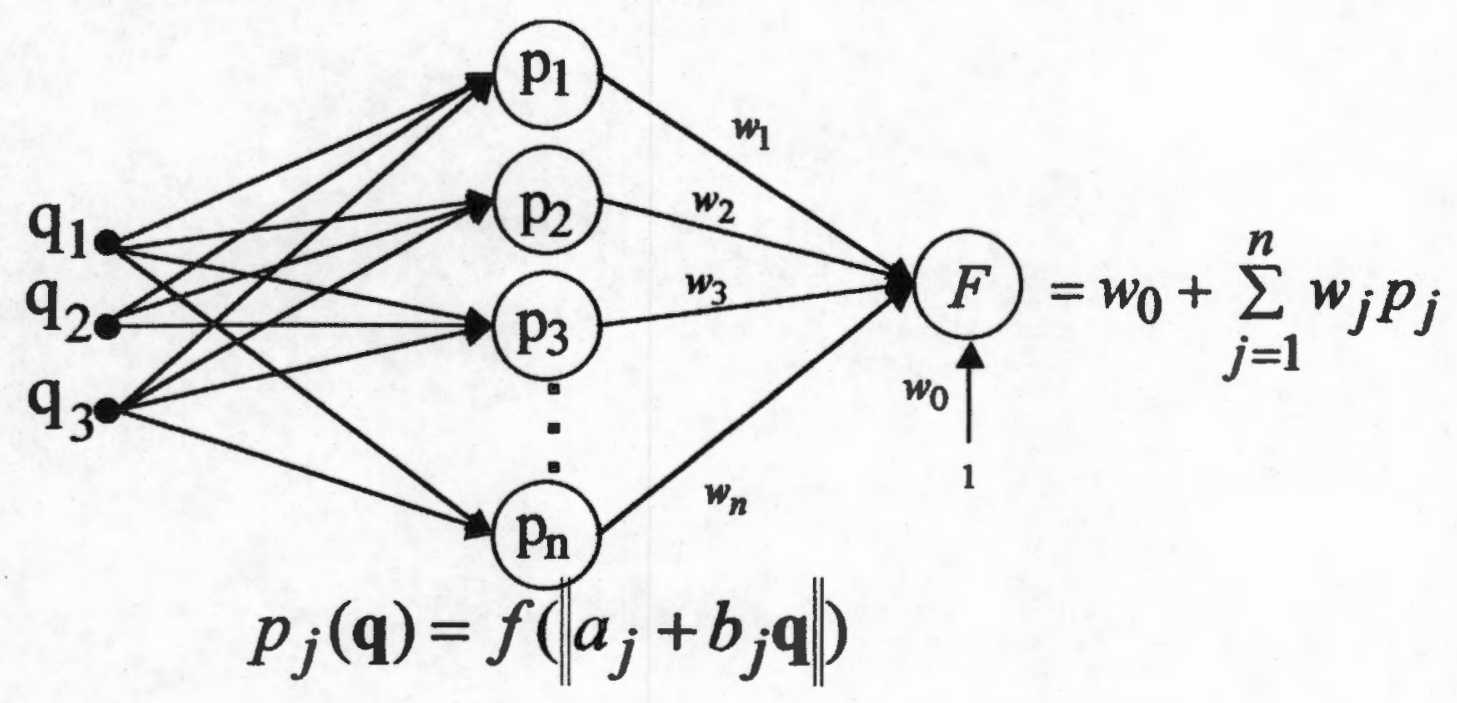

Figura 11.4. Estructura general de una Red con Funciones de Base Radial. En la capa oculta $a_{j}$ y $b_{j}$ son parámetros que definen la forma de $f(-)$ y $w_{j}$ son pesos ajustados para el nodo de salida. Todos los parámetros son ajustados en el entrenamiento de la red.

Un esquema frecuente de las funciones de base radial, consiste en definir $f(\cdot)$ como funciones gaussianas multivariadas con parámetros $\mu$ y $\Sigma$. Los pesos $w_{j}$ son calculados considerando que para cada vector de entrenamiento se sabe si pertenece o no a la clase deseada; bajo esta perspectiva la red se comporta como estimador de la función de densidad de probabilidad posterior de los datos. El error en esta estimación se deriva del empleo del modelo del perceptrón (nodo de salida) para reemplazar la transformación bayesiana [5].

Para la pre-segmentación de imágenes cerebrales multiespectrales de RM, se propuso una modificación a la estructura general de la red, al agregar dos entradas a la capa de salida, que corresponden a las coordenadas cilindricas del voxel a clasificar.

Se realizaron diversos análisis sobre la estructura del pre-segmentador, tales como: número de nodos en la capa oculta, análisis de componentes principales de las características, inclusión de coordenadas cilíndricas, consideración de información multiespectral y desempeño del clasificador ante condiciones de ruido. 


\begin{tabular}{|l|c|}
\hline Clase & Proporción \\
\hline fondo & $16 \%$ \\
\hline $\mathrm{lcr}$ & $13 \%$ \\
\hline $\mathrm{mg}$ & $15 \%$ \\
\hline $\mathrm{mb}$ & $15 \%$ \\
\hline $\mathrm{g}$ & $12 \%$ \\
\hline $\mathrm{p}$ & $14 \%$ \\
\hline $\mathrm{h}$ & $14 \%$ \\
\hline
\end{tabular}

Tabla II-3. Proporción de clases en el conjunto para entrenamiento y validación de la RFBRec.

Las imágenes fueron ajustadas a una malla de 256x256 píxeles; así mismo, las coordenadas cilindricas fueron ajustadas para obtener radios máximos de $\sqrt{2}$, considerando como origen el centro de la imagen en el plano axial. Las alturas de las imágenes fueron ajustadas dos órdenes de magnitud, tomando valores en [0.01, 1.81]. Del conjunto obtenido de vectores, se reservó el $60 \%$ para entrenamiento de la red y el restante $40 \%$ para dos conjuntos de validación.

La capa oculta de la red está formada por trece unidades de procesamiento con funciones de activación de tipo gaussianas multivariadas; en un modelo de mezcla de distribuciones gaussianas, se requiere determinar los parámetros de cada una de las gaussianas involucradas en la mezcla y el peso relativo de cada una de ellas. La función de densidad de los datos queda expresada como se muestra en la Ec. II-5 (se repite por claridad):

$$
f(q \mid \Phi)=\sum_{j=1}^{13} P_{j} p\left(q, \mu_{j}, \Sigma_{j}\right)
$$

Los parámetros de la mezcla fueron calculados con un estimador de máxima verosimilitud (algoritmo de Expectation-Maximization para mezclas de distribuciones normales [15]).

La capa de clasificación está formada por seis nodos, uno por cada clase deseada: materia blanca, fondo, materia gris, liquido cefalorraquídeo, piel y hueso; sus funciones de activación son lineales. Los pesos de conexión en esta capa $\left(w_{j}\right)$ se calcularon para cada uno de los nodos de la siguiente manera:

Para el nodo de materia blanca, se tiene la siguiente expresión:

$$
F_{m b}(q)=w_{0}+\sum_{j=1}^{13} w_{j} p_{j}(\mathbf{q})+w_{14} \rho+w_{15} z=w^{T} \mathbf{p}
$$

donde:

w vector de pesos de conexión, tiene dimensiones $16 \times 1$

p vector formado por las salidas de los nodos de la capa oculta y las coordenadas cilindricas, tiene dimensiones $16 \times 1$ 
Para cada vector de entrenamiento $q_{\mathrm{i}}$ se define una salida deseada en el nodo de clasificación, de la siguiente manera:

$d_{i}=\left\{\begin{array}{cc}1 & \text { si } q_{i} \in \text { clase mb } \\ -1 & \text { si } q_{i} \notin \text { clase mb }\end{array}\right.$

La suma de errores cuadráticos (SEC) queda descrita como:

$S E C=\Sigma\left|F_{m b}\left(q_{i}\right)-d_{i}\right|^{2}=\Sigma\left|w_{m b}^{T} p_{i}-d_{i}\right|^{2}$

para todos los $\mathbf{N}$ vectores $\mathbf{q}$ del conjunto de entrenamiento

Los pesos de conexión óptimos se calculan mediante la solución de la pseudoinversa para minimizar la función de costo de la suma de errores cuadráticos.

$\mathbf{w}_{m b}=\mathbf{P}^{\mp} \mathbf{d}$

donde:

$\mathbf{P}^{\mp} \quad$ es la pseudoinversa de la matriz $\mathbf{P}$, tiene dimensiones $16 \times \mathbf{N}$

d vector de salidas deseadas, tiene dimensiones $\mathrm{N} \times 1$

$\mathbf{w}_{m b}$ vector de pesos de conexión de la capa oculta al nodo de salida

Este procedimiento se repite para cada uno de los nodos de salida.

\section{II.3.3 Propiedades}

La salida de cada uno de los nodos de la capa de clasificación de la RFBRcc se interpreta como un mapa discriminante para la clase correspondiente. El análisis conjunto de los mapas discriminantes representa un modelo del efecto del volumen parcial para el estudio de RM. En esta propuesta de red, en donde la capa oculta se entrena como una mezcla de gaussianas, la similitud con el procedimiento de agrupamiento de $k$-means radica en que éste último se convierte en el caso límite del caso de la mezcla, si se asume que los cúmulos tienden a comportarse como gaussianas [5]. 


\section{II.4 Contornos Activos con Splines Cúbicos (CASC)}

En los modelos de contornos activos, los problemas de inicialización y de convergencia hacia el borde óptimo son recurrentes. En trabajo previo se propuso una formulación de un modelo de contornos y superficies activas, basado en una interpolación con splines cúbicos que permitió asegurar el ordenamiento entre los puntos de control del contorno, así como generar un término de energía de la imagen de alta calidad, ambos aspectos ayudan a converger al contorno activo hacia el borde deseado [46]. A continuación se describe el modelo para contornos.

Considerando que desde el inicio, sólo se cuenta con un conjunto finito $(\mathrm{N})$ de puntos de control, el modelo propuesto de contornos activos plantea que es posible escribir una formulación analítica de una interpolación con splines cúbicos naturales para el contomo y de esta manera, se puede reescribir la suma de derivadas del contorno (energía interna) en una expresión cerrada. La formulación general de la Energia del contorno activo o snake se ve de la siguiente forma:

$$
\begin{aligned}
& E_{\text {svake }}(v)=E_{\text {int }}(v)+E_{\text {ext }}(v) \\
& E_{\text {imt }}(v)=\sum_{i=1}^{N} \alpha_{i}\left|v_{S i}^{\prime}(s)\right|^{2}+\sum_{i=1}^{N} \beta_{i}\left|v_{S i}^{\prime \prime}(s)\right|^{2} \quad s \in[0,1] \\
& E_{\text {ext }}(v)=-\gamma|G * I(v)|
\end{aligned}
$$

donde:

$N \quad$ es el número de puntos de control del contorno

$v_{s i} \quad$ denota el segmento entre los puntos de control i e i+1

$G$ denota una función gaussiana bidimensional con parámetros $\mu$ y $\Sigma$ fijos

$I(v)$ denota los valores de intensidad de la imagen en el contorno $v$

$\gamma \quad$ denota el peso del componente de energía externa en la formulación general de la snake

* denota la operación de convolución bidimensional

Cualquier segmento $v_{s}$ puede ser interpolado con splines cúbicos naturales de la siguiente forma:

$$
v_{S m}(s)=\frac{1}{6}\left[\begin{array}{llll}
s^{3} & s^{2} & s & 1
\end{array}\right] \times\left[\begin{array}{cccc}
-1 & 3 & -3 & 1 \\
3 & -6 & 3 & 0 \\
-2 & -3 & 6 & -1 \\
0 & 6 & 0 & 0
\end{array}\right] \times\left[\begin{array}{c}
V_{m-1} \\
V_{m} \\
V_{m+1} \\
V_{m+2}
\end{array}\right] \quad s \in[0,1] \quad \text { (EC. H-8) }
$$

o bien:

$v_{s m}(s)=\frac{1}{6} s \times \mathbf{M} \times v_{m}$ 
Las expresiones de la primera y segunda derivadas del contorno, respecto al parámetro $s$, pueden ser incorporadas explícitamente en la ecuación de la $E_{\text {snate }}$ (Ec. 5). Al evaluar la derivada de $E_{\text {snate }}$ respecto a un punto $V_{k}$ del contorno y considerando $\alpha$ y $\beta$ constantes, se obtiene la siguiente expresión:

$$
\frac{\partial E_{\text {ence }}}{\partial V_{k}}=\frac{\partial E_{\text {int }}(v)}{\partial V_{k}}+\frac{\partial E_{\text {ext }}(v)}{\partial V_{k}}=\frac{\partial E_{\text {int }}(v)}{\partial V_{k}}-\gamma F(v)
$$

donde:

$v \quad$ contorno activo definido por segmentos

$V_{k} \quad$ késimo punto de control del contorno activo

$$
\begin{aligned}
\frac{\partial E_{\text {int }}}{\partial V_{k}}= & \frac{1}{3} V_{k-3}(2 \alpha)+\frac{1}{3} V_{k-2}(-9 \alpha+36 \beta)+\frac{1}{3} V_{k-1}(-18 \alpha-144 \beta)+ \\
& +\frac{1}{3} V_{k}(50 \alpha+216 \beta)+\frac{1}{3} V_{k+1}(-18 \alpha-144 \beta)+\frac{1}{3} V_{k+2}(-9 \alpha+36 \beta)+\frac{1}{3} V_{k+3}(2 \alpha)
\end{aligned}
$$

$F(v)$ representa la derivada del término de energía externa $\left(\left|G^{*} I(v)\right|\right)$, que corresponde a la derivada de la magnitud del gradiente de la imagen, calculado con un filtro de Canny con parámetros fijos $\mu$ y $\Sigma$ [8].

Considerando todo el conjunto de puntos de control, el proceso de búsqueda del contorno óptimo se realiza mediante el método de descenso por gradiente normalizado, cuya expresión se muestra a continuación:

$$
\begin{aligned}
& \nabla E_{\text {me }}=\mathbf{A} \underline{\boldsymbol{y}}-\boldsymbol{\gamma} F \\
& \underline{v}^{(t+1)}=\underline{v}^{(t)}+\mu \frac{\left(-\nabla E_{\text {ente }}\right)}{\left|\nabla E_{\text {mathe }}\right|} \\
& \underline{v}^{(t+1)}=\underline{v}^{(t)}-\mu \frac{\mathbf{A} \underline{v}^{(t)}-\gamma F\left(\underline{v}^{(t)}\right)}{\left\|\mathbf{A} \underline{v}^{(t)}-\gamma F\left(\underline{v}^{(t)}\right)\right\|}
\end{aligned}
$$

donde:

A matriz de coeficientes de la energía interna

$\mu \quad$ tamaño de paso del método del descenso por gradiente

v vector de puntos de control del contorno activo 


\section{II.5 Acoplamiento RFBRcc-CASC}

Se acopló el modelo de segmentación estadística, basado en una RFBRcc, y un modelo de contornos activos, basado en la interpolación con splines cúbicos [46]. La hibridación se da en dos niveles:

a) Inicialización del contorno activo; e

b) Incorporación de un término de restricción en la expresión de energía del contorno activo.

\section{U.5.1 Inicialización}

La RFBRcc es empleada como un pre-segmentador, de donde se obtiene un contorno prototipo que permite inicializar el modelo de los contornos activos. En la Figura II.6a se muestra la imagen binaria correspondiente a materia blanca, obtenida al umbralizar el mapa discriminante correspondiente. Debido a la distribución de las materias gris y blanca en los volúmenes cerebrales, en las imágenes bidimensionales es frécuente encontrar más de un borde de interés, por lo que es necesario, procesar el mapa discriminante para definir el contorno prototipo. El algoritmo se resume de la siguiente manera:

- Definir la frontera de interés: materia gris-materia blanca

- Recuperar del pre-segmentador la clase materia blanca

- Determinar la cantidad y área de las diferentes regiones que forman a la imagen binaria (Figura II.6b)

- Para las regiones de interés, obtener el contorno definitivo.

En el inciso (c) se muestran los contornos obtenidos de las regiones mayores observadas en (b) graficados sobre la imagen T2.

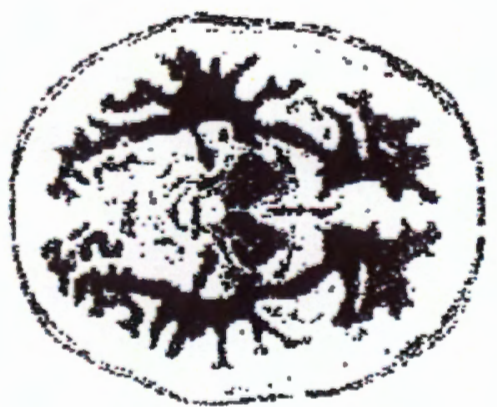

(a)
Inagen etiquetada

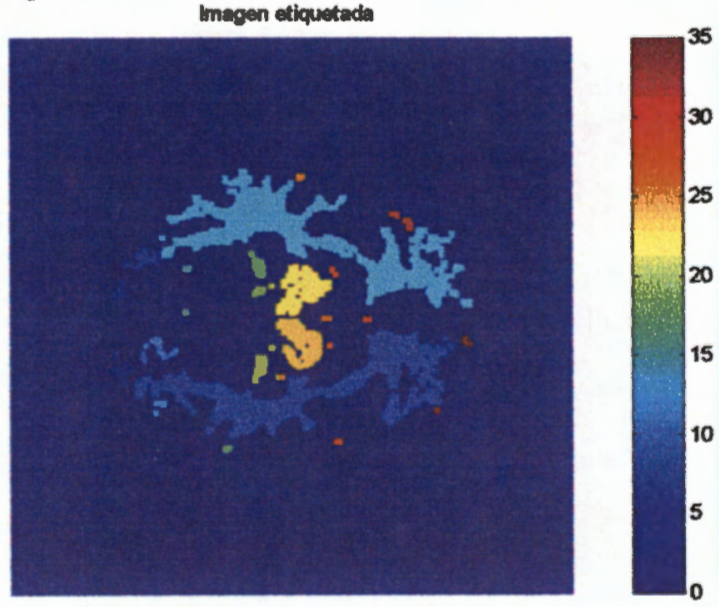

(b) 


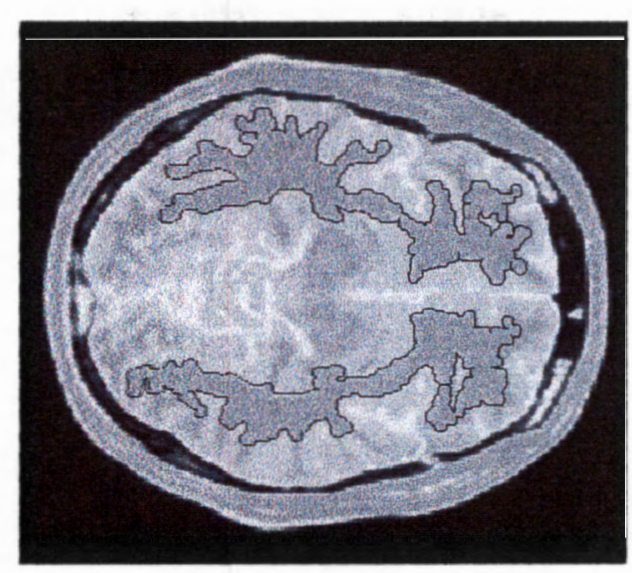

(c)

Figura ll.6. Inicialización del modelo de contornos activos: (a) imagen binaria obtenida de la clasificación de materia blanca con la RFBRcc, (b) regiones separadas y etiquetadas, (c) contomo de las dos regiones mayores de (b), graficado sobre la imagen T2 original.

\section{Ul.5.2 Muestreo de Puntos de Control para el Contorno Inicial}

Se propone un método para ajustar la distribución espacial de los puntos de control de la snake, tomando en consideración una aproximación a la curvatura del contorno, bajo la premisa de que en regiones de curvatura cero o casi cero, sólo son necesarios dos puntos de control para definir la recta que los une, mientras que en regiones de curvatura mayor, es necesario aumentar la densidad de puntos $[25,30,41]$.

El algoritmo para determinar la distribución de puntos de control se describe a continuación:

1. Definir el contorno inicial

2. Hacer una sobre-interpolación spline cúbica, con espaciamiento regular

3. Tomar una muestra reducida del contorno sobre-interpolado

4. Calcular la curvatura para la muestra (medida mediante el ángulo entre dos segmentos consecutivos)

5. Aproximar el número de puntos necesario por segmento, dados los valores de la curvatura y la resolución espacial de la imagen

6. Reducir los puntos de control co-lineales o casi co-lineales (mientras la curvatura acumulada no supere un umbral pre-establecido)

7. Interpolar con espaciamiento irregular, el conjunto reducido de puntos de control, según la aproximación de puntos necesarios calculados en 5 . 
En la Figura II.7a se muestra el contomo inicial, sus puntos de control y una interpolación spline regular (pasos 1-2). En el inciso b se presenta la muestra de puntos (paso 3). En el inciso c se muestra el conjunto reducido (paso 6)- En el inciso d se muestra el conjunto final de puntos de control.

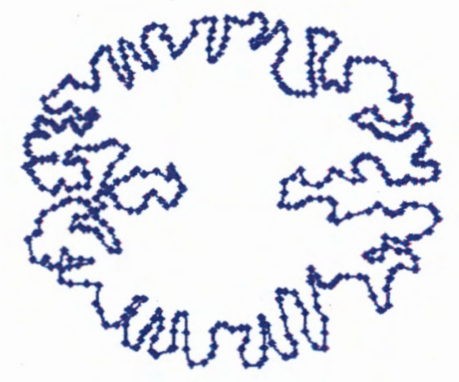

(a)

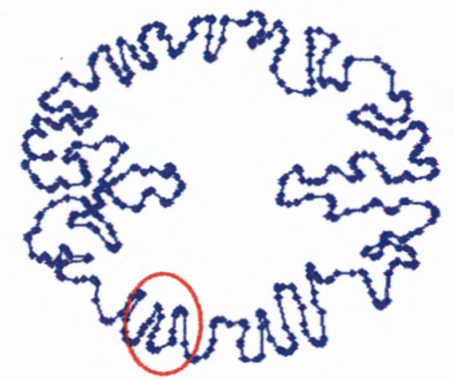

(c)

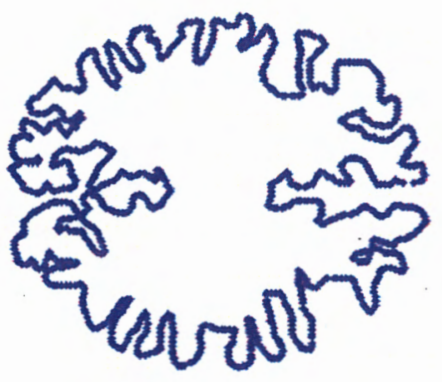

(b)

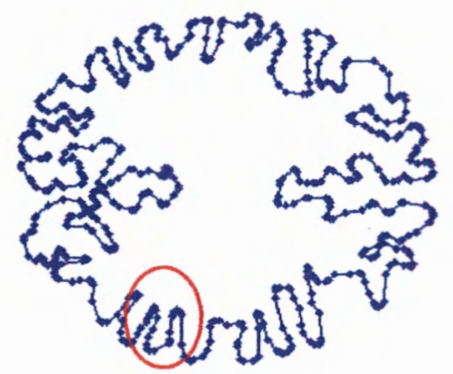

(d)

Figura II.7. Remuestreo de puntos: (a) conjunto original de puntos de control y contorno interpolado con espaciamiento regular, (b) muestra de puntos del contorno interpolado, (c) conjunto ordenado y reducido de puntos de control, (d) conjunto final ordenado e interpolado.

Para el cálculo del término de $E_{\text {inu }}$ de la snake, es necesario tomar en cuenta que después del ordenamiento, la separación entre puntos es irregular. Lo anterior implica que los coeficientes $\alpha$ y $\beta$ no son constantes para todo el contorno. Los nuevos $\alpha_{i}$ y $\beta_{\mathrm{i}}$ se calculan de la siguiente manera: $\alpha_{i}=\frac{\alpha}{h_{i}^{2}}$ y $\beta_{i}=\frac{\beta}{h_{i}^{4}}[10]$ donde:

$h_{j} \quad$ es la distancia euclidiana entre el i-ésimo punto de control y el punto (i-1) $\alpha, \beta$ peso relativo para cada término de la $E_{\text {int. }}$.

Se mantiene la forma de la matriz A (Ec III-8) de los parámetros internos de la snake, es decir, es una matriz heptadiagonal cuadrada $(\mathrm{N} \times \mathrm{N})$, de rango $\mathrm{N}-1$, sólo que los valores de las diagonales no son constantes, como en el caso original. 


\section{II.5.3 Acoplamiento Estático.}

En este caso de acoplamiento de RFBRcc-CASC, la contribución de la primera etapa sobre el modelo de los contornos activos, permanece sin cambio. Al término de la pre-segmentación de la imagen multiespectral, son conocidos los componentes para la inicialización del contorno activo y el término de Energía para la snake.

Se incorporó en el término de Energía del contorno activo, información multiespectral y restricciones sobre la evolución de la snake, esto es:

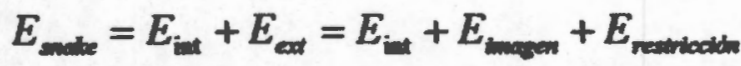

donde:

$E_{\text {int }}$ se define con base a los parámetros de rigidez y elasticidad del modelo y de la formulación explícita del contorno con base en funciones splines cúbicas

$E_{\text {imagen }}$ puede ser definida de diversas formas, a continuación se describen las modalidades evaluadas en esta propuesta.

1) $E_{\text {inagan }}$ como una combinación lineal de las magnitudes de los gradientes de cada banda independiente, por ejemplo el promedio de tales magnitudes, esto se ve de la siguiente forma:

$E_{\text {mom }}: \mathfrak{R}^{3} \mapsto \Re$

$E_{\text {mim }}=-\gamma_{I} \cdot \frac{1}{3}\left(\left|G * I_{1}\right|+\left|G * I_{2}\right|+\left|G * I_{3}\right|\right)=-\gamma_{I} \cdot \frac{1}{m} \sum_{i=1}^{m}\left|G * I_{i}\right|$

donde:

Ii:

Representa la i-ésima banda (T1, T2, FLAIR ó DP) de las imágenes multiespectrales de RM,

$n \quad$ representa el peso del término de la $E_{\text {imagen }}$

$G$ la función derivada de una gaussiana con parámetros $\left(0, \sigma^{2}\right)$; y

* denota convolución bidimensional

2) $E_{\text {imazen }}$ como un gradiente multiespectral, este cálculo sugiere determinar la dirección y magnitud del máximo cambio de la matriz gradiente para una posición definida, esto es:

Sean

$$
D=\left[\begin{array}{ll}
\partial_{1} / \partial u & a_{1} / \partial \nu \\
\partial l_{1} / \partial u & \partial d_{2} / \partial v \\
\partial I_{1} / \partial u & \partial I_{3} / \partial v
\end{array}\right]
$$

la matriz gradiente asociada a un voxel en la imagen multiespectral 
donde:

u,v dimensiones espaciales

y g tal que $\left(D^{T} D\right)=\lambda_{\max } g$,

el vector propio asociado al mayor valor propio de la matriz gradiente.

el término de $E_{\text {imagen }}$ se define de la siguiente manera:

$E_{\text {imagen }}: \mathfrak{R}^{3} \mapsto \Re$

$E_{\text {imagen }}=\gamma_{I} \cdot(+\sqrt{\mathbf{\Lambda}})$ con dirección: $\left(\mathbf{G}_{1}, \mathbf{G}_{2}\right)$

donde:

n

$\boldsymbol{\Lambda}$

representa el peso del término de la $E_{\text {lmagen }}$ es la imagen de la magnitud del gradiente multiespectral ( $\lambda_{\max }$

$\left(\mathbf{G}_{1}, \mathbf{G}_{2}\right)$ para cada pixen)

son las matrices de la dirección espacial del gradiente multiespectral, definido en dos dimensiones $\left(g_{1}\right.$ y $g_{2}$ para cada pixel).

3) E $E_{\text {inagen }}$ puede plantearse utilizando la definición de Xu y Prince para el Flujo del Vector Gradiente (FVG) [54], en donde se describe una función sobre una imagen de la caracteristica a resaltar (los bordes en esta aplicación), que permite ampliar el área de influencia de dicha característica, definiendo un vector cuya dirección apunta perpendicularmente al borde deseado. La expresión para la $E_{\text {inagen }}$ se expresa de la siguiente forma:

$E_{\text {mim }}: \mathfrak{R}^{3} \mapsto \Re$

$E_{\text {ming }}=-\gamma_{1} \cdot F V G(G * I I)$ ó

$E_{\text {mim }}=-\gamma_{1} \cdot F V G\left(\left|G * I_{1}\right|+\left|G * I_{2}\right|+\left|G * I_{3}\right|\right) \quad 6$

$E_{\text {min }}=-\gamma_{1} \cdot F V G(\sqrt{\Lambda})$

donde:

$n$

FVG

representa el peso del término de la $E_{\text {imagen }}$

representa la función del flujo de vector gradiente sobre una imagen de caracteristicas 
En la Figura 11.8 se muestran ejemplos de cada uno de los términos de Energía propuestos anteriormente. Exceptuando la última opción, el campo de dirección de la $E_{\text {imagen }}$ está parcialmente desordenado, lo que reduce el efecto de atracción de este término sobre el contorno activo.

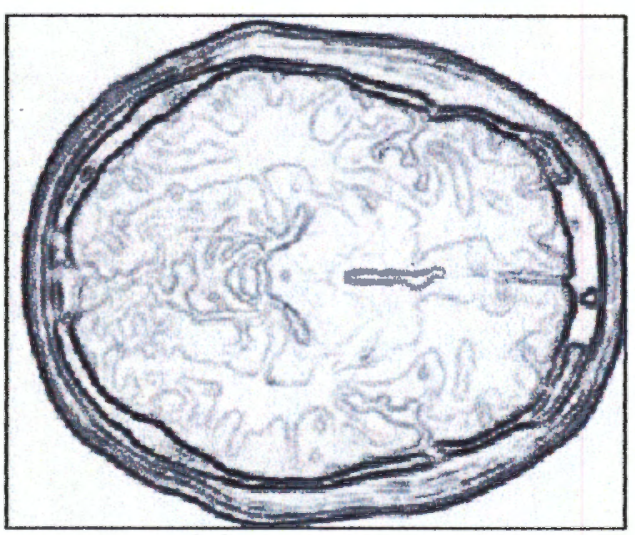

(a)

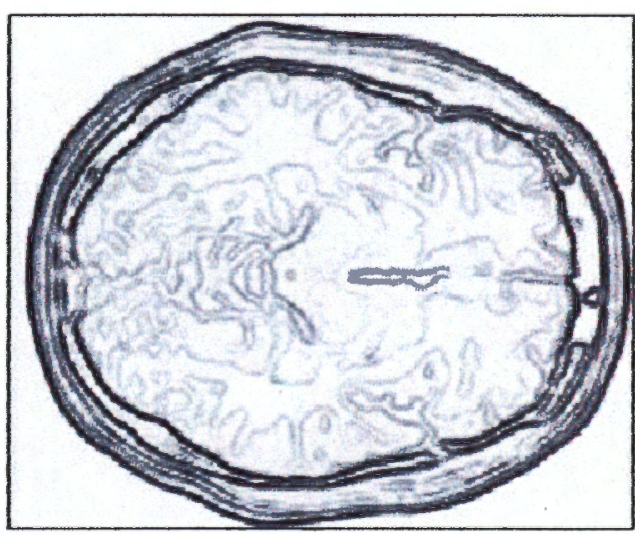

(b)

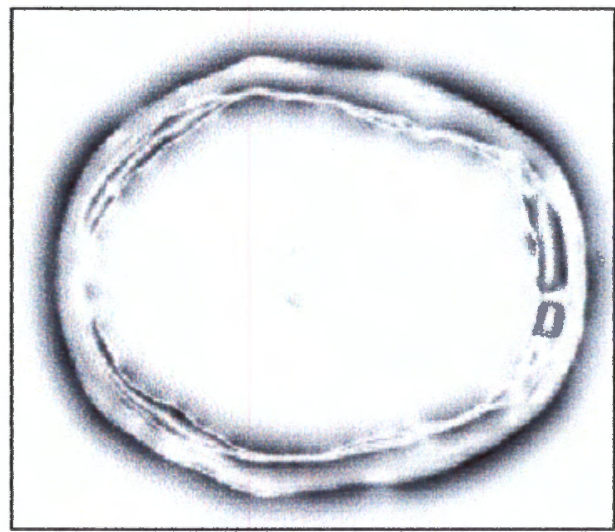

(c)

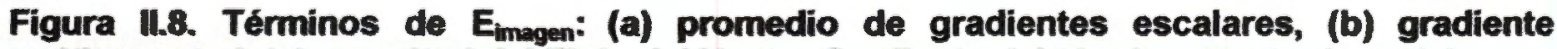
multiespectral, (c) magnitud del Flujo del Vector Gradiente del término mostrado en (a)

A continuación se presenta una modificación para la primera propuesta de $E_{\text {imagen }}$ (combinación lineal de los gradientes monoespectrales):

$$
E_{\text {imagen }}=-\gamma_{I} \Psi\left(\frac{1}{m} \sum_{i=1}^{m} \mid G * I_{i} \|\right)
$$

donde:

$\Psi$ representa una secuencia de operaciones sobre la magnitud promedio del gradiente, que consisten en: una umbralización dura y posteriormente una convolución con un kemel gaussiano de media cero y varianza $\sigma^{2}$. 
En la Figura ll.9 se muestra un ejemplo de este término y un acercamiento en una zona de interés, en donde se muestra la dirección de la fuerza asociada a éste término.

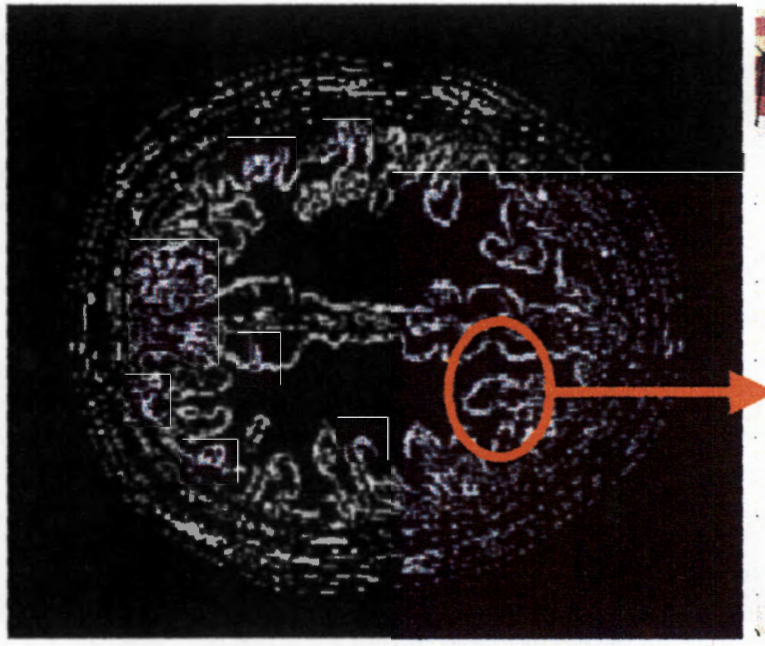

Figura ll.9. Tórmino de $E$ asociado en paleta de colores inversa.
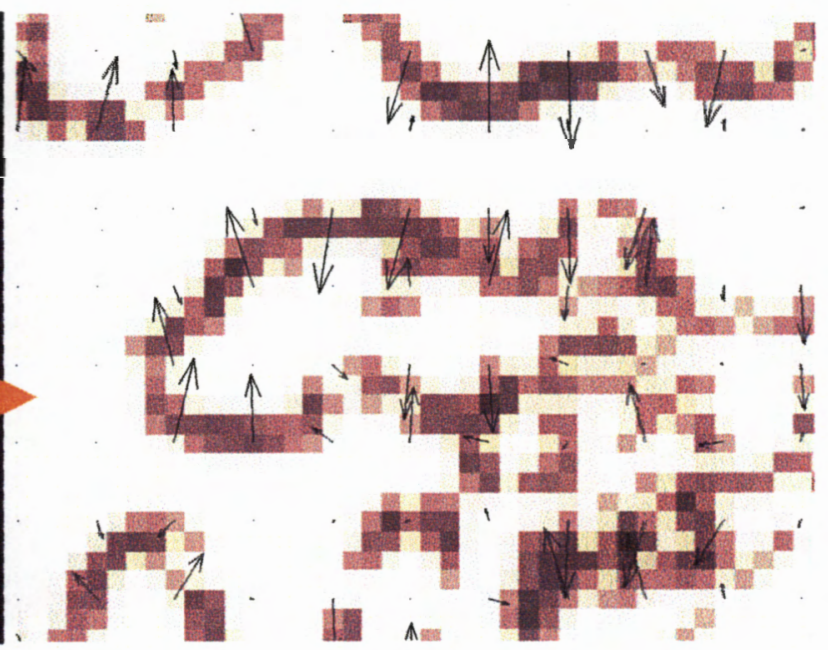

(b) dirección del campo de fuerza

El término de restricción $E_{\text {restriccion, se define como la energía determinada por una }}$ función de la fuerza de las imágenes discriminantes $\left(F_{D}\right)$, que se obtienen en la preclasificación bayesiana realizada con la RFBRcc. En el contexto de la preclasificación, se seleccionaron cuatro clases: materia gris (MG), materia blanca (MB) líquido cefalorraquídeo (LCR) y fondo (F), por lo que se genera para cada elemento de la imagen multiespectral un correspondiente vector tetradimensional, en donde se incluye el valor del discriminante para cada una de las clases propuestas; se construyen entonces los mapas discriminantes considerando la máxima probabilidad posterior.

De la fuerza discriminante deseada se obtiene el término de restricción al filtrarlo con un filtro pasabajas, con la intención de homogeneizar el mapa y favorecer la dirección deseada en el término de restricción. Esto es:

$$
E_{\text {restricción }}(v)=-\sum_{v}\left(\gamma_{m g} F_{m g}+\gamma_{m b} F_{m b}+\gamma_{l c r} F_{l c r}+\gamma_{f} F_{f}\right)
$$

donde:

$\gamma_{C} \quad$ es el peso del término de restricción debido a la clase $C=\{$ materia gris, materia blanca, líquido cefalorraquídeo, fondo\}

$F_{C} \quad$ es la fuerza del mapa discriminante de la clase $C$.

Una posibilidad más es buscar una combinación lineal entre las fuerzas discriminantes de todas las clases, pesando la importancia relativa de cada una de ellas en el término de restricción. En la Figura II.10 se muestra la imagen de la 
fuerza discriminante para materia gris y un acercamiento, mostrando la dirección de su gradiente.

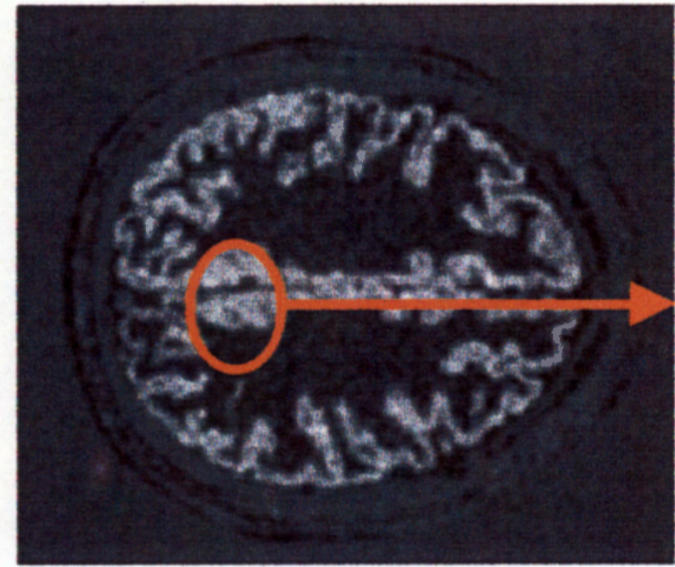

(a)

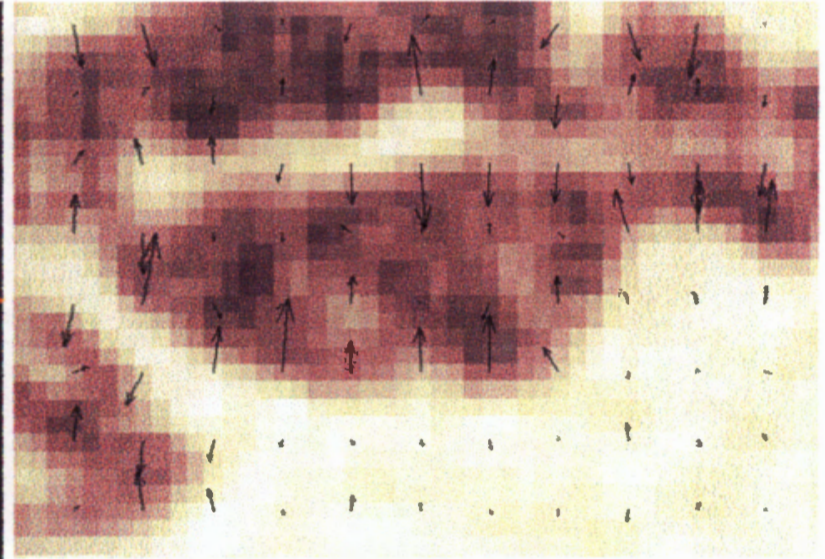

(b)

Figura II.10. Fuerza de restricción: (a) mapa discriminante de materia gris suavizado, (b) dirección del campo gradiente de fuerza asociado, en paleta de colores inversa.

El problema de la búsqueda del contorno óptimo es planteado como un problema de optimización, en donde se busca minimizar el término de Energía asociado al contorno activo [24]. Integrando en el término de la $\mathrm{E}_{\text {snake }}$ todos los componentes descritos anteriormente, es posible obtener el gradiente de la función objetivo respecto al contorno. A continuación se muestra la expresión evolutiva del contorno según el método de descenso por gradiente normalizado:

$$
\begin{aligned}
& \underline{v}^{(t+1)}=\underline{v}^{(t)}+\mu \frac{\left(-\nabla E_{\text {smake }}\right)}{\left\|\nabla E_{\text {sacket }}\right\|} \\
& \underline{v}^{(t+1)}=\underline{v}^{(t)}-\mu \frac{\mathbf{A} \underline{v}^{(t)}-\gamma_{I} F\left(\underline{v}^{(t)}\right)-\gamma_{m g} F_{m g}\left(\underline{v}^{(t)}\right)-\gamma_{m b} F_{m b}\left(\underline{v}^{(t)}\right)-\gamma_{l c r} F_{l c r}\left(\underline{v}^{(t)}\right)-\gamma_{f} F_{f}\left(\underline{v}^{(t)}\right)}{\| \underline{v}^{(t)}-\gamma_{I} F\left(\underline{v}^{(t)}\right)-\gamma_{m g} F_{m g}\left(\underline{v}^{(t)}\right)-\gamma_{m b} F_{m b}\left(\underline{v}^{(t)}\right)-\gamma_{l c r} F_{l c r}\left(\underline{v}^{(t)}\right)-\gamma_{f} F_{f}\left(\underline{v}^{(t)}\right)}
\end{aligned}
$$

(Ec. $\mid 1-15$ )

donde:

t denota el número de iteración

A es la matriz que contiene los parámetros de la $E_{\text {int }}$

$\mu \quad$ es el paso del descenso por gradiente

\section{II.5.4 Acoplamiento Dinámico.}

En la Figura II.11 se muestran algunos casos en donde la RFBRcc es ambigua para decidir, por ejemplo, si la clase es materia gris o materia blanca, como se espera en un segmentador por regiones. Por otro lado, en el ajuste iterativo del 
contorno hacia el borde deseado, se presume que la estimación del borde mejora, y esta condición puede aportar información útil al pre-segmentador, para tratar de reducir la ambigũedad en la frontera entre dos regiones. Aunado al comportamiento propio de la red en tales fronteras, se tiene el efecto de suavizado que se ocasionó al filtrar el mapa discriminante. Si en el ajuste del contorno se afirma que se encuentra cercano a la frontera entre regiones de interés, es posible que la RFBRcc sea capaz de realizar un pequeño ajuste en esa región particular.

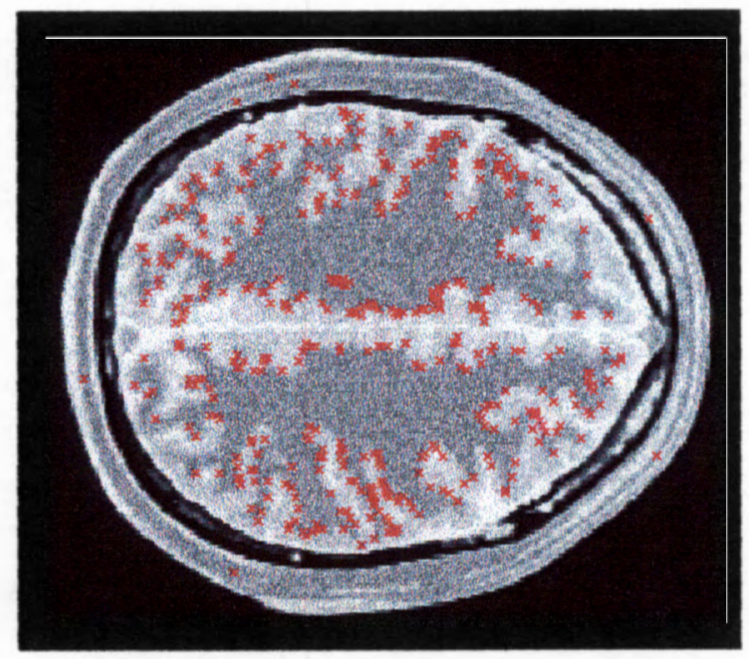

Figura ll.11. Ambigloedad de la RFBRcc

Se propuso una estrategia de retroalimentación entre el modelo de contornos activos y la RFBRcc que permitiera adaptar los pesos de ésta para cada iteración del contomo y para cada imagen, de tal forma que, iterativamente se mejore el término de restricción de la snake y el desempeño de la red. En la Figura II.12 se muestra un esquema del modelo propuesto.

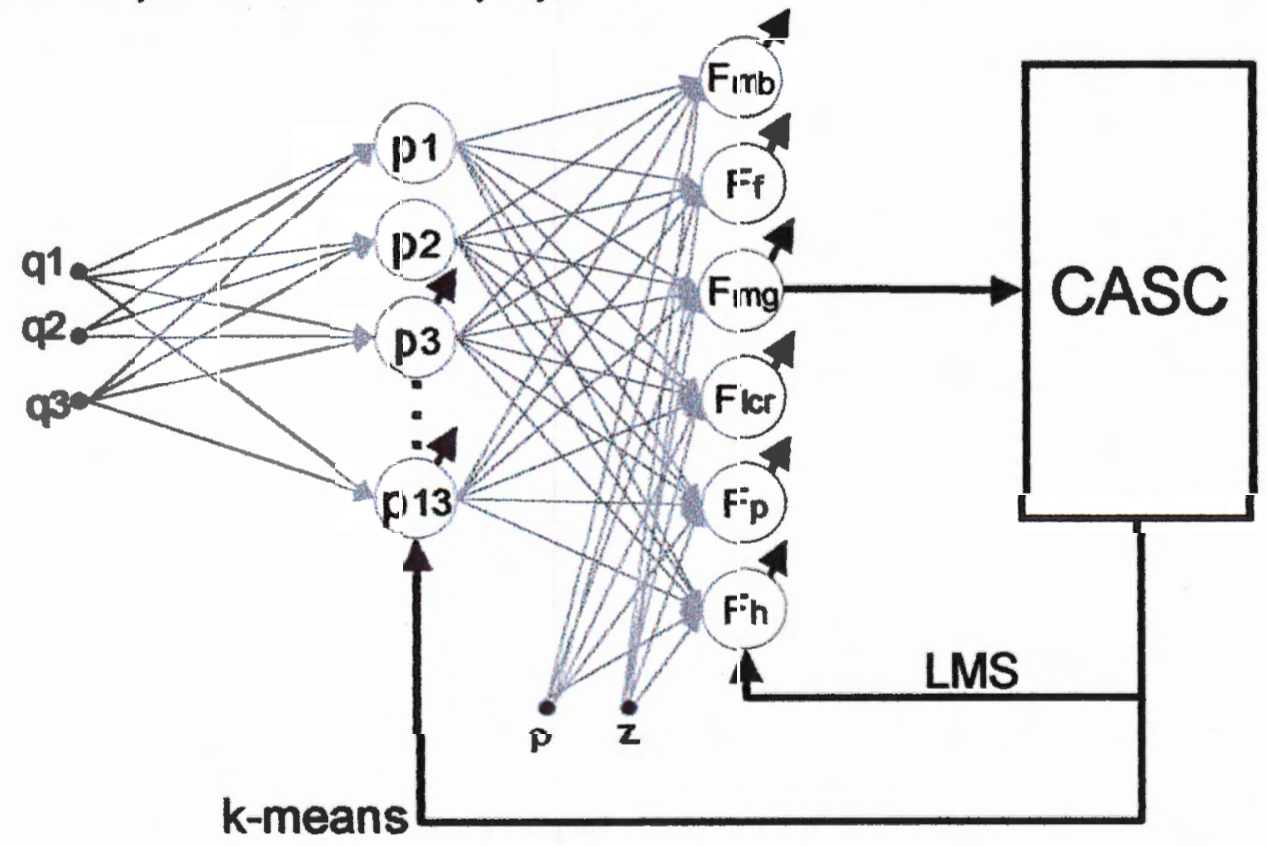

Figura ll:12. Esquema del acoplamiento dinámico entre la RFBRcc y el CASC 
La adaptación se hace en dos puntos: actualización de los parámetros de la mezcla de gaussianas de la capa oculta de red y actualización de los pesos para la capa de clasificación.

1. Actualización de parámetros de la mezcla de gaussianas

- Definir un conjunto provisional de vectores que corresponden a la mezcla de gaussianas ajustada.

- Para cada punto de control del contorno activo:

- Recuperar sus valores de intensidad normalizada q1,q2 y q3

- Determinar a cuál de las medias de las gaussianas próximas a la clase de interés en la mezcla se encuentra más cercano

- Incluir el nuevo dato en el subconjunto de vectores provisionales asignados a tal media.

- Actualizar las medias y matrices de covarianza del conjunto de vectores provisionales, emplearlos como los nuevos parámetros de la mezcla.

- Conservar el conjunto provisional actualizado.

2. Actualización de los pesos de la capa de clasificación. Esta adaptación se realiza vía el algoritmo de LMS para cada uno de los nodos de la etapa de clasificación.

Con estos nuevos parámetros se actualiza el término de restricción en la snake. Para cada iteración del contorno activo, se hace el ajuste de los parámetros de la red descrito anteriormente.

\section{II.6 Evaluación de Desempeño}

El Instituto Neurológico de Montréal (INM) de la Universidad de McGill, provee de un volumen etiquetado que es considerado el volumen de referencia (VR) anatómica para la generación de sus volúmenes simulados; con tal volumen de referencia es posible obtener las Imágenes Binarias de Referencia (IBR), para una clase de tejido pre-establecida (Figura II.13(a)), para cada voxel incluido en la clase de interés se asigna el valor 1, al resto de los voxeles se les asigna el valor de cero.

En el caso de la segmentación por contomos, se considera el área interna delimitada por el contorno resultante, como la región de interés correspondiente. Con esta información es posible generar una Imagen Binaria Calculada (IBC) que es comparable con su IBR equivalente. 
En la Figura II.13 se muestra un ejemplo de la IBR y la IBC (incisos a y c). Es posible generar una imagen de evaluación de las diferencias entre IBR e IBC, calculando la función lógica o-exclusiva entre ambas; en el inciso (b) se muestra la Imagen Binaria Diferencia (IBD) entre las imágenes mostradas en los dos incisos anteriores. Es posible calcular también la IBD entre dos diferentes resultados, por ejemplo entre el resultado del modelo híbrido no adaptable contra el modelo adaptable.

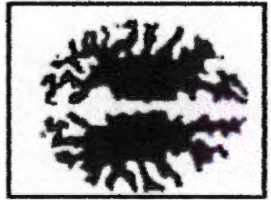

(a)

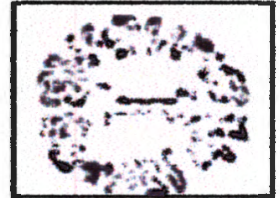

(b)

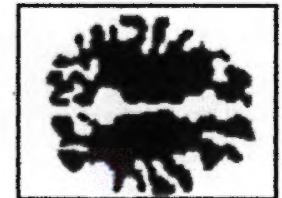

(c)

Figura Il.13. Evaluación del desempeifo del modelo: (a) imagen Binaria de Referencia (IBR) (b) imagen Binaria Diferencia (IBD=xor(IBR,IBC)) (c) imagen Binaria Calculada (IBC)

Cualitativamente la IBD proporciona una noción del desempeño del modelo en prueba, para cada imagen. Con la intención de cuantificar esta calidad del resultado y poder hacer un análisis para todo el conjunto de prueba se calcularon los momentos geométricos hasta de segundo orden para las IBD y su diferencia respecto a los momentos correspondientes de la IBR [46]. El momento geométrico de orden $M$ para una región de interés (ROI) en una imagen binaria, se define como:

$$
m_{k l}=\underset{\forall(x, y) \in R O l}{\sum x^{k} y^{l}} \quad \text { para } \quad M=k l \text { (orden del momento geométrico) }
$$

donde:

$x, y$ coordenadas de un pixel en la ROI

Los momentos geométricos centrales de orden $\mathrm{M}$, se definen como [42]:

$$
\begin{array}{r}
\mu_{k l}=\sum_{\forall(x, y) \in R O I}\left(x-\frac{m_{10}}{m_{\infty}}\right)^{k}\left(y-\frac{m_{\infty}}{m_{\infty}}\right)^{l} \text { para } M=k l \text { (orden del momento } \\
\text { geométrico central) }
\end{array}
$$

Estos momentos se han empleado para caracterizar procesos cuyas imágenes muestran un efecto de asimetría y/o dispersión simétrica alrededor del centro de masa de la ROI [46]. Sin embargo dadas las características de las imágenes binarias calculadas en la segmentación de imágenes cerebrales, donde los bordes encontrados entre la materia blanca y la materia gris por ejemplo, son asimétricas por naturaleza, con tramos con curvatura alta y tramos con curvatura suave, el análisis de los momentos geométricos no arroja resultados concluyentes, excepto por el área de la IBD $\left(m_{00}\right)$. 
En la literatura sobre evaluación de métodos de segmentación, la medida de desempeño con mayor frecuencia empleado es un índice de similitud entre imágenes conocido como el Índice de Tanimoto [42] que representa un indicador cuantitativo global. Este índice se define para imágenes binarias como:

$$
I T=\frac{|I B C \cap I B R|}{|I B C \cup I B R|} \quad 0 \leq I T \leq 1
$$

donde:

14 denota cardinalidad

En la interpretación de este índice $I T=0$ significa que ambas imágenes son completamente diferentes e $I T=1$ significa que ambas imágenes son iguales.

El indice de similitud de Dice (ID) [58], cuya interpretación es similar al IT se define como:

$$
I D=\frac{2 *|I B C \cap I B A|}{|I B C|+|I B E|} \quad 0 \leq I D \leq 1
$$

En la Figura II.14 se muestra la relación lineal entre ambos índices medidos sobre un conjunto de imágenes de prueba; se obtuvo un $r^{2}=0.98$

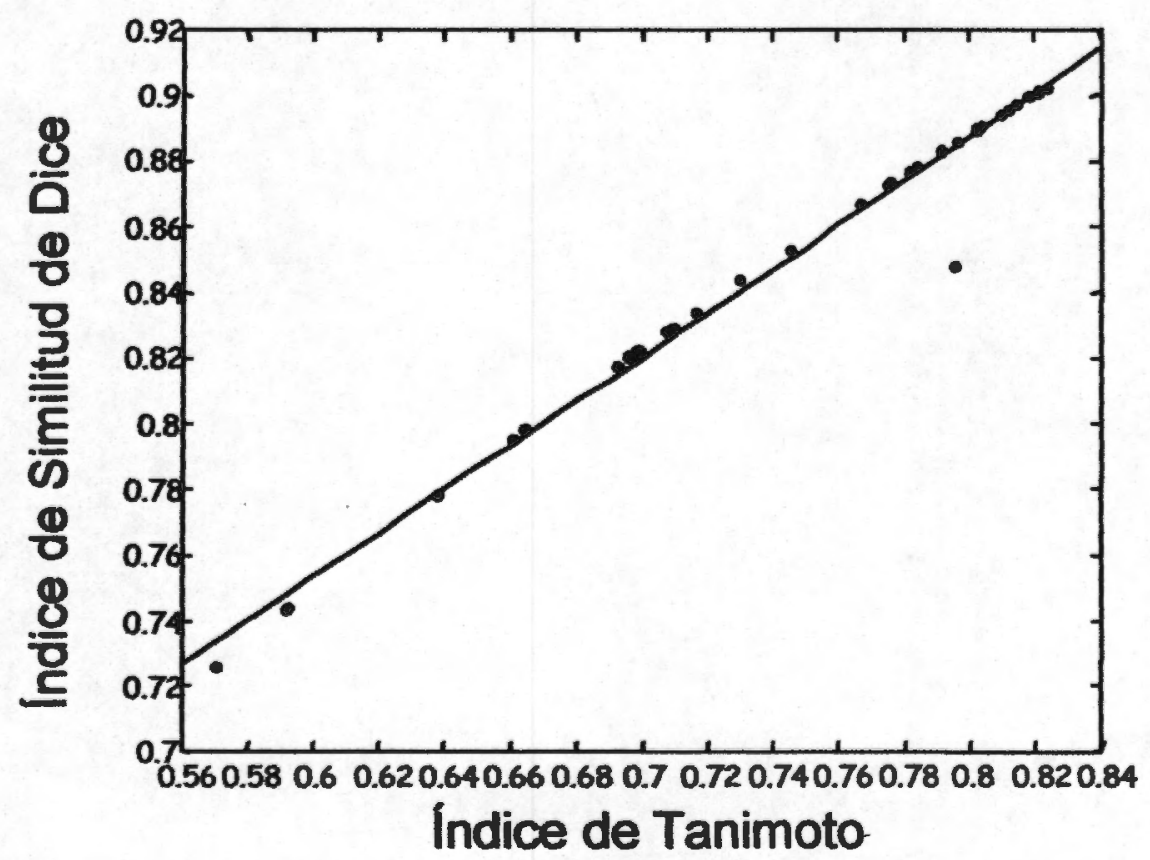

Figura 11.14. Relación lineal entre los indices de similitud más frecuentemente usado en la segmentación de imágenes cerebrales. 
Dado este comportamiento lineal entre los indices y que se observó una relación inversa consistente entre el índice de Tanimoto y el área de la IBD. En este trabajo se empleó el índice de Tanimoto como criterio de desempeño global para la valoración de resultados. 


\section{Resultados y Discusión.}

La evaluación de la propuesta de segmentación de imágenes cerebrales multiespectrales por Resonancia Magnética, que implica el acoplamiento de diversas fases de modelos más simples, como lo son la Red con Funciones de Base Radial y el modelo de los Contomos Activos con Splines Cúbicos, ha significado la valoración a nivel individual y global de las diversas variantes que el mismo modelo híbrido permite. En este capítulo se presentan y discuten los resultados obtenidos en las variaciones propuestas para el modelo híbrido de segmentación, tal como se presentaron en el capítulo anterior. Se analizan también los resultados obtenidos en la segmentación de imágenes reales, y finalmente, se presenta una comparación y discusión de los resultados obtenidos con otros paradigmas de segmentación.

\section{III.1 Variaciones del modelo híbrido}

En esta sección se presentan y discuten los resultados de la etapa de preprocesamiento de las imágenes, que consiste en una normalización en el espacio cartesiano o registro y una normalización del espacio de intensidades. Igualmente, se presentan los resultados de la Red con funciones de Base Radial, de la inicialización del contorno activo, de los términos de energía externa para los CASC, y de la variante en el acoplamiento entre el pre-segmentador y el modelo de CASC.

\section{III.1.1 Registro de Imágenes Reales}

Este procedimiento se realizó en la primera etapa del proyecto, para la depuración del pre-segmentador. Se emplearon las imágenes reales provistas por el Hospital $A B C$; de los cinco volúmenes se tomó uno como volumen de referencia espacial y para la selección del conjunto de entrenamiento de la red.

Para la validación del procedimiento de registro se realizaron un conjunto de transformaciones conocidas sobre el volumen de referencia y posteriormente se aplicó el proceso de registro para tratar de recuperar las imágenes originales; se procesaron las imágenes $\mathrm{T} 1$ para hacer el registro. El error en el registro se contabilizó mediante el porcentaje de diferencias residuales (PDR) [56]:

$$
P D R=\frac{100}{N} \sqrt{\sum \frac{\left(y_{R}-y_{T}\right)^{2}}{y_{R}^{2}}}
$$


donde:

$Y_{R}$ representa la intensidad del pixel en la imagen de referencia,

$y_{T} \quad$ representa la intensidad del pixel en la imagen transformada; y

$\mathrm{N}$ total de pixeles en las imágenes

EI PDR medio fue de $0.36 \pm 0.15 \%$.

Sobre la precisión en cada uno de los parámetros de la transformación global, se obtuvieron los resultados que se muestran en la Tabla III-1.

\begin{tabular}{|l|l|}
\hline Parámetro & Precisión \\
\hline Escala en eje antero-posterior & $0.001 \pm 0.002$ \\
\hline Escala en eje izq-der & $0.001 \pm 0.003$ \\
\hline $\begin{array}{l}\text { Ángulo de rotación } \\
\text { en plano axial (radianes) }\end{array}$ & $0.001 \pm 0.002$ \\
\hline Desplazamiento en eje antero-posterior (pixeles) & $0.300 \pm 0.600$ \\
\hline Desplazamiento en eje izq-der (pixeles) & $0.300 \pm 0.500$ \\
\hline
\end{tabular}

Tabla III-1. Precisión de parámetros de la transformación global para registro de imágenes

La Figura III.1 muestra ejemplos del registro de los cuatro volúmenes de prueba. Todas las imágenes están registradas respecto a la imagen de referencia mostrada en la primera columna, la tercer columna muestra las imágenes originales, y en la columna central se muestran las correspondientes imágenes registradas. Es importante notar que para el segundo y cuarto caso, la transformación de escalamiento es muy importante, especialmente en el segundo caso, en donde la corrección se hizo en ambas dimensiones. El tercer caso, presentó un problema de rotación, que fue sobre-compensado por el algoritmo de registro. 


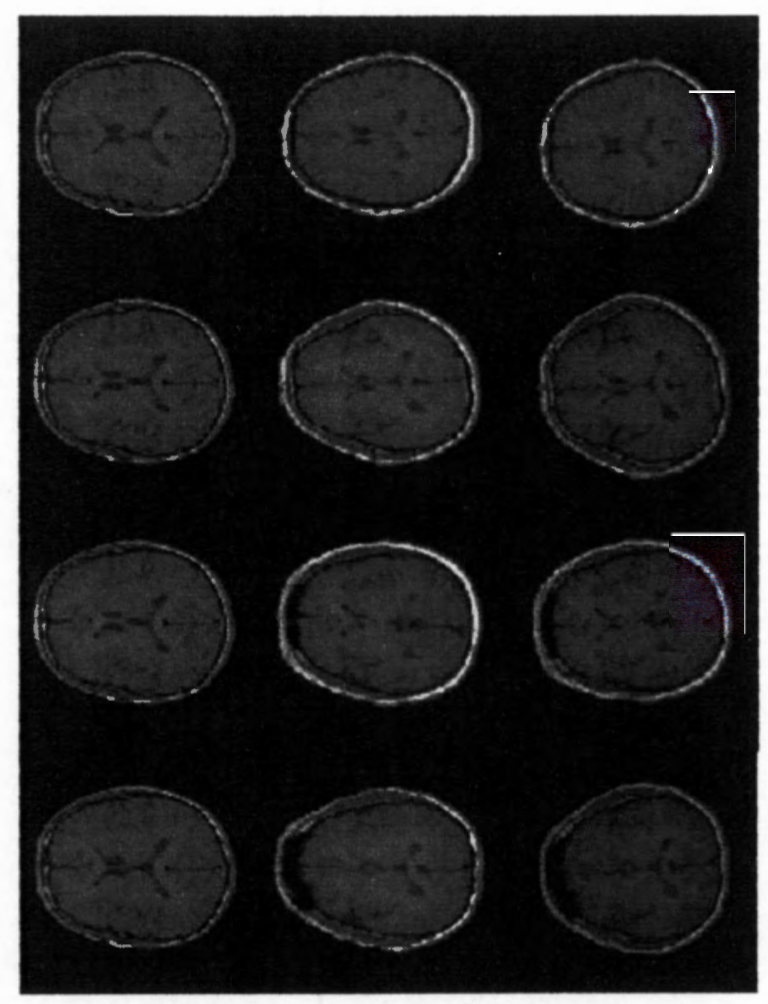

Figura Ill.1. Resultados del registro de cuatro volúmenes de imágenes reales. Primera columna muestra la imagen de referencia, la tercera columna muestra la imagen objetivo y en la segunda columna se muestra la imagen transformada.

\section{III.1.2 Normalización del Espacio de Intensidades}

En la Figura III.2 se muestra el nuevo espacio normalizado de acuerdo al Estudio I en azul y el estudio III en rojo, de acuerdo al mínimo loglikelihood obtenido para la transformación K-L. (Tabla III-2).

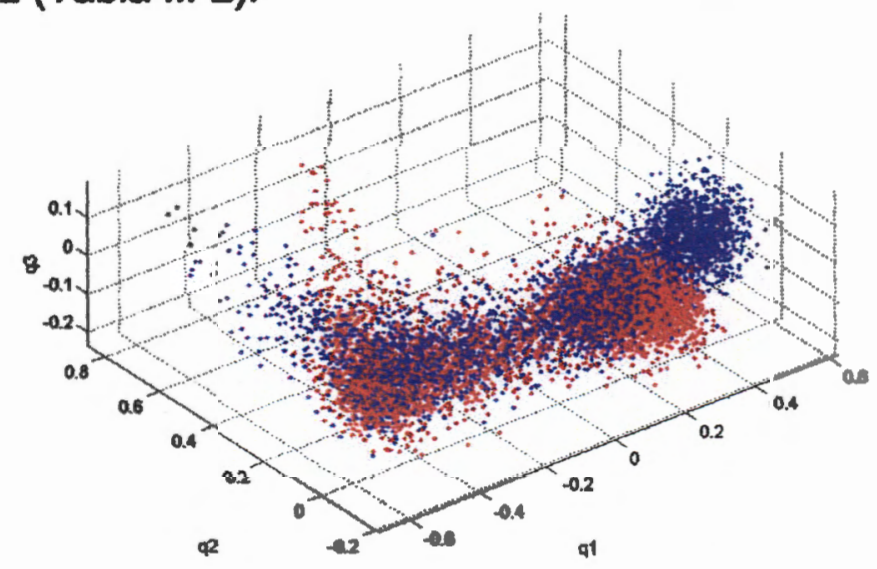

Figura III.2. Espacio normalizado de intensidades. Se muestran vectores de materia gris, materia blanca y Icr. En azul, el estudio de referencia (estudio I), en rojo el estudio III. 


\begin{tabular}{|l|l|l|l|}
\hline & \multicolumn{3}{|l|}{ Estudios } \\
\hline $\begin{array}{l}\text { combinación de } \\
\text { vectores propios }\end{array}$ & II & III & IV \\
\hline$q 1, q 2, q 3$ & 1.396 & 1.740 & 1.601 \\
\hline$q 1, q 2,-q 3$ & 1.395 & 1.740 & 1.589 \\
\hline$q 1,-q 2, q 3$ & 1.468 & 1.621 & 1.753 \\
\hline$q 1,-q 2,-q 3$ & 1.467 & 1.621 & 1.737 \\
\hline$-q 1, q 2, q 3$ & 1.605 & 1.561 & 1.825 \\
\hline$-q 1, q 2,-q 3$ & 1.606 & 1.550 & 1.835 \\
\hline$-q 1,-q 2, q 3$ & 1.661 & 1.479 & 1.893 \\
\hline$-q 1,-q 2,-q 3$ & 1.659 & 1.476 & 1.894 \\
\hline
\end{tabular}

Tabla III-2. Valores del loglikelihood para los estudios de prueba*

"q1,q2,q3 refieren a los vectores propios unitarios ordenados descendentemente de acuerdo a la máxima varianza, el signo menos representa cambio de sentido del vector

En la Figura III.3 se muestra una imagen segmentada del Estudio IV antes y después de la normalización.

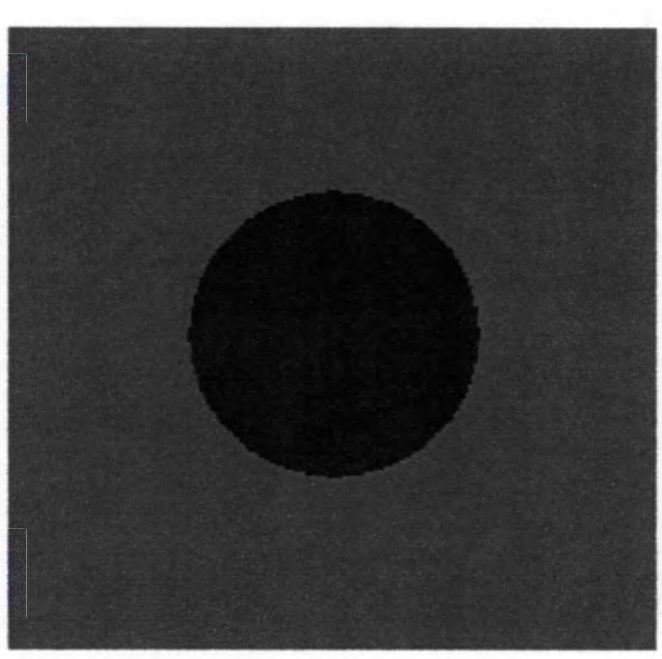

(a)

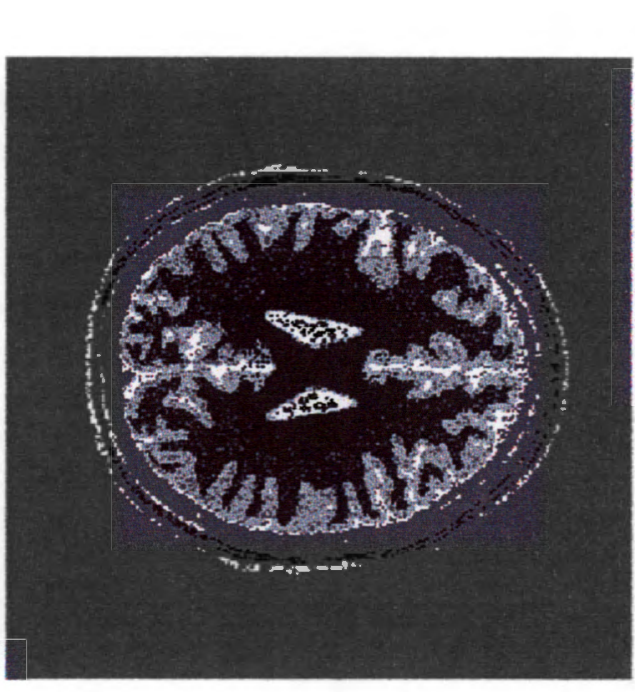

(b)

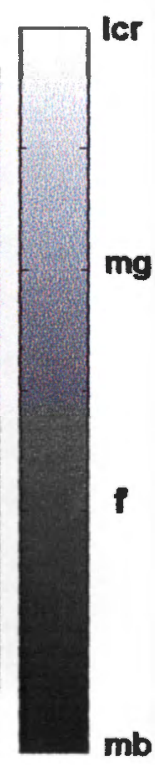

$\mathrm{mb}$

Figura III.3. Imagen Segmentada del Estudio N, para cuatro clases: materia blanca, materia gris, Icr y fondo: (a) sin normalización, clases fondo y materia blanca, (b) imagen multiespectral normalizada.

Se sabe que en un proceso de clasificación supervisada, se logran obtener altas tasas de rendimiento, en la medida en que el espacio de características se haya modelado correctamente con la muestra de entrenamiento. Sin embargo, ante estudios de RM con diferentes protocolos de adquisición, la estadística de los datos cambia, por lo tanto el clasificador previamente diseñado, está completamente fuera de especificación, como se observa en la Figura III.3a que muestra una imagen etiquetada completamente como clase fondo. Al transformar 
el espacio original de intensidades a un espacio de características normalizado es posible entrenar la RFBRcc bajo esta nueva estadística, y a pesar de que los vectores de entrenamiento provienen de estudios de RM con parámetros distintos a los de las imágenes de prueba, la red responde satisfactoriamente (Figura III.3b).

\section{III.1.3 Red de Funciones de Base Radial Modificada}

Durante la etapa de definición de la estructura de la RFBRcc, se concluyó experimentalmente sobre la relevancia de la información de localización para el clasificador y sobre su inclusión en la capa de salida. En el análisis de la relevancia de la información de las intensidades T1, T2 y DP, se muestra a continuación los coeficientes de correlación obtenidos entre bandas:

\begin{tabular}{|c|c|c|c|}
\hline & T1 & T2 & $\overline{D P}$ \\
\hline T1 & 1 & 0.7707 & 0.9870 \\
\hline T2 & & 1 & 0.7706 \\
\hline DP & & & 1 \\
\hline
\end{tabular}

Tabla III-3. Coeficientes de correlación entre las intensidades T1, T2 y DP del conjunto de vectores de entrenamiento

Es claro que la intensidad T2 posee el menor coeficiente de correlación entre las dos intensidades restantes y que la intensidad T1 y DP tienen un alto coeficiente de correlación. Experimentalmente se confirmó que con la inclusión sólo de las intensidades T1 y T2, se obtuvieron tasas de clasificación elevadas, sin embargo con la inclusión de las tres intensidades, se obtuvieron las mejores tasas de clasificación, principalmente para las clases materia gris, materia blanca y líquido cefalorraquídeo, la ganancia obtenida bajo esta última consideración fue de alrededor de un punto porcentual.

La estructura final de la RFBRcc quedó definida con los parámetros mostrados en el Apéndice A-I. La matriz de confusión obtenida con la estructura propuesta se muestra a continuación:

\begin{tabular}{|l|l|l|l|l|l|l|}
\hline clase & $\mathrm{mb}$ & $\mathrm{f}$ & $\mathrm{mg}$ & $\mathrm{lcr}$ & $\mathrm{p}$ & $\mathrm{h}$ \\
\hline $\mathrm{mb}$ & 90 & 0 & 5 & 0 & 2 & 3 \\
\hline $\mathrm{f}$ & 0 & 70 & 0 & 0 & 0 & 30 \\
\hline $\mathrm{mg}$ & 3 & 0 & 89 & 1 & 4 & 3 \\
\hline $\mathrm{lcr}$ & 0 & 0 & 3 & 81 & 12 & 3 \\
\hline $\mathrm{p}$ & 2 & 0 & 2 & 20 & 73 & 3 \\
\hline $\mathrm{h}$ & 1 & 0 & 0 & 1 & 7 & 91 \\
\hline
\end{tabular}

Tabla 111-4. Matriz de confusión para la RFBR mostrada en la Figura II-5. Los valores representan puntos porcentuales 
Si se considera el total de vectores clasificado correctamente, se obtiene un $82 \%$ de clasificación correcta de vectores, sin embargo la clase fondo y la clase piel/grasa se encuentran disminuidas en su tasa de acierto. En la Figura II.3, se muestra la distribución de vectores en el espacio de características. El proceso de normalización se hace sólo para una región que contiene voxeles de materia blanca, materia gris y líquido cefalorraquídeo, en consecuencia, no es posible garantizar que al transformar, el resto de las clases queden igualmente distribuidas en el espacio. La clase fondo queda prácticamente embebida en un extremo de la clase hueso; entre las clases líquido cefalorraquídeo y piel/grasa se da una superposición significativa en el espacio de características; si se considera el caso de fundir las clases de hueso y fondo en una sola clase, la tasa general de aciertos se eleva al $88 \%$. De hecho en las imágenes pre-segmentadas, donde sólo se muestran las clases $\mathrm{mb}, \mathrm{mg}$, Icr y fondo, ésta última etiqueta incluye a las clases de hueso y piel/grasa.

Es importante hacer notar desde la misma Figura II-3, el papel de las caracteristicas de localización espacial (coordenadas cilindricas) en el clasificador. Si bien el fondo y el hueso están completamente confundidos en cuanto a sus características multiespectrales, la información espacial ayuda a diferenciarlos. Algo similar sucede con la clase piel/grasa y el líquido cefalorraquídeo.

En la Figura III.4 se muestra el resultado de la pre-segmentación para una imagen multiespectral (inciso a) del Estudio II, en el inciso (b) se muestran los mapas discriminantes para cada una de las clases predeterminadas: materia blanca, fondo, materia gris, líquido cefalorraquídeo, piel/grasa y hueso. En la paleta de grises el blanco corresponde a la probabilidad máxima estimada de pertenencia a la clase deseada y el nivel negro corresponde a lo opuesto. Finalmente en el inciso (c) se muestra la imagen etiquetada de acuerdo a la máxima probabilidad a posteriori, se fundieron las clases hueso, fondo y piel/grasa, se presentan todas con la etiqueta de fondo. Se puede observar sobre la imagen segmentada la confusión del clasificador entre la clase piel/grasa y lcr, asi como algunos errores también entre materia blanca y la clases piel/grasa.

De los mapas de salida, se puede observar que la RFBRcc no construye mapas binarios con indicación de pertenencia, sino que estima una función de probabilidad de pertenencia a cada clase. Esta información permite modelar el efecto de volumen parcial presente en los estudios tomográficos de RM. 


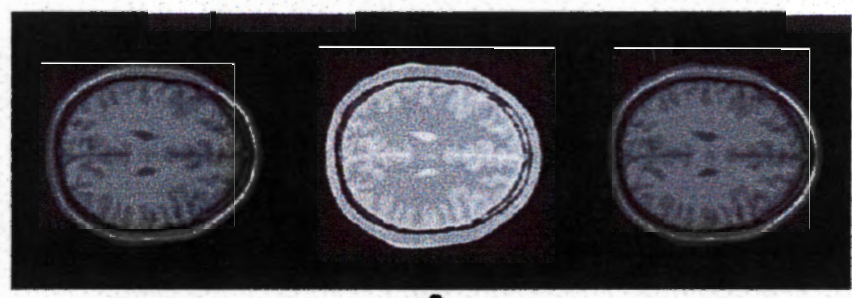

91

q2

q3
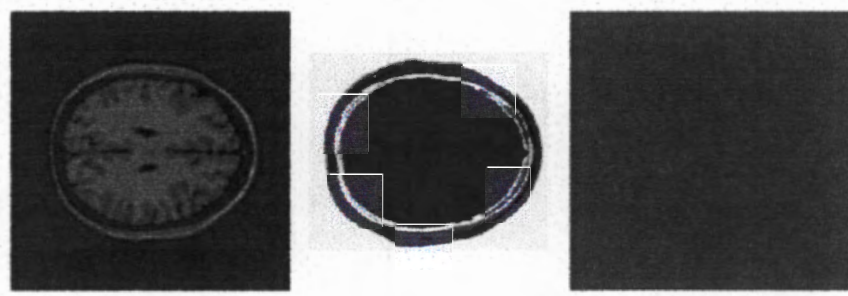

(a)

mb fondo mg
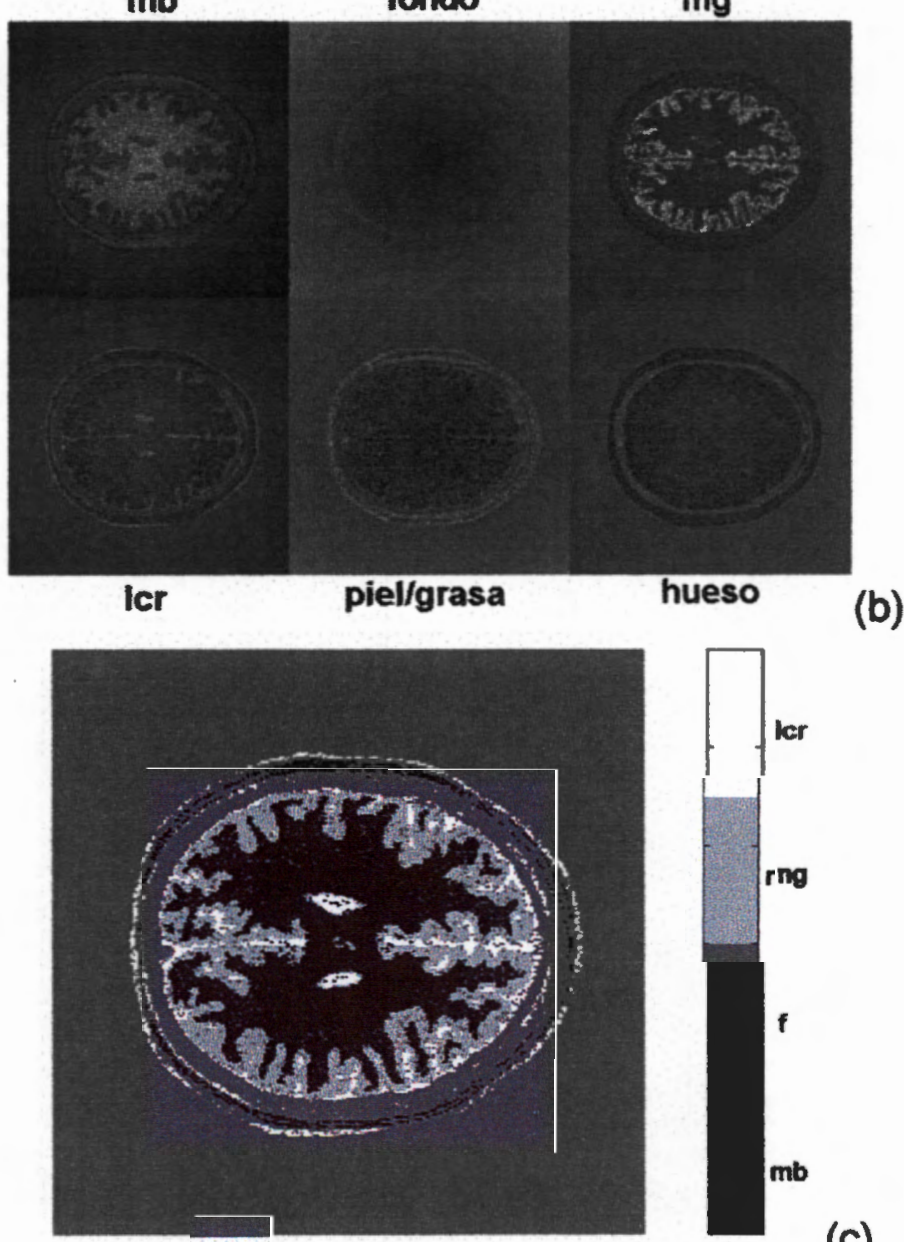

(b)

(c)

Figura Ill.4. Resultado de la pre-segmentación: (a) imágenes T1, T2 y DP, de izquierda a derecha, abajo imágenes en espacio de intensidades normalizado (b) mapas discriminantes: materia blanca, fondo y materia gris, en el segundo renglón: líquido cefalorraquideo, piel/grasa y hueso, (c) imagen segmentada considerando la máxima probabilidad posterior: en blanco se muestra la clase Icr, en gris claro se muestra la materia gris, en gris oscuro se muestra la clase fondo, y en negro se muestra la clase materia blanca. 
En la Figura III.5 se muestran cortes del volumen del Estudio II presegmentado, en diferentes planos de visualización; el etiquetado de cada voxel del volumen, corresponde a la máxima probabilidad posterior estimada por le RFBRcc.

a)

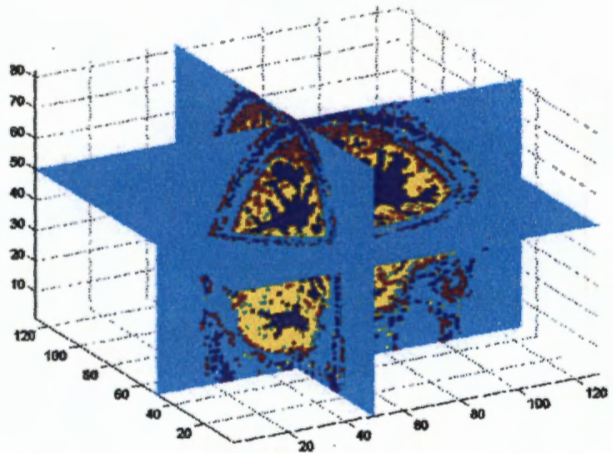

c)

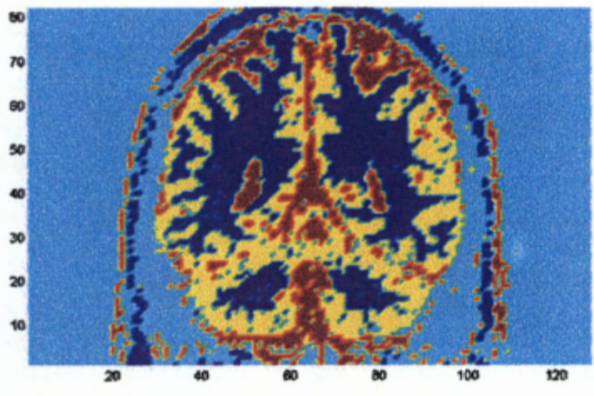

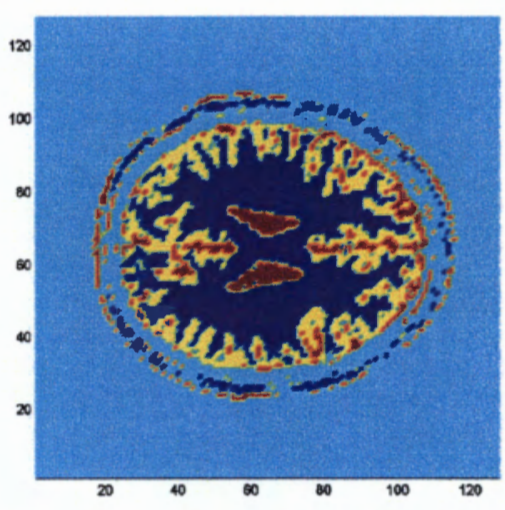
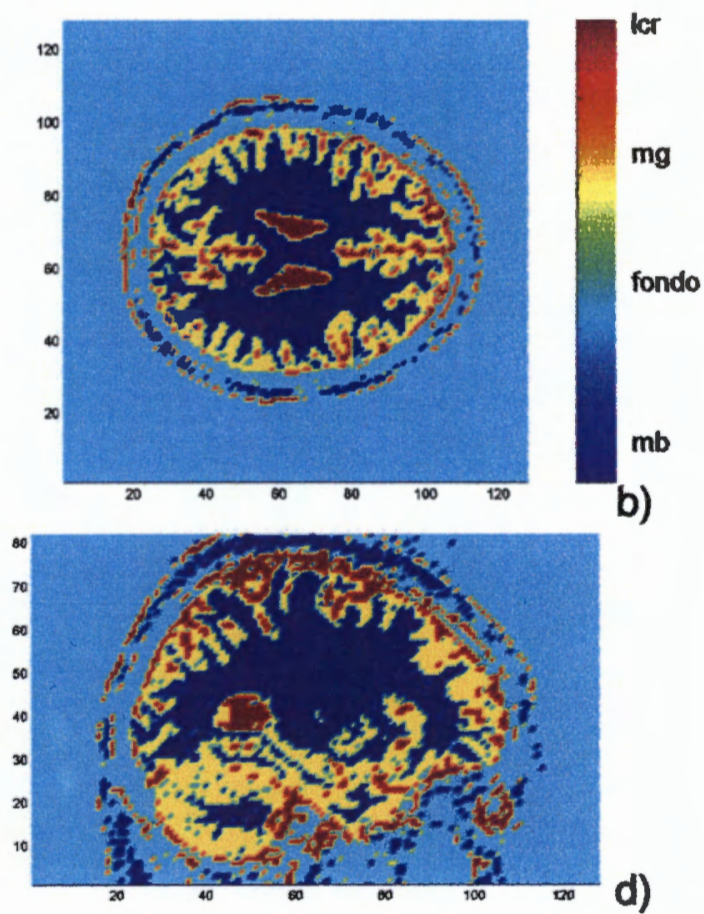

Figura ill.5. Vistas del volumen segmentado: (a) planos de corte (b) axial (c) coronal (d) sagital.

En la Figura III.6 se muestran las representaciones volumétricas de la materia gris, materia blanca y ventrículos cerebrales; a partir del volumen segmentado, se obtuvieron imágenes binarias para cada una de las estructuras propuestas, que fueron procesadas con una operación morfológica simple, para reducir el efecto del ruido en la segmentación, esta información espuria se muestra en la Figura III.5. En el volumen construido para materia blanca, no alcanzaron a eliminarse todos los artefactos de la segmentación, básicamente en los cortes inferiores. Los ventrículos fueron recortados manualmente, a partir del resultado para la clase líquido cefalorraquídeo. 


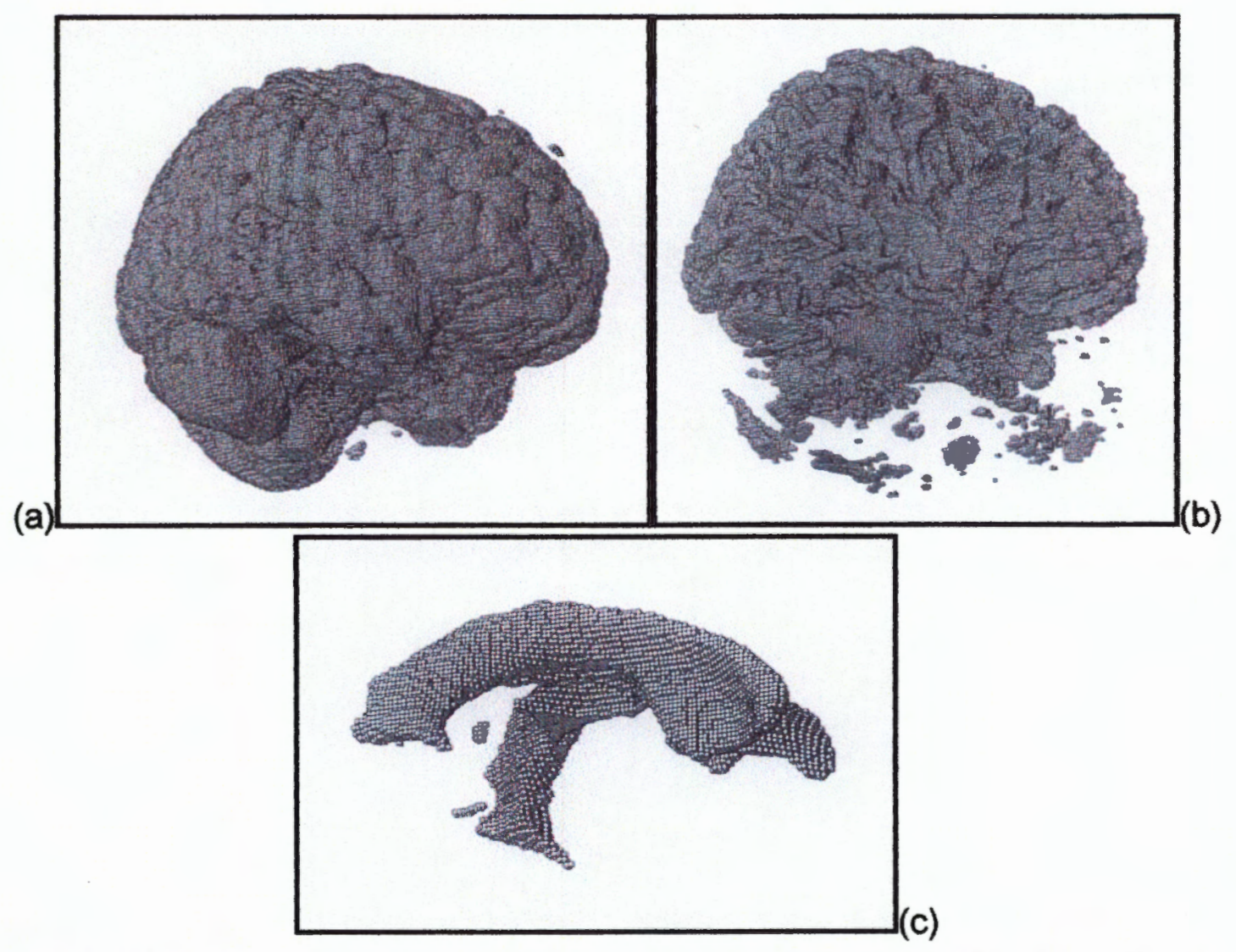

Figura III,6. Representación volumétrica de algunas estructuras cerebrales segmentadas con la RFBRcc: (a) materia gris (b) materia blanca (c) ventrículos cerebrales

\section{III.1.4 Análisis del desempeño de la RFBRcc en condiciones de ruido.}

En la etapa de prueba del pre-segmentador, se planteó un modelo de ruido aditivo blanco gaussiano con media cero y varianza $\sigma^{2}$ para corromper los vectores de características. En la Figura III.7 se muestran las razones de acierto en la clasificación contra la varianza del ruido para el conjunto de validación. Sólo se consideraron vectores de las clases de materia blanca, fondo y materia gris.

En un primer experimento, el modelo de ruido se limitó a las características de las intensidades T1, T2 y DP de los vectores, que probablemente sea el escenario más frecuente (incisos a y $b$, con $\sigma^{2}=0.01$ y 0.05 ). En los incisos (c) y (d) se muestran la gráfica correspondiente a un modelo de contaminación para todas las características de los vectores, a un mismo nivel de varianza (mismo caso de a y b). En los incisos (e) al (g) se muestran las razones de acierto en la clasificación contra la varianza del ruido asumiendo distorsión sólo en las coordenadas cilíndricas, para tres niveles de varianza: $\sigma^{2}=0.01,0.05$ y 0.10 . En el inciso $(h)$ de la misma figura se presenta un caso de contaminación en las cinco características pero con niveles de varianza distintos: para características espectrales (CE) $\sigma^{2}=0.05$ y para coordenadas cilindricas $(c c) \sigma^{2}=0.10$. 


\begin{tabular}{|c|c|c|c|}
\hline clase & $\mathbf{m b}$ & $f$ & $\mathrm{mg}$ \\
\hline$m b$ & 93 & 2 & 4 \\
\hline$f$ & 0 & 100 & 0 \\
\hline $\mathbf{m g}$ & 4 & 3 & 93 \\
\hline
\end{tabular}

\begin{tabular}{|c|c|c|c|}
\hline clase & $\mathrm{mb}$ & $f$ & mg \\
\hline mb & 78 & 14 & 8 \\
\hline$f$ & 0 & 100 & 0 \\
\hline mg & 26 & 20 & 54 \\
\hline
\end{tabular}

\begin{tabular}{|c|c|c|c|}
\hline clase & $m b$ & $f$ & $m g$ \\
\hline$m b$ & 93 & 2 & 5 \\
\hline$f$ & 0 & 100 & 0 \\
\hline$m g$ & 4 & 3 & 93 \\
\hline
\end{tabular}

$\sigma^{2}=0.01$

\begin{tabular}{|c|c|c|c|}
\hline clase & $m b$ & $f$ & $m g$ \\
\hline$m b$ & 79 & 14 & 8 \\
\hline$f$ & 0 & 100 & 0 \\
\cline { 1 - 3 } $\begin{array}{c}\sigma^{2}=0.01 \\
\text { (d) }\end{array}$ \\
\hline
\end{tabular}

\begin{tabular}{|c|c|c|c|}
\hline clase & $m b$ & $f$ & $m g$ \\
\hline$m b$ & 94 & 2 & 5 \\
\hline$f$ & 0 & 100 & 0 \\
\hline$m g$ & 3 & 2 & 95 \\
$\sigma^{2}=0.01$ \\
$(\theta)$
\end{tabular}

\begin{tabular}{|c|c|c|c|}
\hline clase & $m b$ & $f$ & $m g$ \\
\hline$m b$ & 93 & 2 & 5 \\
\cline { 1 - 3 }$f$ & 0 & 100 & 0 \\
\cline { 1 - 3 } & $\begin{array}{c}\sigma^{2}=0.01 \\
(f)\end{array}$ \\
\hline
\end{tabular}

\begin{tabular}{|c|c|c|c|}
\hline clase & $m b$ & $f$ & $m g$ \\
\hline$m b$ & 93 & 2 & 5 \\
\hline$f$ & 0 & 100 & 0 \\
\hline$m g$ & 4 & 3 & 93 \\
\hline
\end{tabular}

\begin{tabular}{|c|c|c|c|c|}
\hline clase & $\mathrm{mb}$ & f & $\mathrm{mg}$ & \multirow{4}{*}{$\begin{array}{c}\text { CE: } \sigma^{2}=0.05 \\
\text { cc: } \sigma^{2}=0.10 \\
\text { (h) }\end{array}$} \\
\hline $\mathrm{mb}$ & 75 & 18 & 7 & \\
\hline f & 1 & 99 & 0 & \\
\hline $\mathrm{mg}$ & 27 & 21 & 52 & \\
\hline
\end{tabular}

Figura III.7. Desempeño de la RFBRcc bajo diversas condiciones de ruido aditivo gaussiano. Matrices de confusión para: $(a, b)$ contaminación en intensidad $(c, d)$ contaminación en intensidad y coordenadas cilindricas; (e-g) contaminación en coordenadas cilindricas; (h) diferentes varianzas de ruido para intensidad y coordenadas cilindricas.

De las matrices de confusión mostradas anteriormente, se observa que la RFBRcc es más robusta para la contaminación de coordenadas cilíndricas que para la contaminación de las características espectrales; en el inciso $(\mathrm{g})$ se muestra un buen desempeño del pre-segmentador ante un caso de contaminación severa en las coordenadas cilíndricas. Al observar la distribución de intensidades de las clases materia gris y materia blanca (Figura II-3) se explica el efecto mostrado en los incisos (b), (d) y (h), en donde la detección de la materia gris se deteriora al confundirse los vectores con la clase materia blanca. Es precisamente entre estas clases donde se presenta el mayor traslape de características.

\section{III.1.5 Imágenes de Prueba}

Se seleccionaron algunas imágenes del volumen simulado para valorar el desempeño del modelo híbrido propuesto. En la Figura III.8 se muestran las imágenes T2 seleccionadas del Estudio II, como se puede observar (arregladas por columna) se consideraron tercias de imágenes axiales a diferentes alturas de 
la cabeza, cuyo borde entre la materia gris y la materia blanca fuera similar, así como diferentes tercias para valorar el desempeño con bordes morfológicamente distintos (arreglados en renglón). En la columna (a) se muestran las imágenes más bajas, donde se distinguen bordes pequeños pero con concavidades severas. En la columna (b) se muestran imágenes medias-inferiores donde el borde es de mayor longitud con concavidades profundas pero con regiones con curvatura muy suave. En la columna (c) se muestran imágenes medias-superiores donde el borde es de mayor longitud y en dos de ellas, puede extraerse un solo borde para todo el cerebro. En la columna (d) se muestran imágenes superiores donde se distingue la separación hemisférica y donde se tienen regiones de curvatura suave y regiones donde aparecen circunvoluciones profundas.
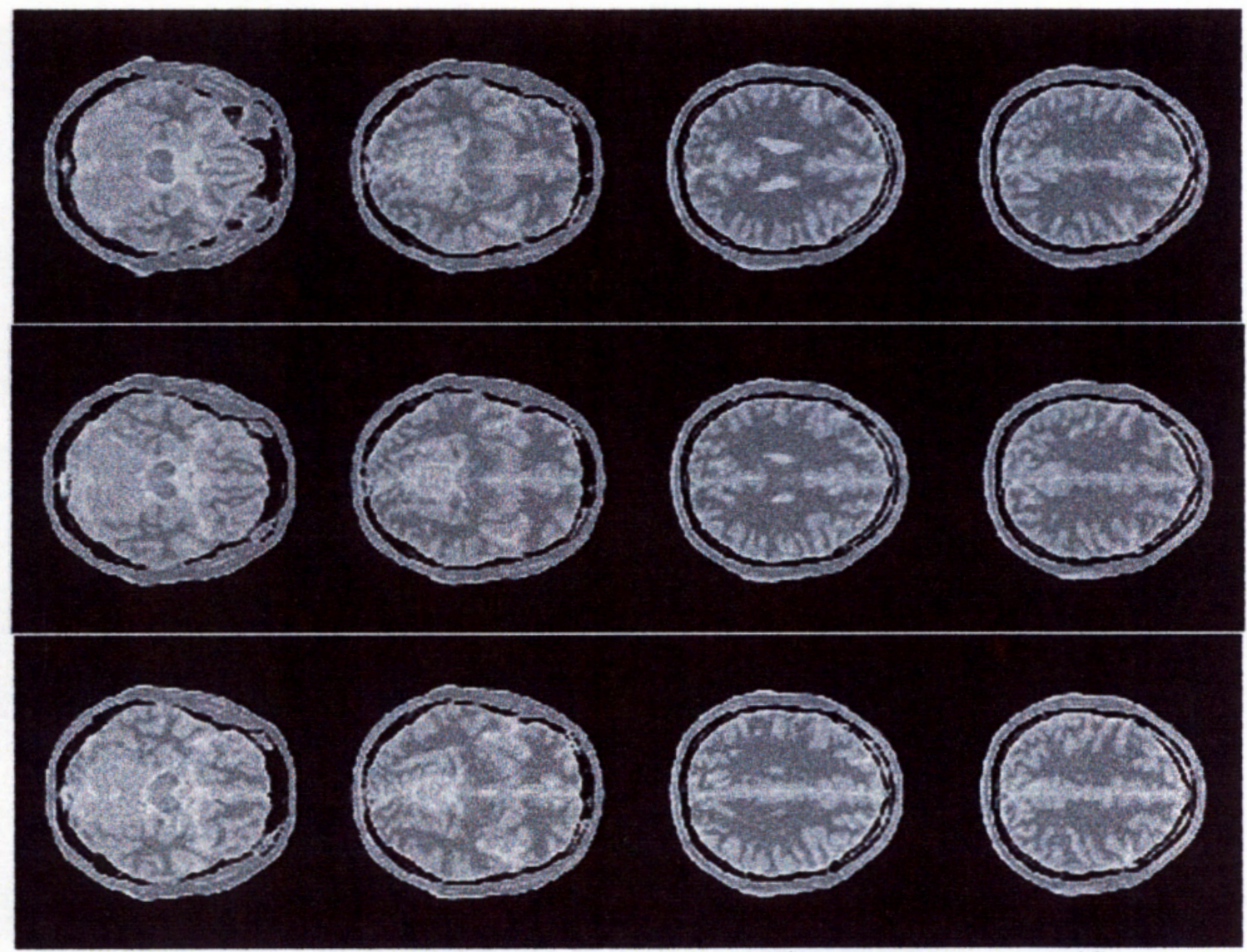

(a)

(b)

(c)

(d)

Figura III.8. Imágenes T2 de prueba del Estudio Il: (a) imágenes bajas (b) imágenes mediabajas (c) imágenes media-altas (d) imágenes superiores 


\section{III.1.6 Contorno Inicial}

En la primera aproximación del modelo, los contornos prototipos fueron generados manualmente a partir de las imágenes binarias de los mapas discriminantes de materia gris, para cada imagen de prueba. En diez de las doce imágenes empleadas, se obtuvieron contornos para cada hemisferio cerebral y fueron tratados individualmente. El índice de Tanimoto promedio obtenido para el conjunto de imágenes de prueba, considerando su contorno prototipo fue de: $0.70 \pm 0.08$, que significa una muy buena calidad para dicho contorno.

Como se describió en el capítulo anterior, es posible obtener un contorno prototipo a partir del resultado del pre-segmentador de una forma semi-automatizada. En las 12 imágenes de prueba se distinguieron claramente la(s) región(es) de interés.

A continuación se muestra en el inciso (a) la imagen binaria dilatada a partir de la salida del nodo de materia blanca de la RFBRcc, en rojo se muestra el contorno prototipo calculado, con el algoritmo propuesto. En el inciso (b) se muestran los contornos iniciales obtenidos manualmente (verde) y semi-automáticamente (rojo) para la misma imagen. Las diferencias entre ambos prototipos es pequeña, la razón de índices de Tanimoto fue de: 0.99 . En imágenes donde se presenta mayor "fragmentación" de la materia blanca, el algoritmo propuesto podrá recuperar más de dos contornos prototipos, atendiendo sólo a un criterio de interés, como puede ser que la región involucrada exceda un mínimo de área pre-establecido. Un ejemplo de ello se puede observar en Figura III.9(c).

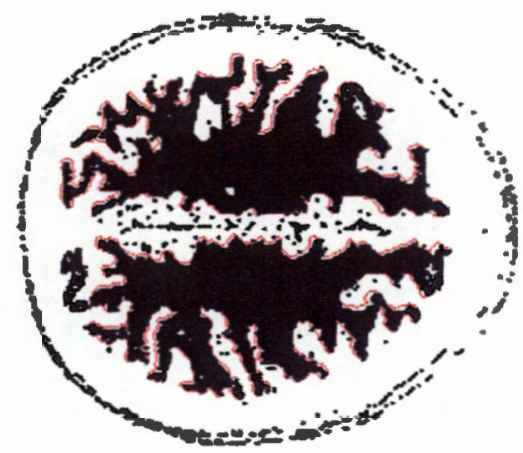

(a)

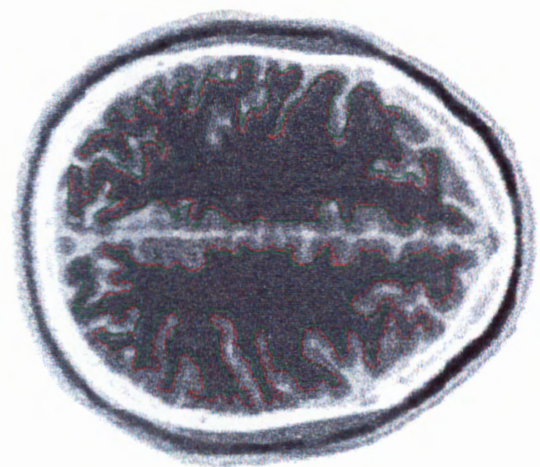

(b) 


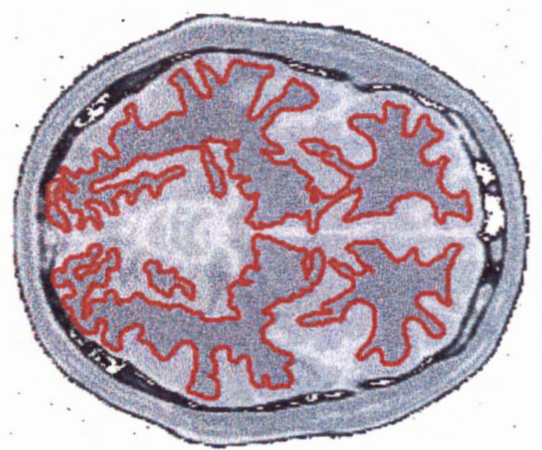

(c)

Figura Ill.9. Contorno inicial: (a) imagen binaria dilatada de la clase materia blanca, en rojo se muestra ef contorno inicial obtenido, (b) imagen T2 con contornos iniciales manual (vende) y semi-automático (rojo), (c) contomo semi-automático para cuatro regiones con área significativa.

\section{III.1.7 Contorno Activo basado en Splines Cúbicos}

Los parámetros usados en el modelo de contornos activos se resumen en el Apéndice A-II

En la Figura III.10a se muestra un ejemplo de contorno resultante para el término de $E_{\text {imagen }}$ propuesto (combinación lineal de gradientes monoespectrales, sección II.5.3). En los incisos (b)-(d) se muestran las imágenes de la magnitud de los gradientes escalares para las bandas T1, T2 y DP respectivamente, mostradas en una paleta inversa de grises. En ellas se puede observar que los bordes entre el fondo y piel y entre el parénquima cerebral y el espacio subaracnoide generan una señal intensa, mientras que el borde entre las materias gris y blanca tiene una intensidad menor. También se puede observar que se resalta el ruido de las imágenes originales. Estas dos características provocan un campo de fuerza desordenado para la $E_{\text {imagen }}$ propuesta, como se puede observar en el inciso (e). Como se observa en el inciso (a) el contorno activo puede perder el borde deseado (materias gris y blanca) y detenerse hasta los bordes de mayor intensidad. El índice de Tanimoto medio para los contornos obtenidos con esta propuesta fue de $0.70 \pm 0.07$.

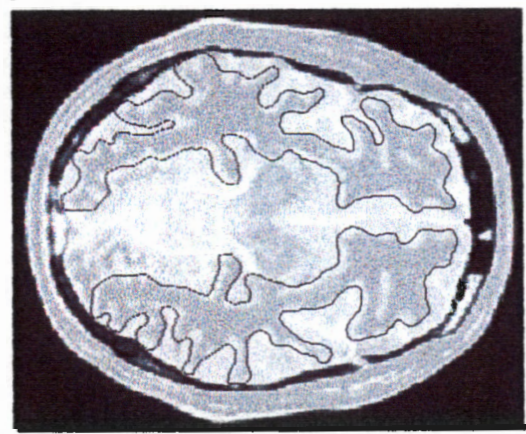

(a) 


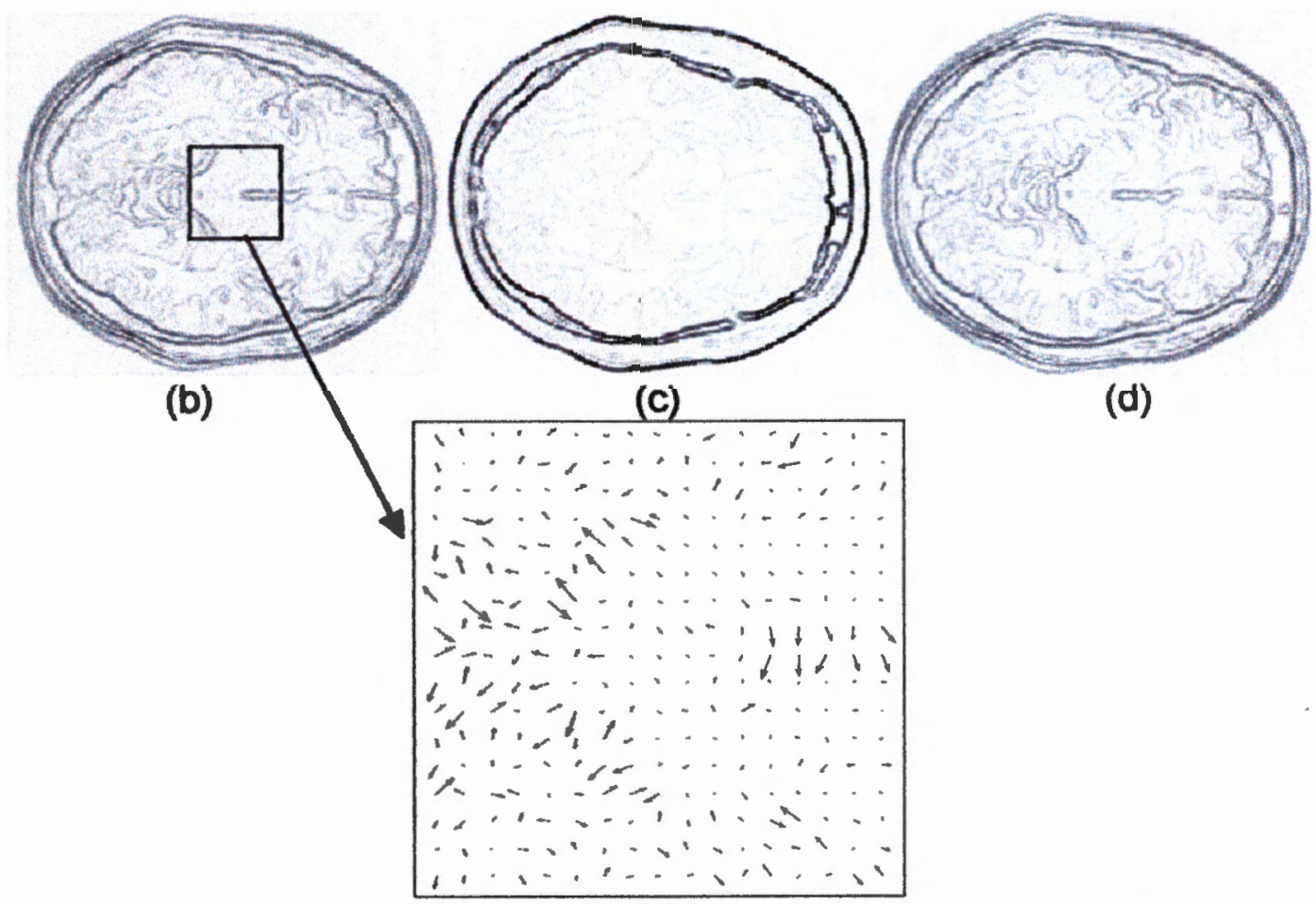

(e)

Figura III.10. Combinación lineal de las magnitudes de los gradientes multiespectrales; (a) contorno resultante obtenido con el termino propuesto de $E_{\text {meaen }}$, (b-d) magnitud del gradiente para las imágenes T1, T2 y DP respectivamente, (e) región de interés que muestra la naturaleza desordenada del campo de fuerza del término $E_{\text {mmegen }}$ IT medio: 0.70 \pm 0.07

En la Figura III.11(b) se muestra el contorno resultante del modelo empleando el cálculo del gradiente multiespectral como $E_{\text {imagen }}$ (Figura III.11(a)). Para el cálculo de las derivadas parciales se empleó el filtro de Canny con los mismos parámetros para las tres bandas de Resonancia Magnética ( $n=3, \mu=0, \sigma^{2}=0.5$ ); para la banda T2 se ajustó el negativo de su gradiente.

El gradiente multiespectral resultó similar al promedio de los gradientes escalares, ampliado aquel en un factor de 2 respecto al último. Las diferencias se observan en los bordes de mayor intensidad. Retomando la ecuación (II-12), la matriz ( $\left.D^{T} D\right)$ queda expresada como:

$D^{T} D=\left[\begin{array}{cc}\left(\frac{\partial I_{1}}{\partial u}\right)^{2}+\left(\frac{\partial I_{2}}{\partial u}\right)^{2}+\left(\frac{\partial I_{3}}{\partial u}\right)^{2} & \left(\frac{\partial I_{1}}{\partial u}\right)\left(\frac{\partial I_{1}}{\partial v}\right)+\left(\frac{\partial I_{2}}{\partial u}\right)\left(\frac{\partial I_{2}}{\partial v}\right)+\left(\frac{\partial I_{3}}{\partial u}\right)\left(\frac{\partial I_{3}}{\partial v}\right) \\ \left(\frac{\partial I_{1}}{\partial u}\right)\left(\frac{\partial I_{1}}{\partial v}\right)+\left(\frac{\partial I_{2}}{\partial u}\right)\left(\frac{\partial I_{2}}{\partial v}\right)+\left(\frac{\partial I_{3}}{\partial u}\right)\left(\frac{\partial I_{3}}{\partial v}\right) & \left(\frac{\partial I_{1}}{\partial v}\right)^{2}+\left(\frac{\partial I_{2}}{\partial v}\right)^{2}+\left(\frac{\partial I_{3}}{\partial v}\right)^{2}\end{array}\right]$

si los términos cruzados se hacen cero, $D^{T} D$ se vuelve una matriz diagonal, cuyo valor propio máximo es igual a 


$$
\lambda_{\max }=\left(\frac{\partial I_{1}}{\partial u}\right)^{2}+\left(\frac{\partial I_{2}}{\partial u}\right)^{2}+\left(\frac{\partial I_{3}}{\partial u}\right)^{2}+\left(\frac{\partial I_{1}}{\partial v}\right)^{2}+\left(\frac{\partial I_{2}}{\partial v}\right)^{2}+\left(\frac{\partial I_{3}}{\partial v}\right)^{2}=\sum_{i=1}^{3}\left(\left(\frac{\partial I_{i}}{\partial u}\right)^{2}+\left(\frac{\partial I_{i}}{\partial v}\right)^{2}\right)
$$

la relación entre este resultado y la expresión del promedio de las magnitudes de los gradientes monoespectrales (Ec. II-11) es evidente.

Los términos cruzados de $D^{T} D$ se maximizan cuando se encuentran puntos aislados con un gradiente de intensidad. Relativo a este máximo, cuando se encuentran bordes la contribución es menor, puesto que el gradiente de intensidad en una dirección es alto, sin embargo en la otra dirección el gradiente es menor. Por consiguiente en regiones suaves, estos términos se hacen mínimos. El caso de las imágenes cerebrales multiespectrales de RM, para sujetos normales, se observan grandes regiones homogéneas, sin puntos aislados con un contraste alto de intensidad.

Como se esperaba, el campo de fuerza asociado a este término es desordenado. El índice de Tanimoto medio para los contomos obtenidos con esta propuesta fue de $0.70 \pm 0.07$.

Debido a lo anterior y al menor costo computacional asociado al cálculo, el término de $E_{\text {imagen }}$ modificado que se propuso, se basó en el resultado del promedio de los gradientes monoespectrales.
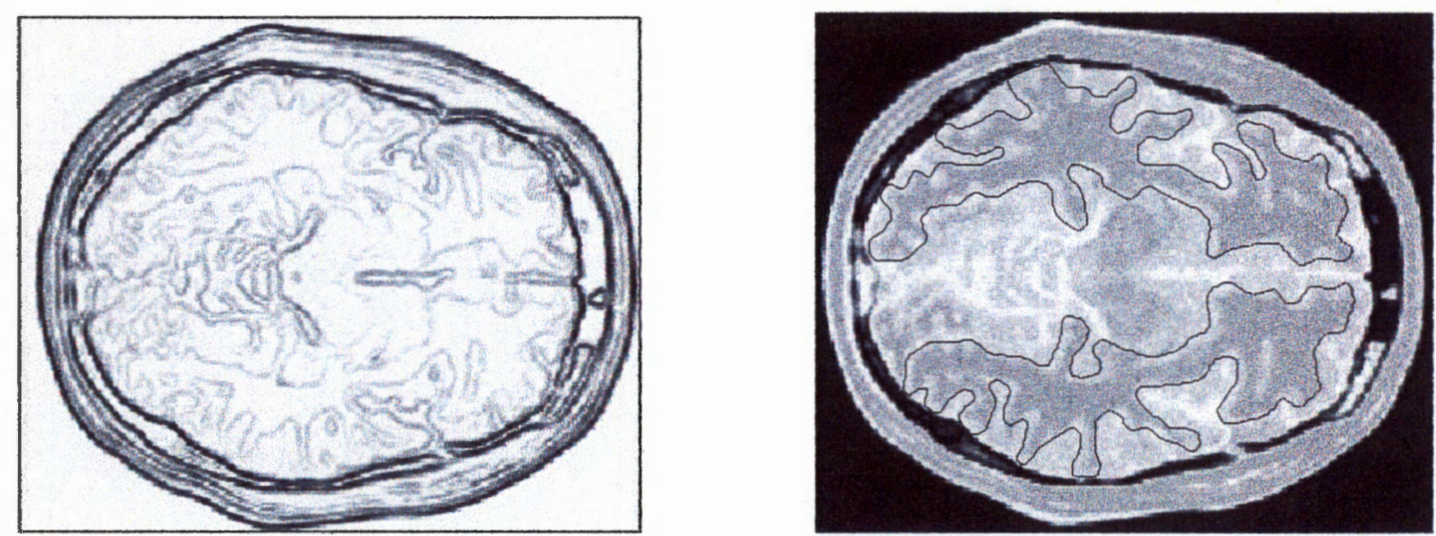

Figura Ill.11. Gradiente multiespectral: (a) magnitud del gradiente multiespectral, (b) contomo resultante. IT medio: $0.70 \pm 0.07$

En la Figura III.12 se muestra un contorno resultante del modelo híbrido empleando como $E_{\text {imagen }}$ el FVG del promedio de los gradientes escalares. Este término posee un área de influencia amplia alrededor de los bordes; sin embargo, padece del mismo efecto que el término primario, la diferencia de intensidades o fuerza de los bordes encontrados, inclusive se acentúa más. En el inciso (b) se muestra la imagen del logaritmo de la magnitud del FVG, se puede observar que se detectan más bordes pero tienen una magnitud pequeña, por lo que en el término original empleado en el modelo híbrido, pasan desapercibidos. En (c) se muestra la dirección del campo del FVG en una región de interés señalada en (b). 
Como se esperaba, la dirección y área de influencia de los bordes se ven muy favorecidas con este término; sin embargo, el peso relativo en el borde fondo/ piel y entre el parénquima cerebral y el espacio subaracnoide, reduce el impacto de la organización del campo de fuerzas en el borde deseado. El índice de Tanimoto medio para los contornos obtenidos con esta propuesta fue de $0.66 \pm 0.08$.

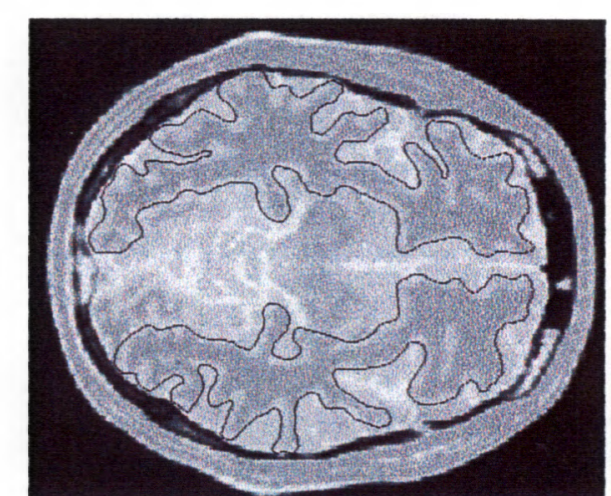

(a)

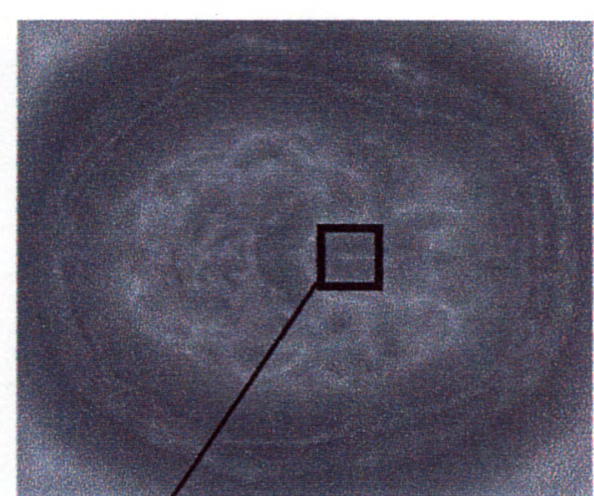

(b)

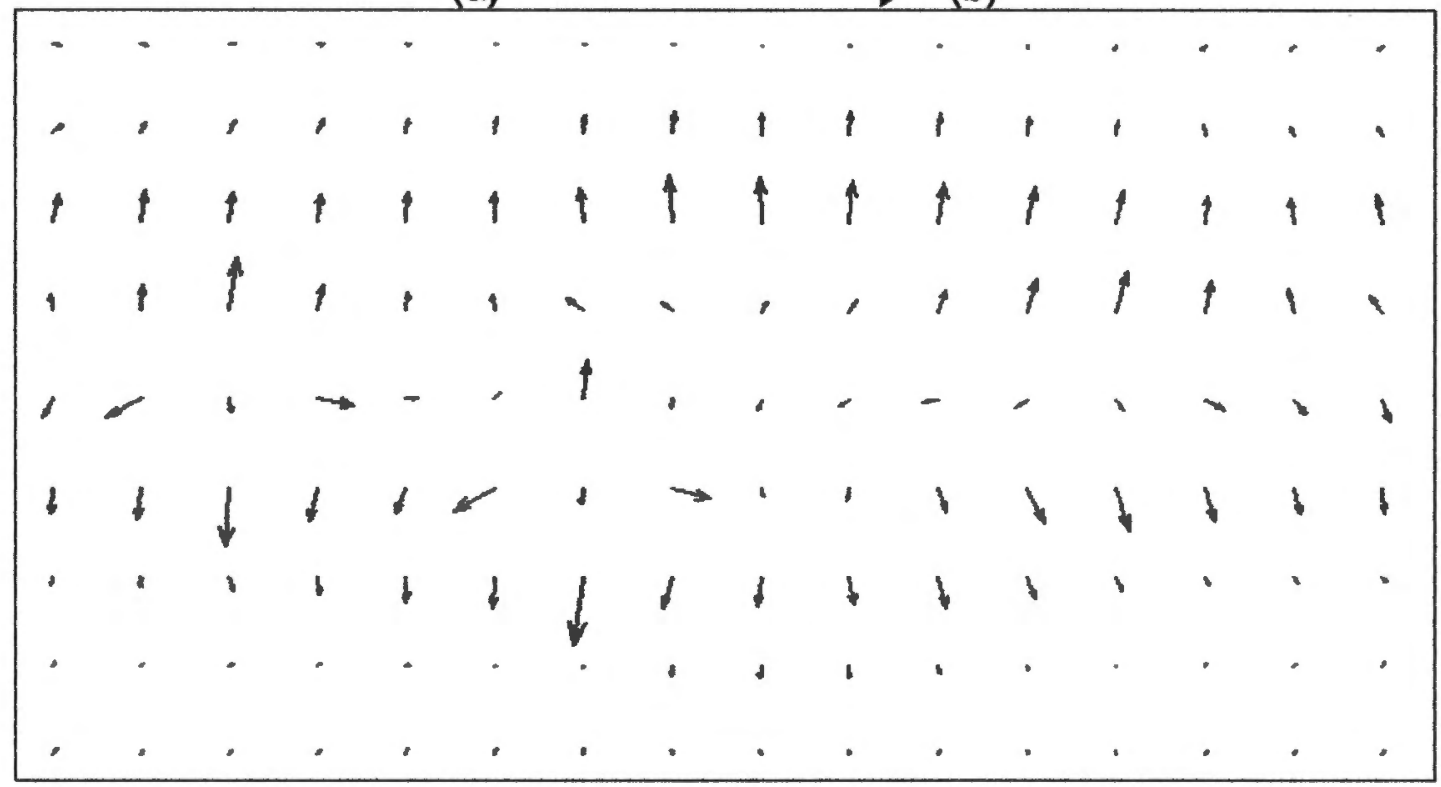

(c)

Figura III.12. Flujo del Vector Gradiente [54]: (a) contorno resultante, (b) logaritmo de la magnitud del Campo del Flujo del Vector Gradiente, paleta inversa de grises, (c) dirección del Campo del Flujo del Vector Gradiente para una región de interés. IT medio: 0.66+0.08

El resultado obtenido con este término contrasta con los resultados reportados por $\mathrm{Xu}$ y Prince [55], es importante señalar que el mapa de bordes sobre el que se calcula el FVG ya muestra un desbalance en la intensidad de los diferentes bordes. Por otro lado, en la aproximación numérica propuesta por los autores, se requiere de la definición de tres parámetros que se relacionan con el tamaño del paso en el proceso iterativo y que impactan sobre la calidad del campo de fuerzas calculado. 


\section{III.1.8 Muestreo de Puntos de Control}

Se consideraron algunas imágenes de prueba para evaluar el efecto del umbral en la calidad del contorno inicial, así como el efecto de reducción de puntos (sección 1I.5.2). En la siguiente figura (Figura III.13) en el inciso (a) se muestra la gráfica del índice de Tanimoto entre las imágenes binarias generadas con el contorno original y con el contorno ordenado e interpolado. En el inciso (b) se muestra la gráfica de la relación porcentual de puntos entre el contorno original y el contorno ordenado e interpolado, respecto al valor del umbral. Cada una de las curvas, es un caso de prueba.
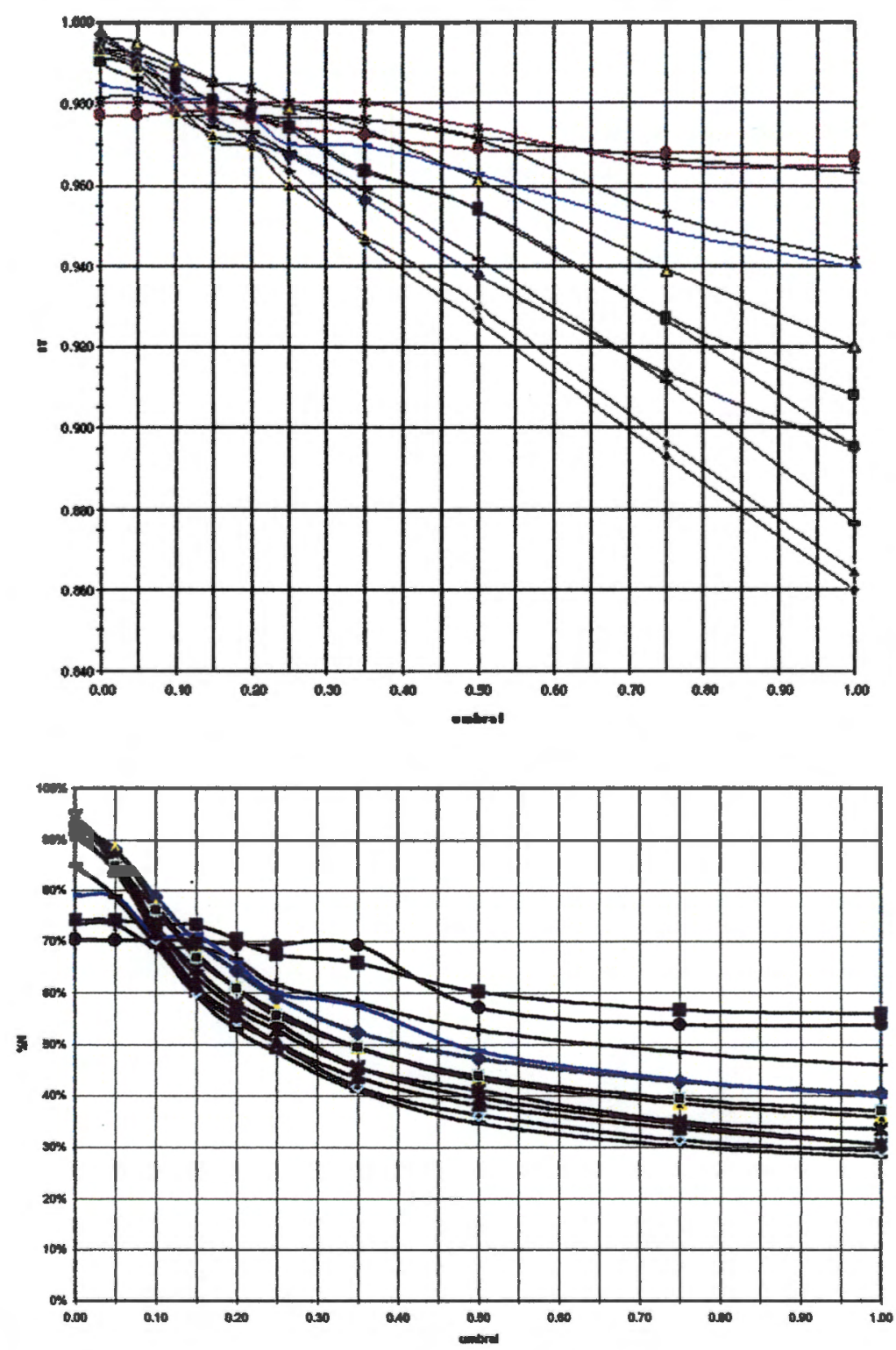

Figura III.13. Efecto del umbral en el ordenamiento de puntos de control del contomo: (a) variación del índice de Tanimoto respecto a la variación en el umbral (b) efecto del umbral en la reducción de puntos de control, se muestra una relación porcentual respecto al número de puntos de la muestra original. 
Como era de esperarse aumentar el umbral, reduce la cantidad de puntos de control, y para un intervalo importante $(0.25<$ umbral $<0.75)$ la pérdida de calidad, medida con el indice de Tanimoto, aparentemente no es considerable. Sin embargo, en la Figura III.14 se muestran los contornos resultantes para una imagen de prueba, considerando umbrales de $0.25,0.50$ y 0.75 respectivamente. Es posible observar que para un umbral grande, aparecen demasiadas regiones lineales; sin embargo la diferencia entre el umbral medio y menor, es menos notoria. Al emplear un umbral de 0.25 la reducción de puntos de control alcanza un $40 \%$, que resulta muy conveniente para disminuir los tiempos de cálculo sin comprometer la calidad del resultado final.

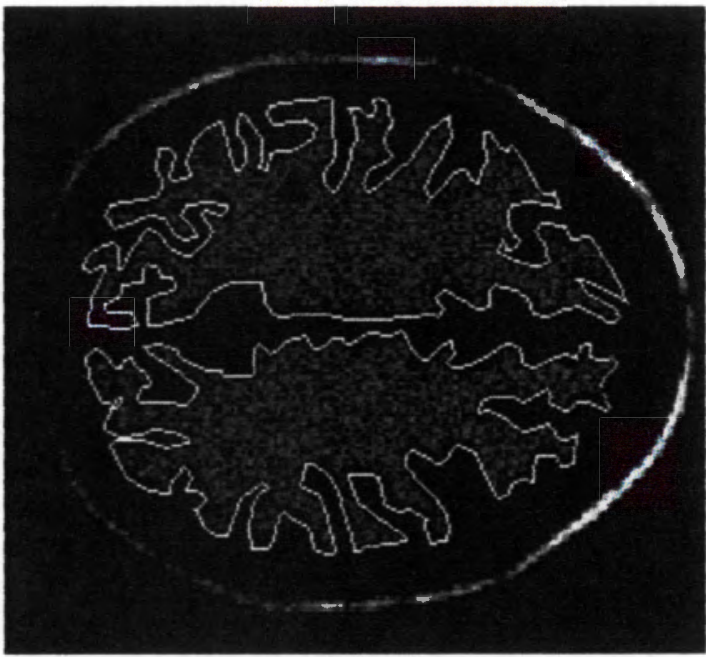

(a)

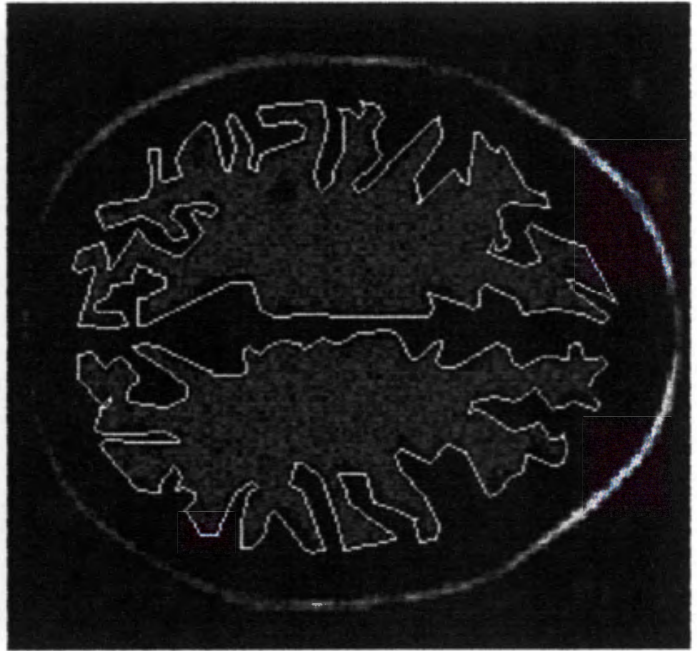

(b)

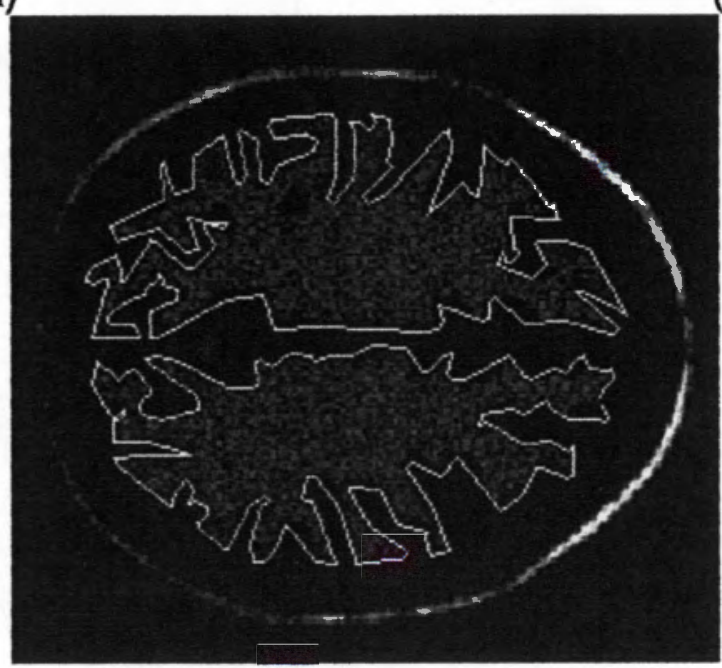

(c)

Figura IIl.14. Efecto del umbral en el ordenamiento de puntos de control del contomo para una imagen de prueba, se muestra la banda T1: (a) umbral $=0.25$ (b) umbral $=0.50$ (c) umbral $=0.75$ 
Considerando un acoplamiento estático entre la red neuronal y el contorno activo, se obtuvo un índice de Tanimoto promedio de $0.74 \pm 0.07$. Comparando individualmente se obtuvo un incremento en el índice medido de un $3 \%$ aproximadamente, respecto a los resultados obtenidos con el acoplamiento estático con muestreo regular.

En la Figura III-14 se muestra en amarillo el contorno obtenido con remuestreo, en blanco se muestran los puntos de control equi-espaciados. Puede apreciarse en los giros mas pronunciados el efecto de suavizado en el muestreo regular, sin embargo en el remuestreo el contorno puede adherirse al borde deseado con mayor fidelidad.

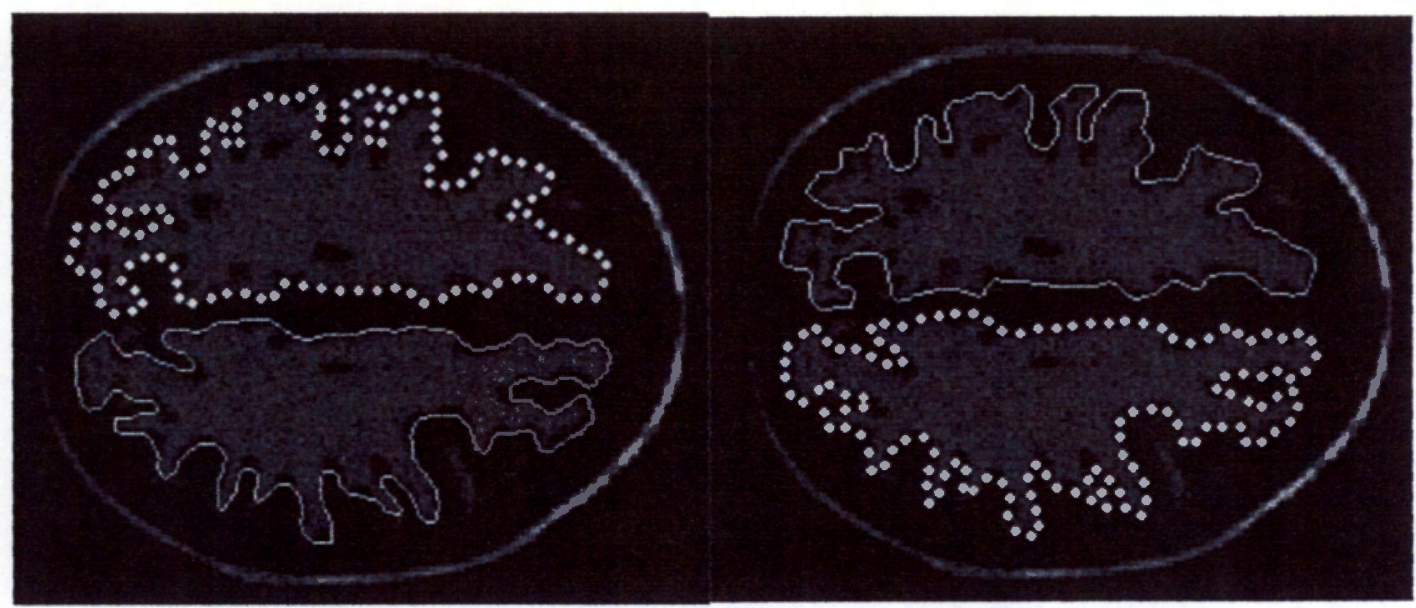

(a)

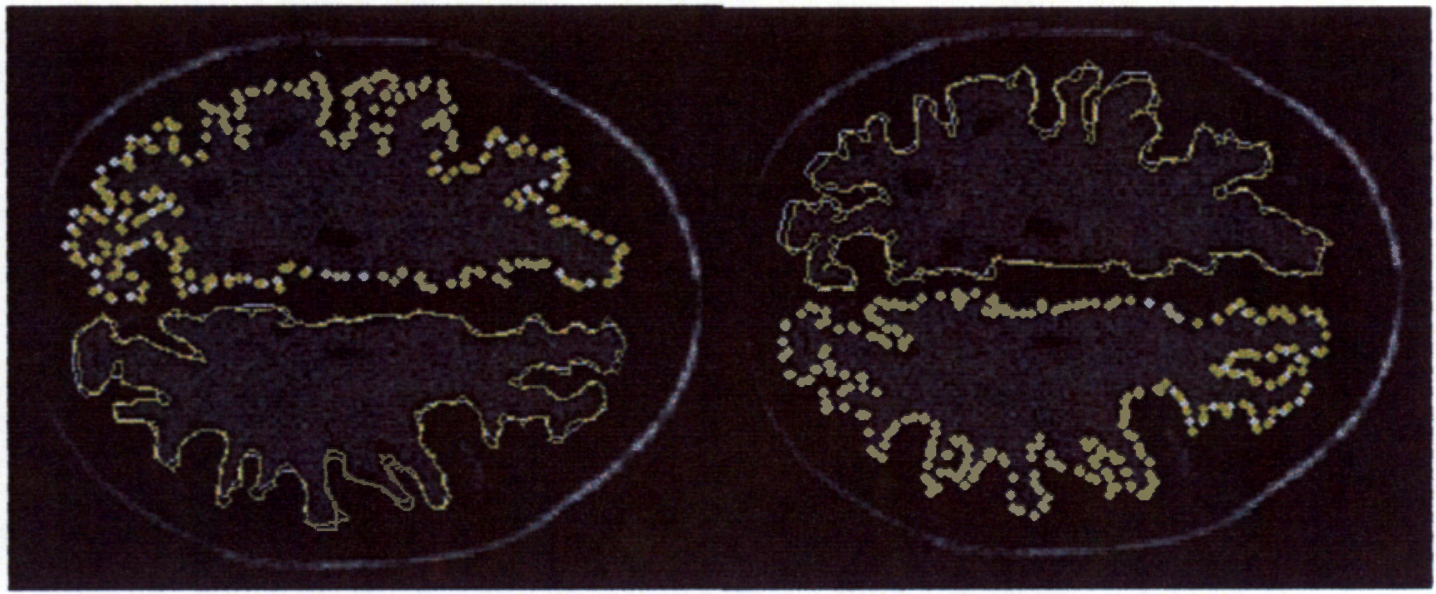

(b)

Figura III.15. Efecto del muestreo de puntos de control del contorno para una imagen de prueba, se muestra la banda T1: (a) muestreo regular (b) muestreo según curvatura del contorno 
Con la propuesta de muestreo ordenado de puntos, se observa que no existe disminución de la calidad de los resultados obtenidos; sin embargo, existe una reducción de orden del modelo, que permite hacer más eficiente el uso de los recursos computacionales.

\section{III.1.9 Modelo Hibrido Adaptable}

Analizando las tasas de clasificación para el conjunto de entrenamiento para el nodo de materia gris y considerando la adaptación de los parámetros de la RFBRcc, se observó que la tasa de clasificación para la materia gris no se deteriora con la evolución del proceso, y existen algunas iteraciones en las que mejora ligeramente, lo que permite, en esa medida, hacer el ajuste apropiado al contorno.

En general los contornos encontrados son similares, sin embargo las diferencias \& Se encuentran en las zonas de circunvoluciones (Figura III.16). En la muestra de imágenes del Estudio II para el procedimiento adaptable se obtuvo un índice de Tanimoto de $0.74 \pm 0.07$

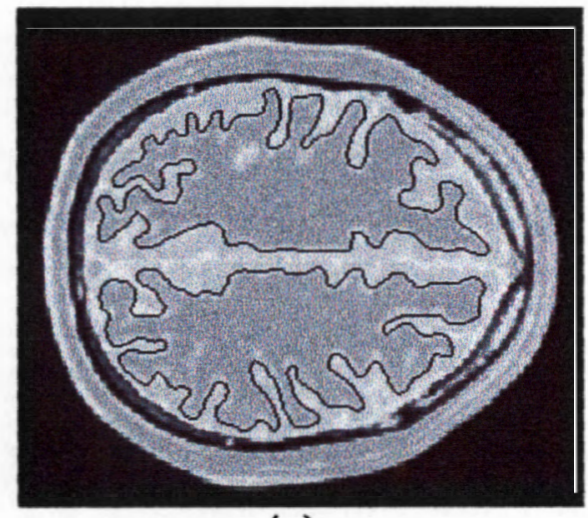

(a)

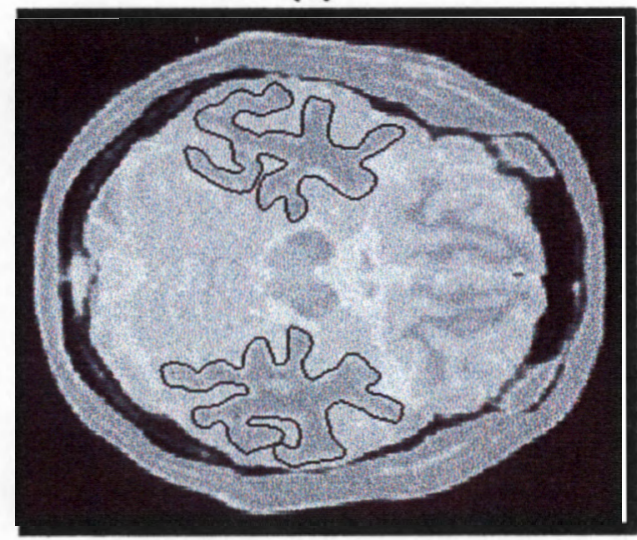

(c)

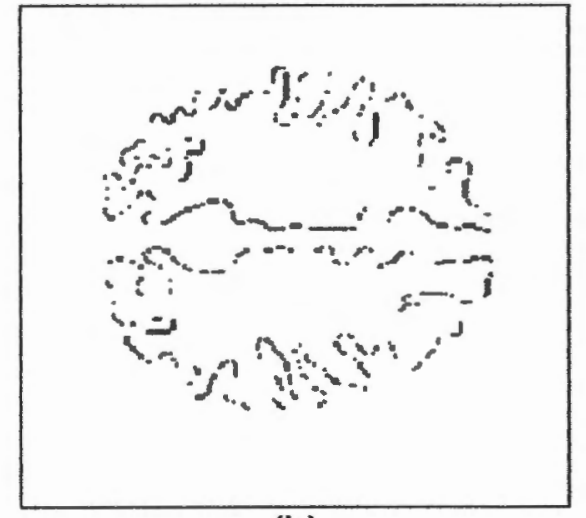

(b)

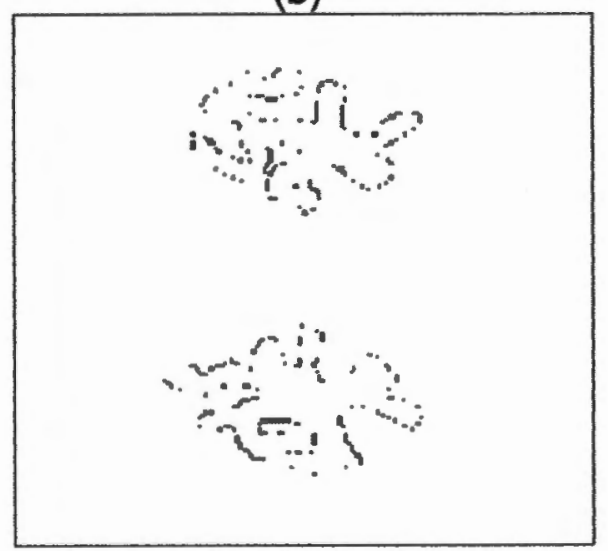

(d)

Figura III.16. Resultados en el esquema adaptable: (a) y (c) contornos resultantes (b) y (d) imagen binaria diferencia para los contomo de los modelos adaptable y sin adaptar. 
En la Figura III.17, se muestra el resultado para una configuración distinta de parámetros del modelo, en donde el contorno se ha estabilizado, pero perdió el borde deseado. Aún en este caso se puede observar la similitud de resultados entre el modelo adaptable y no adaptable, conservando la diferencia en las circunvoluciones, como se aprecia en la imagen binaria diferencia entre contornos (inciso b).

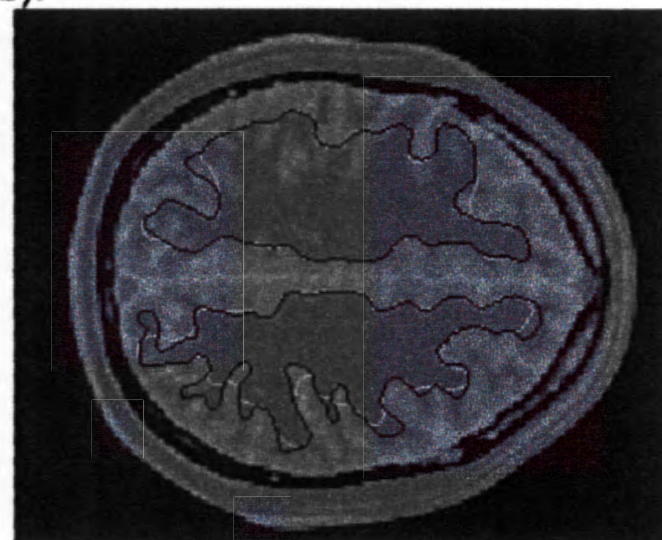

(a)

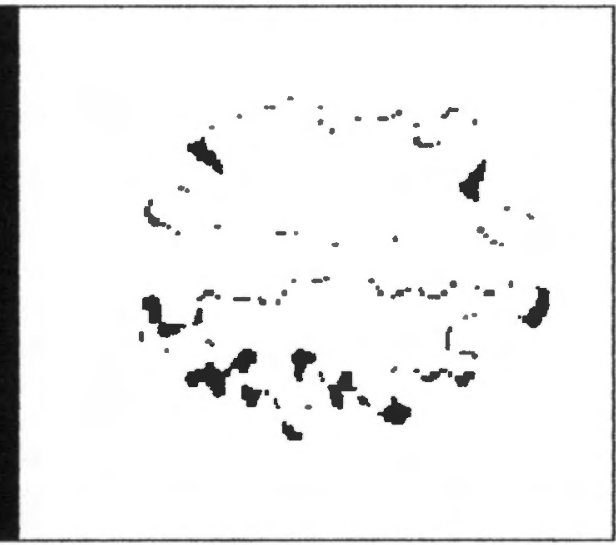

(b)

Figura III.17. Resultados del modelo híbrido de segmentación: (a) contornos resultantes, en blanco el contomo del modelo sin adaptación, en negro el contomo del modelo adaptable (b) imagen binaria diferencia entre los contomos resultantes.

Aunque la RFBRcc se diseña con un conjunto de entrenamiento de alta calidad, imágenes nuevas presentan particularidades que eventualmente pueden disminuir la calidad de la estimación de las probabilidades posterior propias. Por otro lado la segmentación de imágenes puede representarse como un problema dual entre la segmentación por regiones y la segmentación de los contornos de dichas regiones. Por lo anterior, se supone que el resultado del modelo de contornos activos puede "ayudar" al pre-segmentador proveyéndole de información de calidad en la definición de la frontera entre dos clases de tejido, cerrando el lazo de retroalimentación. El ajuste sobre los parámetros de la red le ofrece al modelo de contomos activos una fuerza de restricción de mejor calidad para la siguiente iteración. Las actualizaciones de los parámetros de la red se basaron en un procedimiento análogo al $k$-means para la capa de gaussianas y vía el algoritmo LMS para la capa de clasificación, tratando de conservar la metodología del propio entrenamiento de la red.

Como se describió anteriormente, los contornos obtenidos con el esquema no adaptable y adaptable alcanzan indices de Tanimoto que no muestran diferencias estadísticamente significativas, sin embargo en el análisis detallado de cada par de contornos, se observa que en algunas regiones de circunvoluciones pronunciadas, el contorno resultante del esquema adaptable se adhiere mejor al borde deseado, en tanto el contorno del esquema no adaptable se observa suavizado. El tiempo de cálculo en el esquema no adaptable representa aproximadamente dos tercios del tiempo que consume el esquema adaptable. 


\section{III.1.10 Desempeño del Modelo Híbrido con Ruido}

Se probó el modelo propuesto bajo un ambiente de ruido gaussiano aditivo con diferentes varianzas $\left(\sigma^{2}=0.01,0.02,0.03,0.05,0.075\right.$ y 0.10$)$, con el objetivo de valorar el desempeño en la convergencia del modelo híbrido de segmentación; esto es, se empleó el contorno inicial previamente definido en las imágenes sin ruido. En la Figura III.18, se muestra el comportamiento del índice de Tanimoto promedio para los esquemas adaptable y no adaptable respecto a los diferentes niveles de ruido (inciso a), así como el comportamiento de la razón promedio de tales índices entre el índice de Tanimoto calculado en un esquema sin ruido, para ambos modelos. En triángulo se muestra la serie de resultados del modelo sin adaptar, en diamante se muestra la serie de resultados del modelo adaptable. Se puede observar que para condiciones de mayor ruido, el esquema adaptable genera un resultado ligeramente mejor. Se muestran también algunos ejemplos de los contornos resultantes, en (c) se muestra, en blanco, el resultado en un ambiente sin ruido, en negro se muestra el resultado del modelo adaptable con ruido.

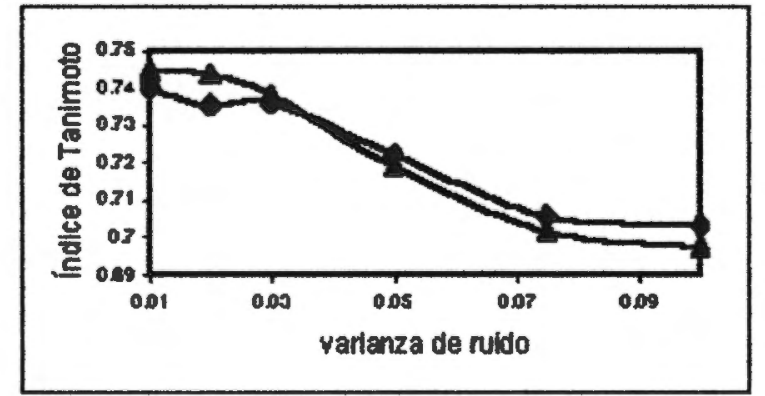

(a)

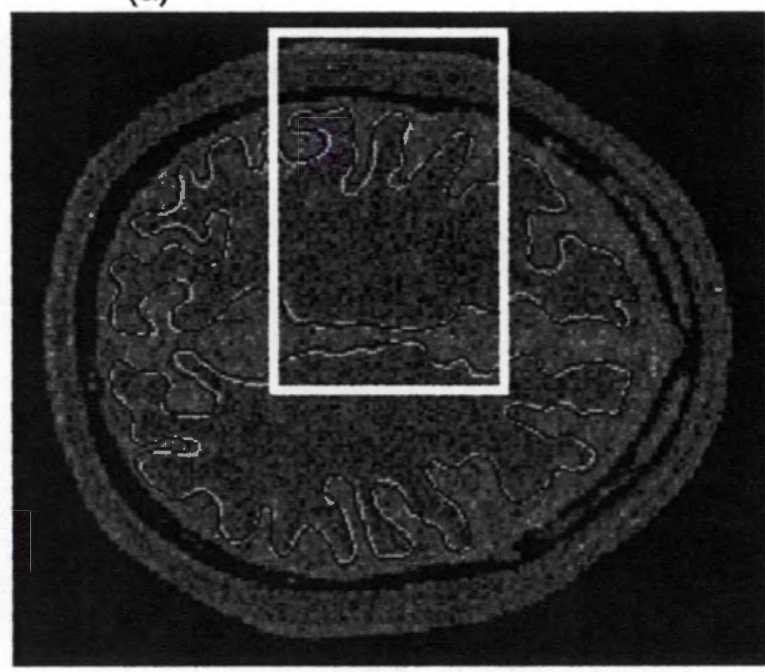

(c)

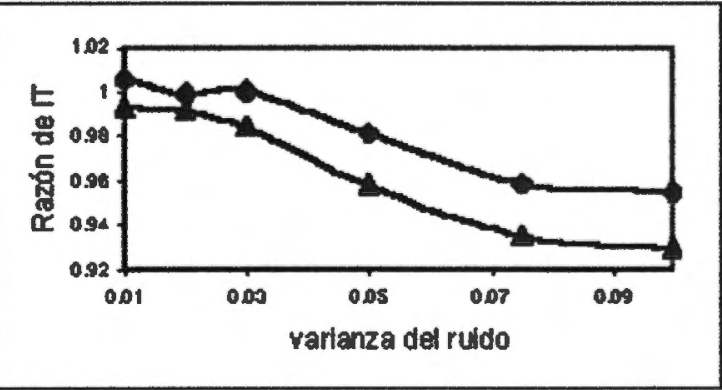

(b)

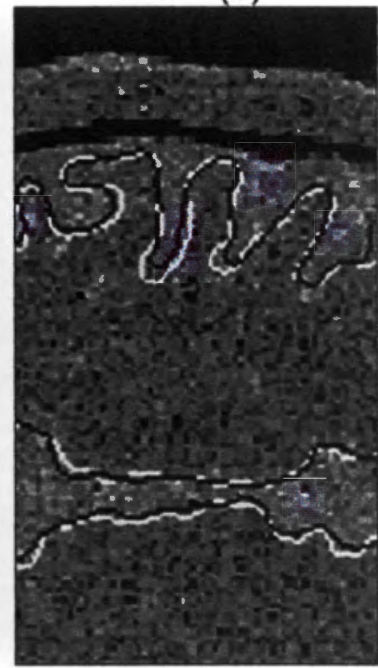
Figura Ill.18. Desempeño del modelo propuesto respecto a ruido gaussiano aditivo: (a)
indice promedio de Tanimoto, b) razón promedio del indice de Tanimoto. En triángulo se muestra la serie de resultados del modelo sin adaptar, en diamante se muestra la serie de resultados del modelo adaptable c) ejemplo de imagen T2 con varianza de ruido de $\sigma^{2}=0.10$, en blanco se muestra el resultado en un ambiente sin ruido, en negro se muestra el resultado del modelo adaptable con ruido. 
Se repite la tendencia descrita anteriormente, los contornos resultantes de los modelos adaptable y no adaptable son similares, aún en ambientes ruidosos; sin embargo existen diferencias locales, principalmente en las zonas de mayor curvatura (circunvoluciones profundas) que no son despreciables, pero que el parámetro de evaluación de desempeño empleado no es capaz de resolver. Es importante resaltar la robustez mostrada por el modelo híbrido ante ambientes ruidosos, en cualquiera de sus modalidades de adaptación o no adaptación.

Se observa también que para niveles moderados de ruido $\left(\sigma^{2}<0.05\right)$, el modelo se comporta apropiadamente y no existe un deterioro significativo del contorno resultante. Para los niveles de ruido mayores $\left(\sigma^{2} \geq 0.05\right)$ se observó un comportamiento ligeramente mejor del esquema adaptable en términos generales. También se observó que el deterioro del contorno resultante bajo condiciones ruidosas respecto al contorno resultante sin ruido, es más pronunciado en el esquema no adaptable.

\section{III.1.11 Segmentación de otras estructuras}

En la Figura II-18 se muestra un corte sagital del volumen del estudio II y los correspondientes mapas discriminantes para las clases materia blanca, materia gris, fondo y líquido cefalorraquídeo, así como la imagen pre-segmentada. Se seleccionaron los bordes de la clases materia blanca y materia gris y el borde entre líquido cefalorraquídeo y materia gris/materia blanca en la región ventricular, para obtener los correspondientes contornos iniciales para procesarlos en el modelo de CASC estático.
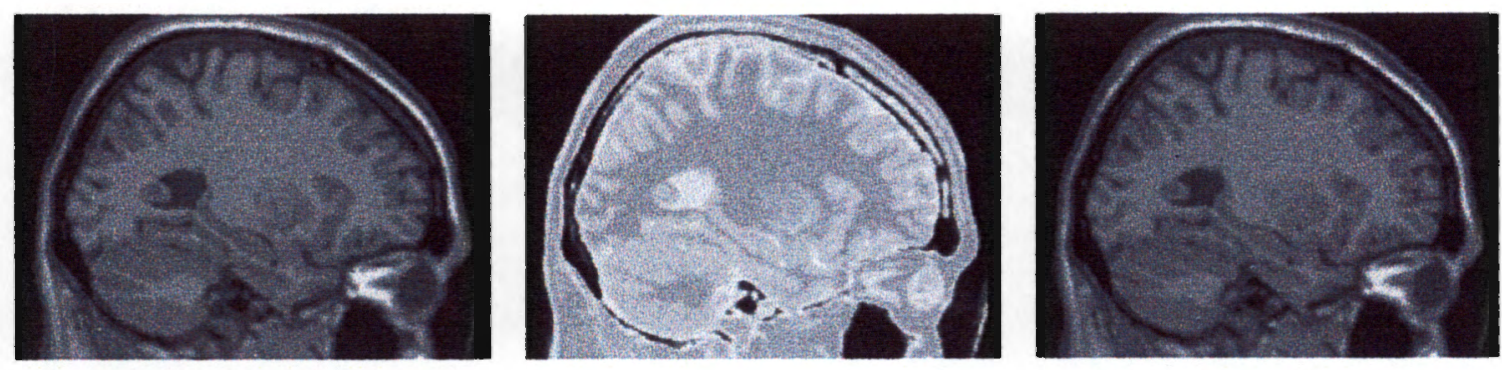

(a) 


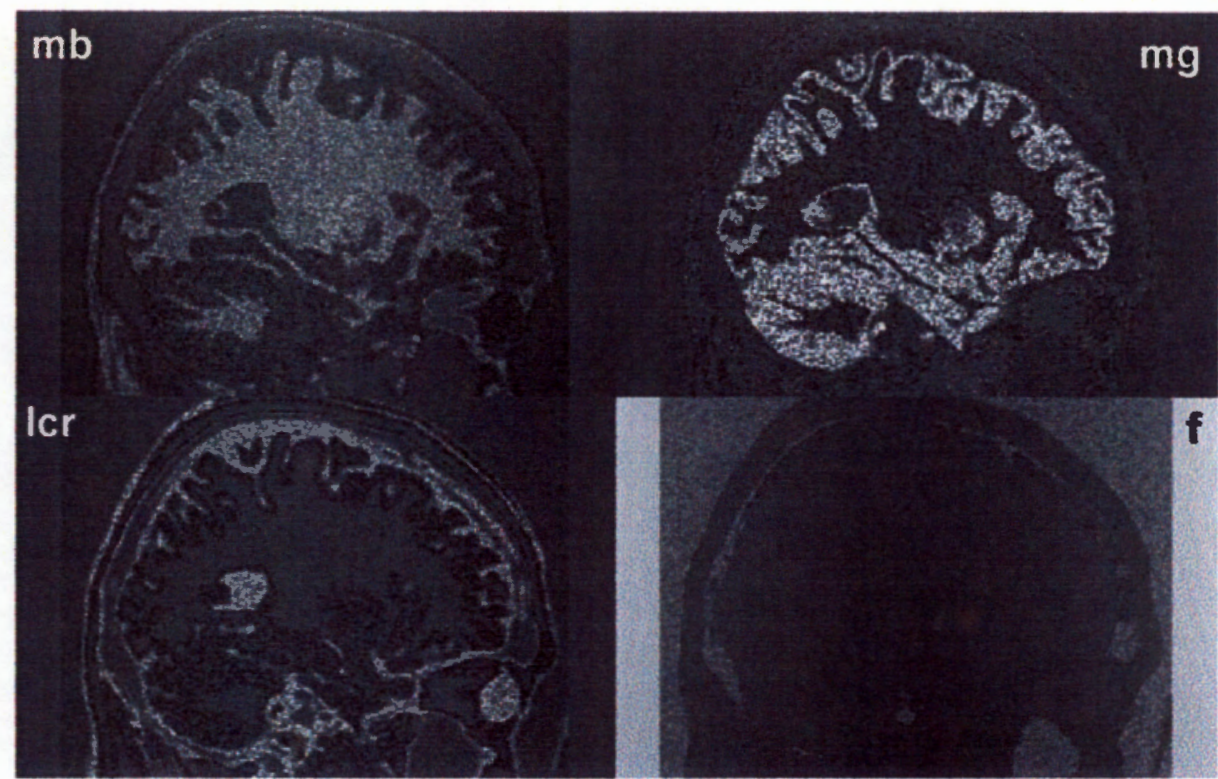

(b)

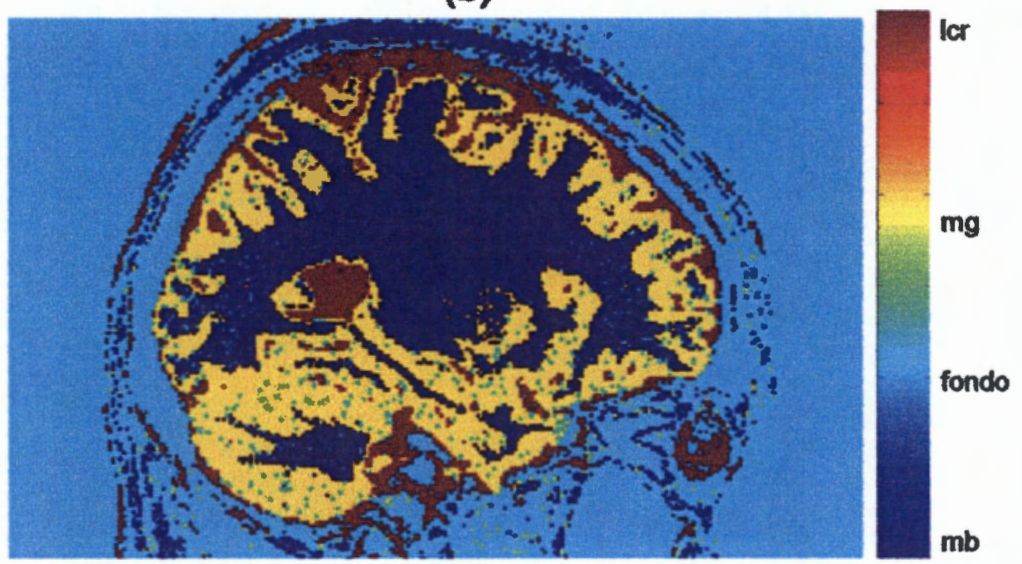

(c)

Figura III.19. Segmentación de otras estructuras: (a) imagen multiespectral en vista sagital, de izquierda a derecha se muestra T1, T2 y DP, (b) mapas discriminantes para cuatro clases de interés, (c) imagen pre-segmentada, fusionando en la clase fondo, los voxeles de hueso y de piel/grasa.

Como se observa en el inciso (c) de la Figura III-19, existe una región del espacio extra-meníngeo que es etiquetada como materia blanca, en el algoritmo para la definición del contorno inicial, esta región es incluida en el conjunto de prototipos para inicializar el modelo de CASC. En la Figura III-20 se muestra sobre la imagen $\mathrm{T} 1$, los contornos resultantes para el borde materia blanca y materia gris y para la región ventricular.

Los parámetros del modelo híbrido no fueron modificados para la segmentación de los seis contornos activos entre materia blanca y gris, es importante señalar que los contornos fueron optimizados desacoplados. En el caso del contorno ventricular, se modificaron los pesos de los términos de restricción, se 
intercambiaron los valores entre la fuerza discriminante de materia gris y la de líquido cefalorraquídeo (ver Apéndice A-II). En la Figura III-20b se muestra un acercamiento un acercamiento a la región ventricular, se observa un traslape entre los contornos encontrados. Para la región ventricular se obtuvo un índice de Tanimoto de 0.73. Para la materia blanca encerrada por los contornos resultantes, se obtuvo un índice de Tanimoto de 0.74 .

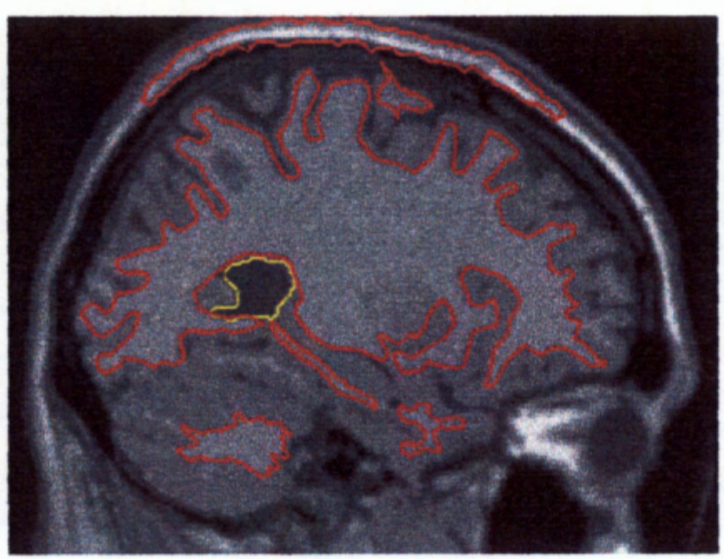

(a)

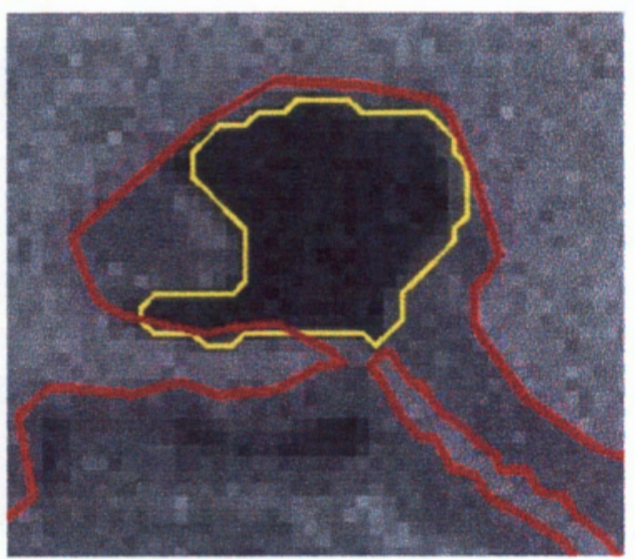

(b)

Figura III.20. Contornos resultantes en imagen sagital: (a) contornos para materia blanca y ventriculo (c) acercamiento a la región ventricular

La estimación volumétrica de las probabilidades a posteriori que realiza la RFBRcc, permite generalizar la obtención de un borde deseado para cualquier plano de corte. La metodología propuesta permite definir la localización de bordes de diferentes estructuras, ajustando en cada caso el peso de las fuerzas discriminantes.

\section{III.2 Segmentación de Volúmenes Reales}

Como se describió en el capítulo anterior, los volúmenes reales fueron generados con parámetros de adquisición completamente diferentes a los parámetros ajustados en los volúmenes simulados, incluyendo el volumen para entrenamiento de la red. Estas diferencias en los protocolos de adquisición, junto con las características inherentes al estudio por RM de sujetos normales, como inhomogeneidad del campo magnético principal y de las antenas, el efecto del volumen parcial, el rango dinámico de la señal adquirida y la normalización al espacio de Talairach; representan en su conjunto, el mayor reto para la generalización del modelo híbrido propuesto. A continuación se describen los resultados obtenidos en las etapas del modelo, aplicado a volúmenes reales. 


\section{III.2.1 Normalización del Espacio de Intensidades}

El primer estudio real (Estudio RI) se empleó para realizar pruebas sobre la selección de la región de muestra, para estimar la matriz de auto-correlación de los vectores de intensidad. En la Figura III.21 se muestran cuatro ejemplos de regiones y su distribución original de intensidades. Como puede observarse en el inciso (a) las regiones muestreadas contienen vectores de materia blanca, materia gris y líquido cefalorraquídeo; sin embargo en el inciso (b) se observan distribuciones de intensidad distintas. Como una referencia, en el inciso (c) se muestra una distribución equivalente para vectores de un conjunto simulado, en donde se observa una distribución consistente para diferentes regiones de la muestra. Se tomaron regiones con diferente localización y la distribución de características no evidencia un efecto mayor respecto a la inhomogeneidad del campo de ganancia. Sin embargo sí existe un componente regional, en donde la distribución de características se afecta y corresponde a la región de la línea interhemisférica (muestras 2 y 3 ), atribuible a un efecto de volumen parcial y/o efecto \& de interpolación en el registro de volúmenes.

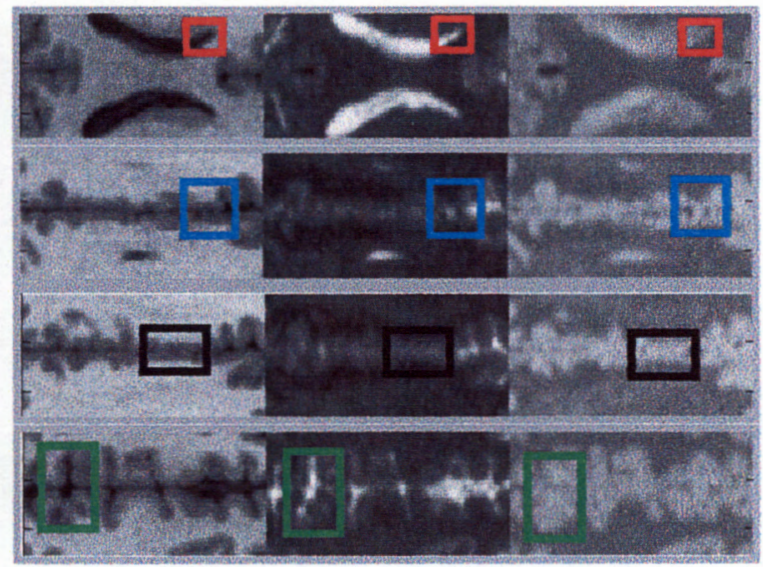

(a)

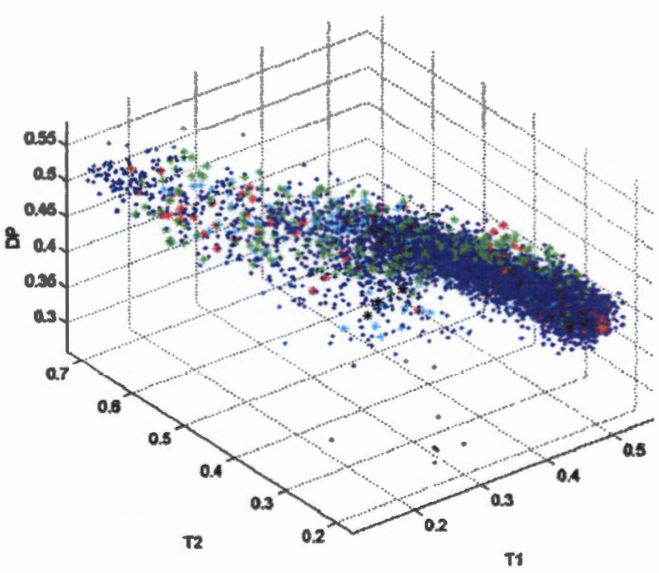

(b) 


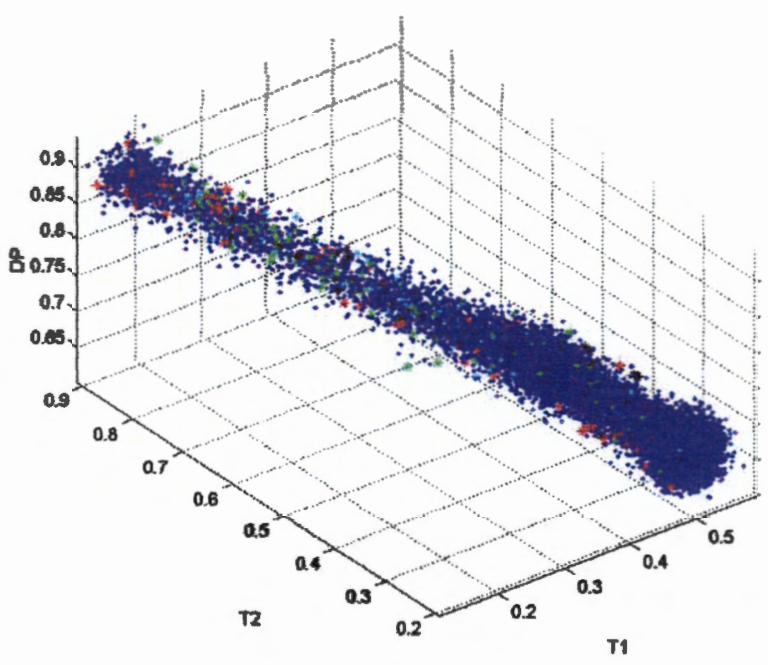

(c)

Figura ill.21. Regiones de muestreo de vectores característicos: (a) muestras 1-4, (b) distribución de características de las cuatro muestras y el conjunto completo, (c) distribución de caracteristicas de las cuatro muestras y el conjunto completo para un volumen simulado (en azul, toda la muestra, en rojo región marcada en la muestra 1, en azul claro, región marcada en la muestra 2, en negro región marcada en muestra 3 y en verde región marcada en la muestra 4).

El rendimiento del proceso de segmentación está completamente sujeto a la calidad de la muestra de vectores para estimar la matriz de auto-correlación de los datos. La generalización del pre-segmentador se ve comprometida cuando los nuevos datos se alejan del espacio de referencia. Mediante la propuesta de normalización es posible recuperar la estadística en un marco de referencia común, pero el proceso tiene sus límites.

Para ejemplificar lo anterior, en la Figura III.22 se muestran resultados de segmentar las mismas imágenes con redes distintas. Para un volumen simulado con el protocolo ICBM, se re-entrenó la red y con ella, se procesaron una imagen del estudio real II (RII) y una imagen del estudio simulado. En la Figura III.22 se muestran las cuatro combinaciones red-imagen. En el inciso (a) se muestra el resultado de la pre-segmentación con la red original para una imagen simulada $(\mathrm{IT}=0.77)$, en (b) la pre-segmentación de la misma imagen con la nueva red $(I T=0.90)$, en (c) la segmentación de la imagen real con la red original y en (d) se muestra la segmentación con la nueva red. 


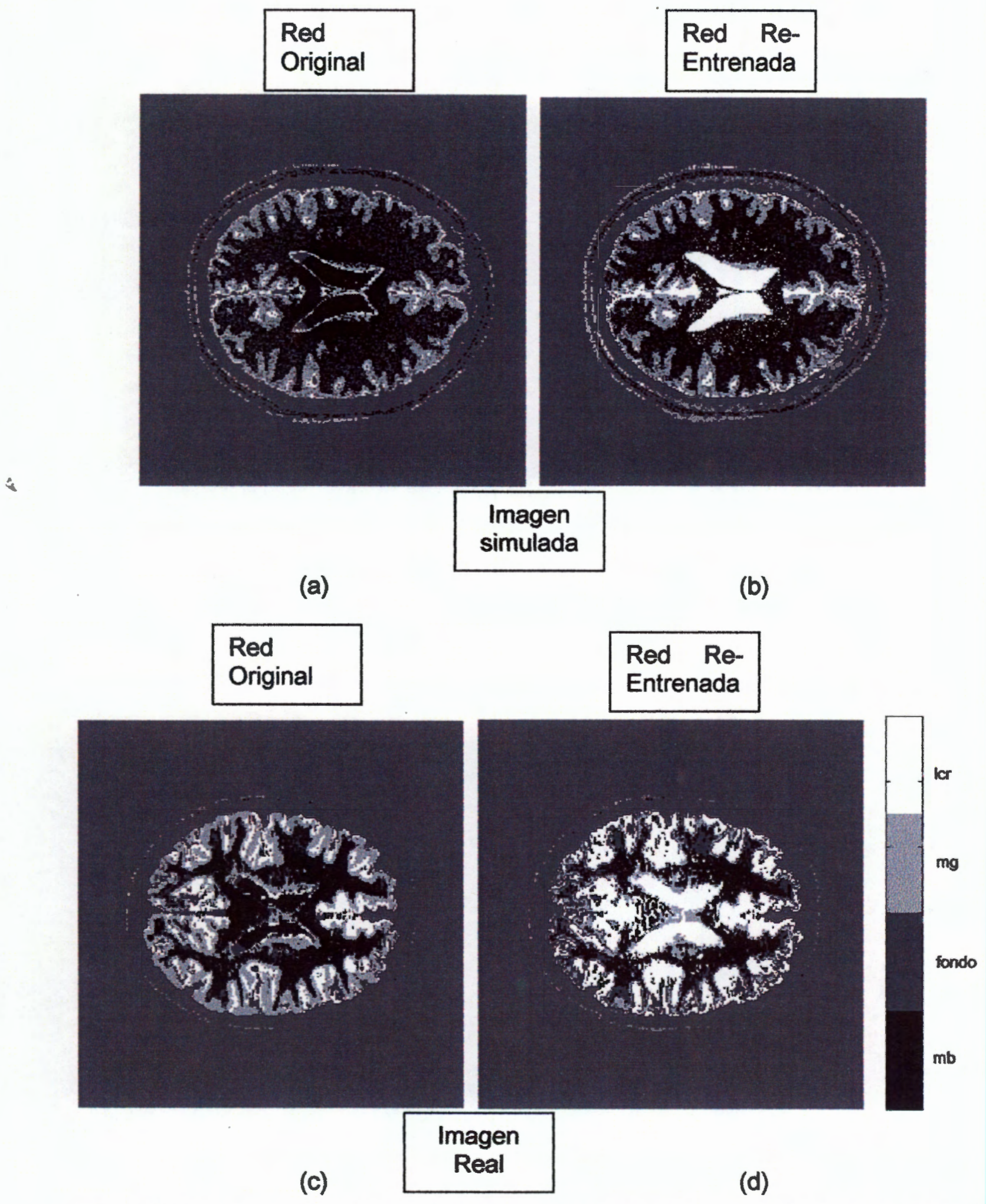

Figura III.22. Imágenes Simulada y Real Pre-segmentadas: (a) imagen simulada segmentada con la red original, (b) imagen simulada segmentada con la red re-entrenada para protocolo ICBM (c) imagen real segmentada con la red original, (d) imagen real segmentada con la red re-entrenada para protocolo ICBM 
En la Figura III.23, se muestran los mapas discriminantes para una imagen del ERII, en el inciso (b) se muestra una imagen etiquetada de acuerdo al máximo valor en los discriminantes, se fusionaron las clases piel, hueso y fondo. En el acoplamiento con el modelo de los contornos activos, los discriminantes de materia gris, materia blanca, líquido cefalorraquídeo y fondo, fueron incluidos en el término de restricción de la Energía externa.(Ec. II-14)

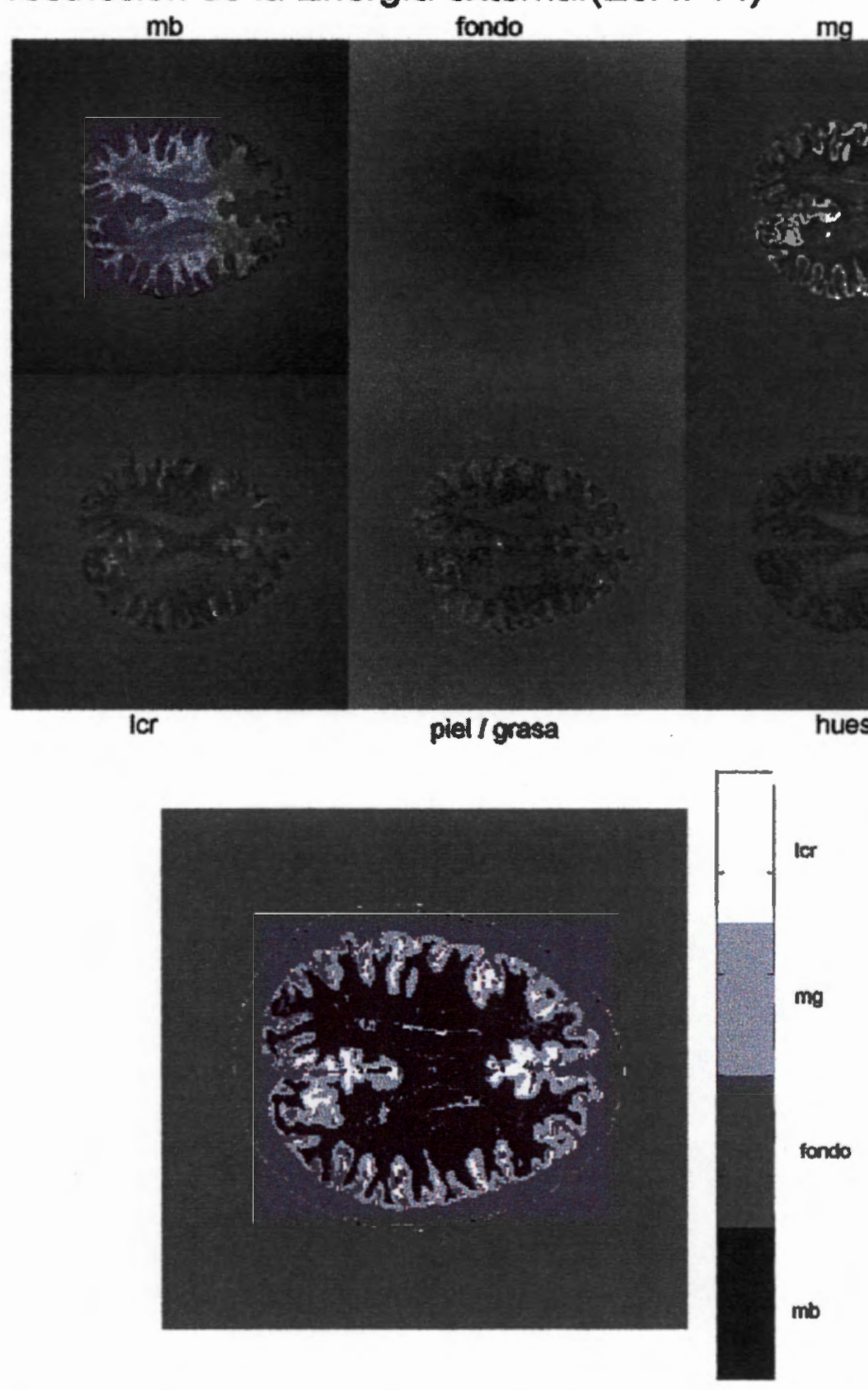

(a)

(b)

Figura III.23. Ejemplo de pre-segmentación de Rll: (a) mapas discriminantes, (b) imagen etiquetada de acuerdo al máximo valor en discriminantes; las clases piel/grasa, hueso y fondo se fusionaron.

Como se observa en el ejemplo de la figura anterior, existe un problema de clasificación en la región ventricular, en donde los voxeles de líquido cefalorraquídeo se etiquetan como clase materia blanca. Sin embargo, la discriminación entre materia blanca y materia gris en la corteza da un buen resultado que permite generar una definición inicial del contorno activo. En la Figura III.24 se muestran tanto el contorno inicial como los contornos resultantes 
para la imagen real, según los esquemas estático y dinámico, dibujados sobre la imagen T1.

(a)

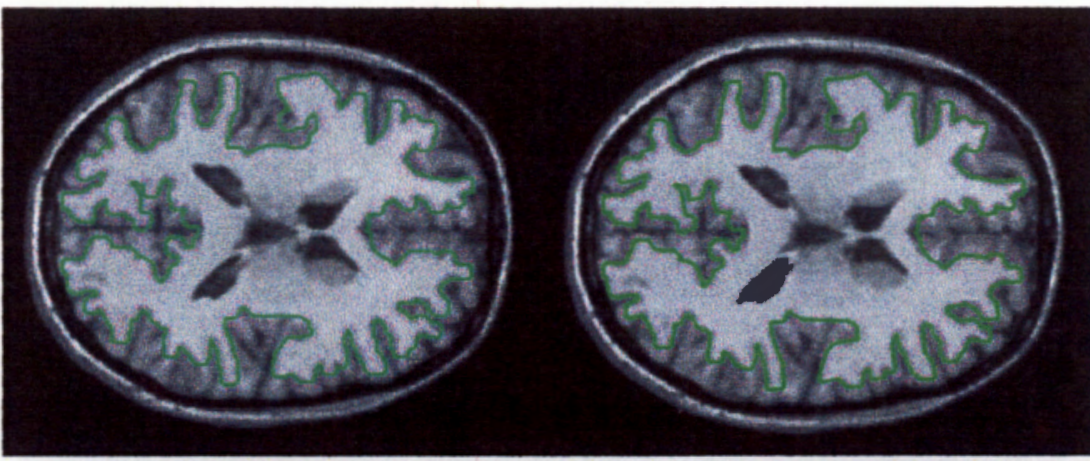

(b)

(c)

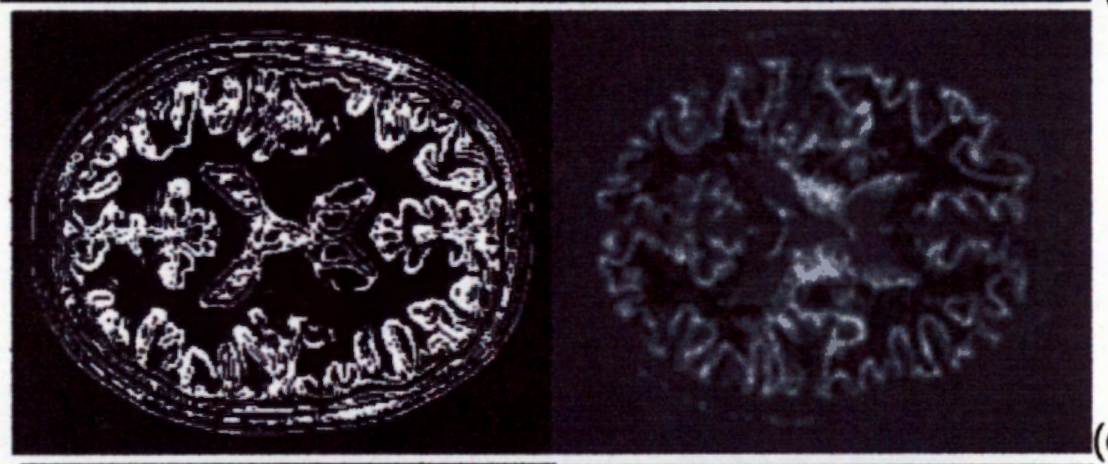

(d)

(e)
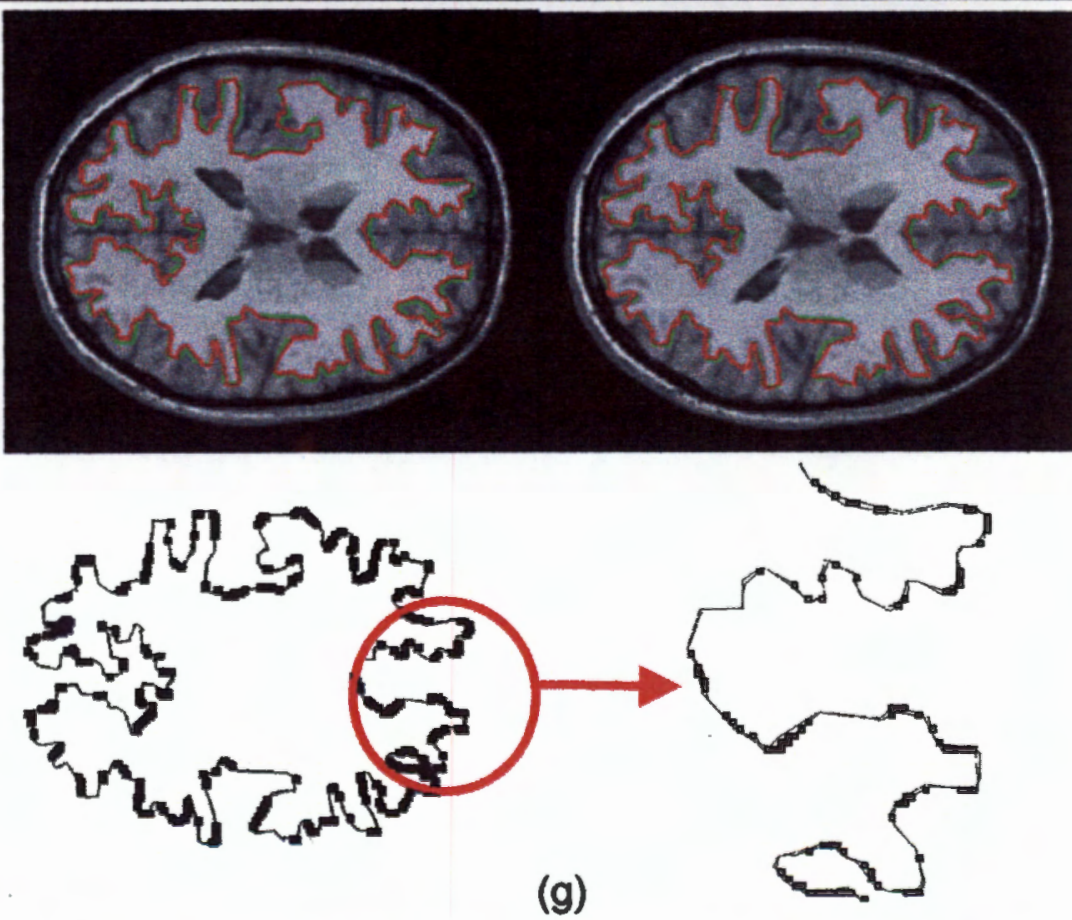

$(f)$

Figura III.24. Ejemplo de contornos inicial y resultantes: (a) contorno inicial (1223 puntos), (b) contomo inicial remuestreado (1067 puntos), IT=0.975 entre (a) y (b), (c) mapa de Energía de la imagen, (d) término de restricción, (e) contorno resultante de la RFBRcc-CASC estático, en rojo se muestra el contorno resultante y en verde se muestra el contomo inicial (f) Contorno resultante de la RFBRcc-CASC dinámico, en rojo se muestra el contomo resultante y en verde se muestra el contorno inicial, $(g)$ IBD entre los resultados estáticos y dinámicos, se han superpuesto los contornos resultantes. 


\section{III.3 Comparación con otros métodos}

En esta sección se discute la comparación de los resultados obtenidos con el modelo híbrido propuesto respecto a los resultados obtenidos con otros paradigmas de segmentación. El parámetro de desempeño empleado es el Índice de Tanimoto. EI IT reportado es referido a la segmentación de la clase materia blanca en un sujeto.

Los algoritmos descritos en la Tabla III-5, se reportan como resultados de la segmentación de imágenes cerebrales de Resonancia Magnética, todos ellos con enfoque de segmentación por regiones [31]. Se agregan en esta tabla dos entradas, la primera muestra el Índice de Tanimoto medio de la segmentación para la clase materia blanca como resultado de la RFBRcc. La segunda entrada, muestra el índice de desempeño de salida para el modelo híbrido [45].

\begin{tabular}{|l|l|}
\hline Método & Indice de Tanimoto \\
\hline adaptive MAP & 0.657 \\
\hline biased-MAP & 0.673 \\
\hline Fuzzy c-means & 0.677 \\
\hline MAP & 0.670 \\
\hline ML & 0.676 \\
\hline K-means (tree) & 0.676 \\
\hline RFBRcc & 0.721 \\
\hline RFBRcc-CASC & 0.740 \\
\hline
\end{tabular}

Tabla III-5. Indices de Tanimoto obtenidos por diversos métodos en la segmentación de imagenes cerebrales (Modificada a partir de [31])

En una comparación entre métodos, empleando las mismas imágenes de prueba (Figura III.7), se obtuvieron los resultados que se muestran en la Tabla III-6. Para el método de la moda realzada (EMD) [17] se emplearon las imágenes T1 cuantizadas a 8 bịts; de la imagen segmentada se recuperó la clase con mayor valor asignado, para todas las imágenes se detectaron entre cinco y seis modas relevantes. En el método de segmentación basado en el algoritmo de corrimiento de la media (mean-shift) [22] se emplearon radios espacial y de intensidad variables, tal que se obtuviera la mejor segmentación.

\begin{tabular}{|l|l|}
\hline Método & Indice de Tanimoto \\
\hline EMD & $0.65 \pm 0.11(0.79 \pm 0.08)^{*}$ \\
\hline Mean-shift & $0.69 \pm 0.14(0.72 \pm 0.11)^{*}$ \\
\hline RFBRcc-CASC & $0.74 \pm 0.07$ \\
\hline
\end{tabular}

Tabla III-6. Indices de Tanimoto obtenidos por diferentes métodos en la segmentación de las imágenes de prueba, "Indice después de eliminar manualmente espacio extrameningeo 
Como se observa de las Tablas III-5 y III-6, los índices de Tanimoto obtenidos con diferentes algoritmos y diferentes imágenes, oscilan alrededor del 0.67. El método propuesto, sólo en el resultado de la pre-segmentación arroja un índice de Tanimoto medio mayor.

Es importante resaltar el alto índice de Tanimoto obtenido por el algoritmo EMD, después de eliminar el espacio extra-meníngeo y que lo coloca como el mejor algoritmo de segmentación por regiones, de los evaluados en esta sección. Es importante resaltar que para el modelo híbrido propuesto, el algoritmo para selección del contorno inicial, es capaz de eliminar cualquier información fuera del contorno.

\section{III.4 Desempeño del Modelo Híbrido. Índice de Similitud}

Como se ha observado en los resultados discutidos, el índice de Tanimoto es un parámetro de evaluación global, que no es capaz de discernir diferencias locales, en la Figura III. 25 se muestran mapas de IT, construidos evaluando la similitud a bloques en un submuestreo e interpolando linealmente el resultado, en (a) el

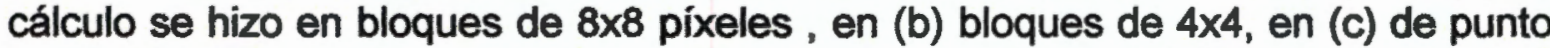
a punto, estos mapas permiten regionalizar el análisis del índice de similitud empleado. Es importante señalar que, conforme disminuye el tamaño del bloque, los mapas tienden a la representación de la IBD mostrada en el inciso (d).
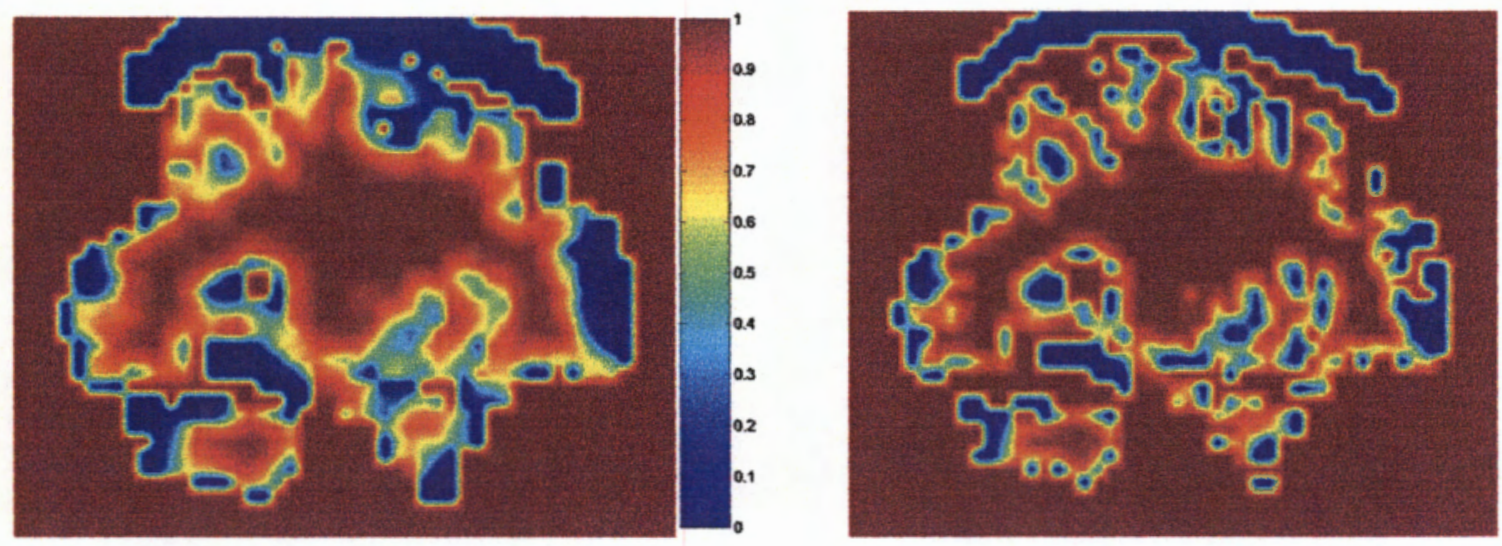

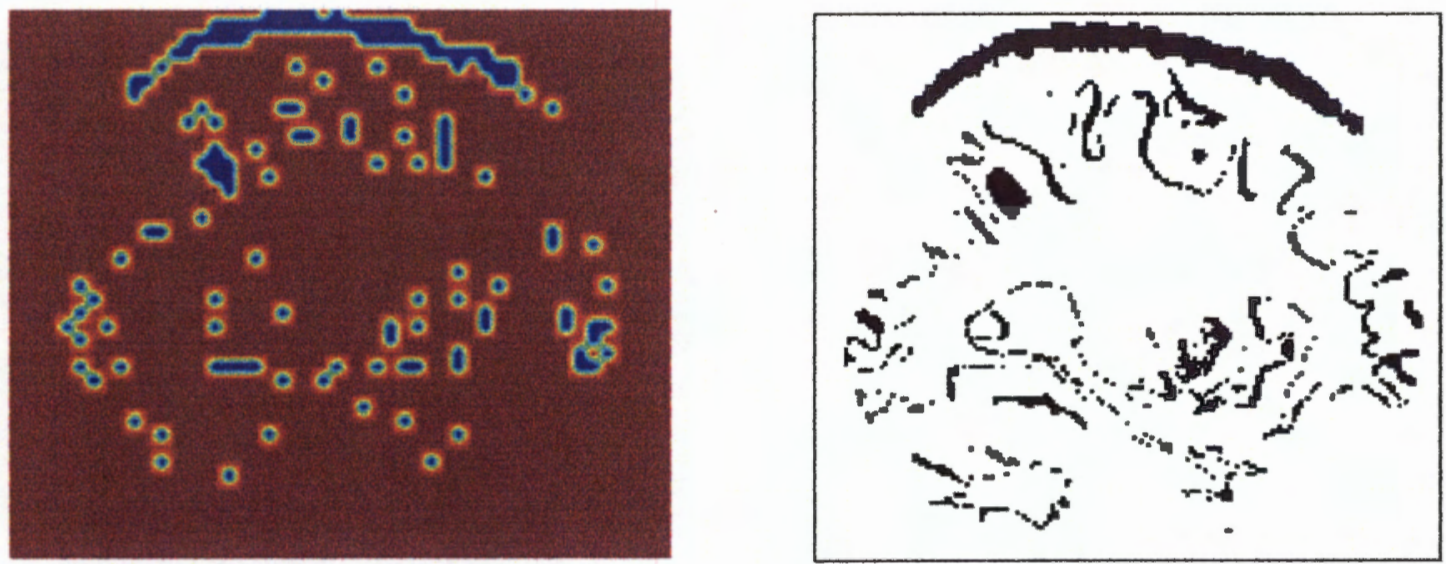

Figura III.25. Mapas de Índice de Tanimoto calculado en diferentes bloques: (a) bloques de $8 \times 8$, (b) bloques de $4 \times 4$, (c) punto a punto, (d) Imagen Binaria Diferencia

El parámetro de evaluación de la convergencia del proceso de optimización del \& CASC, fue la diferencia entre contornos sucesivos, que puede ser un parámetro complementario para el IT, en el caso de comparar entre dos contornos resultantes. Es posible evaluar la distancia media entre los contornos, así como las distancias máxima y mínima para poder interpretar mejor la variación entre contornos. Este segundo parámetro posee una característica de regionalidad en su definición, sólo se observan los contornos resultantes, sin embargo no es sensible a la tendencia de cada uno de los contornos, es decir, su curvatura o la sobre o subestimación de bordes. Una descripción sobre las variaciones de curvatura en cada contorno puede complementar la información que los otros dos parámetros aportan. 


\section{Conclusiones}

Se ha presentado un modelo híbrido de segmentación de imágenes cerebrales multiespectrales de Resonancia Magnética, que combina un modelo de segmentación probabilística basado en una RFBR modificada y un modelo de contornos activos basados en interpolación con splines cúbicos. Se discutieron dos modalidades de la propuesta: un modelo híbrido adaptable o dinámico, y un modelo híbrido no adaptable o estático. Se propuso un método de normalización del espacio de intensidades de las imágenes de RM. Se presentó también una altemativa para mejorar la distribución espacial de los puntos de control del contorno activo. Se han mostrado resultados de evaluación de las diferentes etapas del modelo híbrido, una comparación entre los esquemas no adaptables y adaptable y valoración del desempeño del modelo ante diversas condiciones de ruido y muestreo. Se realizaron pruebas con imágenes simuladas y reales.

Como se mostró en los resultados obtenidos, la calidad del resultado final de la segmentación en el modelo híbrido, es dependiente de la calidad de los resultados parciales de cada una de las etapas del proceso, aún cuando exista una retroalimentación entre ellas. Por lo anterior, vale la pena detenerse en diferentes etapas para hacer comentarios particulares y posteriormente profundizar en los aspectos generales del modelo y de acoplamiento de etapas.

Respecto a la etapa de pre-segmentación, planteado como un caso de clasificación supervisada, la RFBRcc mostró un alto desempeño para las imágenes probadas. La calidad del conjunto de entrenamiento empleado y el refinamiento de la estructura de la red, explican la mejora del desempeño en la clasificación. Durante la fase de definición de la Red, se realizaron pruebas respecto al número de nodos en la capa de estimación, a la reducción de características para los vectores de entrada a la red, a la inclusión de las coordenadas cilíndricas en la capa de estimación y, a la consideración de información multi o monoespectral. La estructura de la RFBRcc con la que se obtuvo el mejor desempeño, permite elaborar una conclusión particular al respecto: la característica multiespectral de las imágenes de RM aporta mejor información para su clasificación que sólo considerar datos monoespectrales. En las pruebas realizadas se observó que las tres características (T1, T2 y DP) son relevantes para la clasificación, resultando las dos primeras como indispensables para lograr tasas elevadas de clasificación correcta.

Por otro lado, el procedimiento de generación de imágenes cerebrales multiespectrales por RM, donde puede definirse una infinidad de protocolos de adquisición, trae consigo la posibilidad de que la estadística de las imágenes nuevas generadas, sea distinta a la de las imágenes de entrenamiento de la Red, por lo que fue necesario proponer una transformación al espacio de intensidades, de tal forma que permitiera mayor generalización del segmentador; sin embargo, si 
el protocolo de adquisición de las imágenes difiere considerablemente del protocolo de referencia, la Red no es capaz de conservar su alta eficiencia de clasificación, por lo que una conclusión particular en este punto es que, para conservar los mas altos indices de desempeño en el segmentador, es necesario que se diseñe la RFBRcc para cada protocolo de adquisición, es importante resaltar que el proceso de normalización que se ha propuesto, resuelve satisfactoriamente el problema de la variación local de parámetros de generación de las imágenes. Por ejemplo, en el caso de las imágenes usadas en esta tesis, se requiere de un diseño para las imágenes reales multiespectrales proporcionadas por el Hospital ABC (T1, T2, FLAIR), y otro diseño para el protocolo ICBM, bajo el cual fueron generadas las imágenes reales provistas por el Instituto Neurológico de Montréal. Variaciones relativamente pequeñas en tiempos de eco y repetición, por mencionar algunos parámetros, dentro de un mismo protocolo, alcanzan a ser compensadas por el proceso de normalización de intensidades.

Respecto a la etapa de los contornos activos, se evaluaron diferentes propuestas

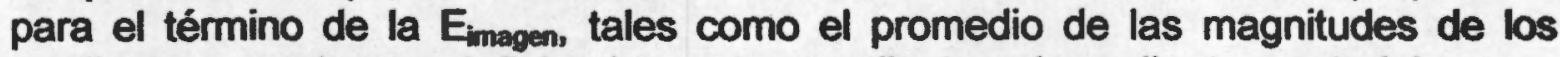
gradientes escalares, el fiujo de vector gradiente, el gradiente vectorial y una operación no lineal sobre la primera de las opciones. La última de las opciones para $E_{\text {magen, recupera la bondad de los resultados de las opciones basadas en }}$ gradiente (localización del borde) y trata de homogeneizar la fuerza de todos los bordes de intensidad media y alta, y en donde se elimina el resto de la información. Sin embargo, este término de $E_{\text {imagen }}$ posee una muy estrecha región de influencia, por lo que es necesario combinarlo con un prototipo de contorno muy cercano a él y combinarlo con términos de restricción, que soporten el proceso de convergencia del contorno activo.

Lo anterior describe el mayor punto de hibridación del modelo propuesto, que integra en la expresión de energía del contorno activo, un término derivado de la RFBRcc. La combinación de este término y la definición de un contorno inicial para el CASC derivado de la RFBRcc, han mostrado que mejoran el desempeño general en la segmentación, como se observa claramente en los ejemplos de segmentación en imágenes reales; en donde, aún cuando el resultado de la Red no es de excelente calidad, el contomo resultante recupera el borde deseado. Una conclusión particular al respecto es que, la combinación de los modelos de présegmentación y del contorno activo mejoran el resultado de la segmentación de las imágenes cerebrales multiespectrales de RM, respecto a los posibles resultados de cada modelo por separado.

Como se ha mencionado anteriormente, la segmentación de imágenes puede representarse como un problema dual entre la segmentación por regiones y la segmentación de los contornos de dichas regiones; por esta razón se supuso que el resultado del modelo de contornos activos podría reforzar al pre-segmentador, proveyéndole de información de calidad en la definición de la frontera entre dos 
clases de tejido, para mejorar su estimación en estas regiones; por otro lado, el ajuste sobre los parámetros del la red le ofrece al modelo de contornos activos una fuerza de restricción de mejor calidad para la siguiente iteración.

Lo anterior describe un lazo de retroalimentación que le da una característica dinámica al acoplamiento RFBRcc-CASC. Los resultados obtenidos mostraron que al paso de las iteraciones, el desempeño del pre-segmentador no se deteriora, que era un riesgo posible al variar los parámetros de la red; sino que, en algunas iteraciones mejora ligeramente.

El mecanismo de adaptación permite hacer ajustes particulares del esquema, ante variaciones especificas, tales como, las diferencias entre imágenes de diferentes sujetos, o imágenes distintas del mismo sujeto.

En un análisis detallado de cada par de contornos resultantes (adaptable vs noadaptable) se observa que en el contomo sin adaptación, se genera una suavización en regiones de alta curvatura, que no se observa en el caso adaptable. Sin embargo, en la evaluación global de la calidad del contorno resultante, no hay evidencia de diferencia estadísticamente significativa. Todo lo anterior, permite concluir que es necesaria la búsqueda de una medida cuantitativa de desempeño de modelos de segmentación, con sensibilidad local que complemente la información global proporcionada por el indice de Tanimoto. Es necesario continuar con la discusión sobre el índice de similitud apropiado para describir resultados comparativos en detección de bordes en imágenes cerebrales. Un parámetro con sensibilidad local permitiria la definición de un criterio inteligente para el proceso de optimización del CASC, que permita medir la calidad del contorno en cada iteración y no sólo saber si ha cambiado respecto a la iteración anterior.

En el modelo propuesto, es la etapa del CASC la que requiere del mayor tiempo de cálculo debido al ajuste iterativo del contorno, que consiste en un conjunto de operaciones que se realizan para cada punto de control de dicho contorno. El número de puntos de control está en función de la imagen y borde buscado, puesto que en el caso de cortes axiales y el borde materias gris y blanca, por ejemplo, en imágenes superiores se encuentran regiones con curvatura media y alta (circunvoluciones) y regiones con curvatura casi cero (línea interhemisférica) por lo que la densidad de puntos es variable aún en la misma imagen; si se observa una imagen baja, se observan regiones con zonas de curvatura muy alta (circunvolución). El número total de puntos de control queda definido por el análisis de curvatura del contorno inicial y por el umbral de curvatura acumulada definido. En la modalidad dinámica del acoplamiento de la RFBRcc-CASC, en cada iteración, es necesario ajustar los parámetros locales de la red además del propio ajuste que los puntos de control del CASC requieren en si mismo, evidentemente, esta retroalimentación incrementa el tiempo de cómputo hasta un $300 \%$ el tiempo de cómputo empleado en la modalidad estática. 
La aplicación del modelo híbrido a la segmentación de otros bordes en las imágenes cerebrales, por ejemplo materia gris con lcr cortical o materia gris con lcr ventricular, es inmediato; basta cambiar las regiones de interés en el proceso de inicialización y en el término de restricción del contorno activo; además de ser equivalente para cualquier plano de visualización. Aún más, el esquema propuesto puede ser ajustado para la segmentación de imágenes multiespectrales, cuya distribución de intensidades presente una geometría similar a la mostrada por las imágenes cerebrales de RM.

La adaptación del modelo híbrido para acoplarse a un modelo de Superficies Activas basadas en una interpolación con Splines Cúbicos (SASC) no parece presentar un problema nuevo. A partir de los modelos de volumen generados por la pre-segmentación de la RFBRcc (Figura III.6), es posible generar un modelo de malla sobre-representada, que se convierte en un buen prototipo para la superficie inicial del modelo SASC. La búsqueda de la superficie óptima bajo este modelo, ya ha sido previamente propuesta y probada en otras imágenes médicas. La implantación de un modelo hibrido con superficies activas, representa un problema para hacer eficiente el uso de recursos computacionales. 
[18]Y. Ge, M. Fitzpatrick, B. Dawant, J. Bao, R.M. Kessler and R.A. Margolin. Accurate Localization of Cortical Convolutions in MR Brain Images. IEEE Trans. Med. Imag. Vol 15. pp. 418-428. Aug 1996.

[19]D.M. Hadley. Neuroimaging of Disease: Anatomical and Functional, in Syllabus ISMRMESMRMB Joint Annual Meeting. Glasgow, UK. pp.483-487. 2001

[20]G. Harikumar and Y. Bresler. Feature Extraction Techniques for Exploratory Visualization of Vector-Valued Imagery. IEEE Trans. Image Processing. Vol 5. pp. 1324-1334. Sep 1996.

[21] International Consortium of Brain Mapping (ICBM), URL: wnw.loni.ucla.edu/lCBM/index.html

[22]J. R. Jiménez A., V. Medina B., O. Yáñez S., Non-parametric density gradient estimation for segmentation of cerebral MRI, 24th International Congress of the IEEE-EMBS, Houston TX,

[23]T. Kapur, W.E.L. Grimson and R. Kikinis. Segmentation of Brain Tissue from MR Images. Proc. of the First International Conference on Computer Vision, Virtual Reality and Robotics in Medicine. Nice, France. 1995.

[24]M. Kass, A. Witkin and D. Terzopoulos. Snakes: Active contour models. Proc. $1^{\star *}$ International Conf. Computer Vision. 1:259-268. 1987.

[25]S. Lobregt and M. Viergever. A Discrete Dynamic Contour Model. IEEE Trans. Med. Imag. Vol 14.pp 12-24. Jan 1995.

[26]Lundervold and F. Godtliebsen. Noise reduction and Brain Classification in MR images. Proc. of IEEE Nuclear Science Symposium and Medical Imaging Conference. Florida, USA. pp. 1265-1267. 1992.

[27] Lundervold and G. Storvik. Segmentation of Brain Parenchyma and Cerebrospinal Fluid in Multispectral Magnetic Resonance Imaging. IEEE Trans. Med. Imag. Vol 14.pp. 339-349 Jun 1995.

[28]R. Malladi, J.A. Sethian and B.C. Vemury. Shape Modelling with front propagation: A level Set Approach. IEEE Trans. Pattern Anal. Machine Intell. Vol 17. Pp.158-175, Feb 1995.

[29]K.R. Maravilla and B.C. Bowen. MR Imaging of the Peripheral Nervous System in Syllabus ISMRM-ESMRMB Joint Annual Meeting. Glasgow, UK. pp.24-31. 2001.

[30]Marin-Hernandez and H.Rios-Figueroa. Eels:Electric Snakes. Computación y Sistemas. Vol. 2(2-3), pp. 87-94. 1999.

[31]Massachusetts General Hospital, Center for Morphometric Analysis. Internet Brain Segmentation Repository, URL: neuro-www.mgh.harvard.edu/cma/ibsr

[32]T. Masters. Advanced Algorithms for Neural Networks. A C++ sourcebook. USA, John Wiley \& Sons. 1995. pp.83:102.

[33]T. Mclnerney and D. Terzopoulos. Deformable Models in Medical Image Analysis: A Survey. Medical Image Analysis, Vol. 1. pp. 91-108. 1996.

[34]T. Mclnerney and D. Terzopoulos, Topology Adaptive Deformable Surfaces for Medical Image Volume Segmentation. IEEE Trans. on Medical Imaging. Vol 18(10). 1999. 
[35]V. Medina, R. Valdés-C, O. Yañez-S, M. Garza, J.F. Lerallut. Automatic initialization for a snakes-based cardiac contour extraction. Proc. $22^{\text {nd }}$ Annual int. Conference of the IEEE EMBS, Chicago, July 23-28, 2000.

[36]L.C. Meiners. MRI in epilepsy in Syllabus ISMRM-ESMRMB Joint Annual Meeting. Glasgow, UK pp.111-118. 2001.

[37]M. Ozkan, B. Dawant and R. Maciunas. Neural-Network-Based Segmentation of multimodal medical images: A comparative and Prospective study. IEEE Trans. Med. Imag. Vol 12.pp. 534-544 Sep 1993.

[38] J. Rajapakse, J.N. Giedd and J.L. Rapoport. Statistical Approach to Segmentation of Single-Channel Cerebral MR Images. IEEE Trans. Med. Imag. Vol 16, pp. 176-186. Apr 1997.

[39]W.E. Reddick, J.O. Glass, E.N. Cook, T.D. Elkin and R.J. Deaton, "Automated segmentation and classification of multispectral magnetic resonance images of brain using artificial neural networks", IEEE Trans. Med. Imag., 16, pp. 911-918, 1997

[40]J. Talairach and P. Toumoux. Coplanar Stereotaxic Atlas of the Human Brain. New York: Thieme Medical. 1988.

[41]H. Tek, D. Comaniciu and J.P. Williams. Vessel detection by mean shift-based ray propagation. Proc 2001 IEEE Computer Society Conference on CVPR. Hawaii, USA. 2001.

[42]S. Theodoridis and K. Koutroumbas. Pattern Recognition. San Diego, CA. Academic Press. 1999. pp.366

[43]R. Valdes, O. Yanez-Suarez, V. Medina. Trachea Segmentation in CT Images using Active Contours. Proc. $22^{\text {nd }}$ Annual Int. Conference of the IEEE EMBS, Chicago, July 23-28, 2000.

[44]R. Valdes and O. Yanez-Suarez, Superficies Activas con Splines Cúbicos para Segmentación Semi-Automática de Tráquea. II Congreso Latinoamericano de Ingenieria Biomédica. La Habana, Cuba. Mayo, 2001.

[45]R. Valdes, V. Medina and O. Yañez-Suarez. Adaptive RBF Network with Active Contour Coupling for Multispectral MRI Segmentation. Medical Imaging 2002: Image Processing, Milan Sonka, J. Michael Fitzpatrick, Editors, Proc. SPIE Vol 4684(2002). pp. 1610-1621. 2002.

[46]R. Valdes-Cristerna and O. Yañez-Suárez. Active Contours and Surfaces with Cubic Splines for Semiautomatic Tracheal Segmentation. Journal of Electronic Imaging. Vol. 12(1), pp. 81-96, Jan 2003.

[47]P. Valizadeh and $H$. Soltanian-Zadeh. A clustering guided deformable model for MRI segmentation. In Medical Imaging 2000: Image Processing, Kenneth Hanson, editor, Proc. SPIE Vol. 3979(2000). pp. 1528-1537. 2000.

[48]J. Valk and M.S. van der Knaap. Pediatric White Matter Disorders and Magnetic Resonance, in Syllabus ISMRM-ESMRMB Joint Annual Meeting. Glasgow, UK pp.147151. 2001

[49]M.A. Van Buchem. Rule out disease-reflections on a screening protocol in Syllabus ISMRM-ESMRMB Joint Annual Meeting. Denver, USA. 2000. pp: 1-5.

[50]F. Velasco, Determinación de Contornos Empleando Contornos Activos Paramétricos. PhD Thesis. Centro de Investigación en Matemáticas AC. Mexico. 1999. 
[51]F.W. Wehrli and R.L. Wolf. Pulse Sequences in Neuro MR:the Essentials in Syllabus ISMRM-ESMRMB Joint Annual Meeting. Glasgow, UK. pp.1-12. 2001

[52]W.M. Wells, W.E.L. Grimson, R. Kikinis and F.A. Jolesz, "Adaptive segmentation of MRI data", IEEE Trans. Med. Imag., 15, pp. 429-442, 1996

[53]Westbrook and C. Kaut. MRI in practice. Blackwell Science. UK. pp. 111-115. 1993.

[54]Ch. Xu and J.L. Prince. Snakes, Shapes and Gradient Vector Flow. IEEE Trans. Med. Imag. Vol. 7. pp. 359-369. March 1998.

[55]Ch. Xu, D. Pham, M.E. Rettman, D.N. Yu and J.L. Prince. Reconstruction of the Human Cerebral Cortex from MR Images. IEEE Trans. Med. Imag. Vol 18. pp. 467-480. June 1999.

[56]O. Yanez-Suarez, R. Valdes, V. Medina and F. Barrios. RBF network with cylindrical coordinate features for Multispectral MRI segmentation. In Medical Imaging 2001: Image Processing, Milan Sonka, Kenneth Hanson, Editors. Proc. SPIE Vol. 4322(2001). pp. 13031310. 2001

[57] Yezzi, S. Kichenassamy, A. Kumar, P.Olver and A. Tannenbaum. A Geometric Snake Model for Segmentation of medical imagery. IEEE Trans. Med. Imag. Vol 16. pp. 199-209. Apr 1997

[58]A. P. Zijdenbos, B.M, Dawant, R.A. Margolin and A.C. Palmer. Morphometric Analysis of White Matter Lesions in MR Images: Method and Validation. IEEE Trans. Med. Imag. Vol 13. pp. 716-724. Dec. 1994 


\section{Índice de Figuras}

Figura 1.1. (a) Sección horizontal a través de los hemisferios cerebrales pasando a través de la comisura anterior y el crus cerebri [Adaptado de Carpenter, pp. 31] (b) Mapa funcional segín el atlas de Tailarach (c) Lámina 121 que corresponde al corte mostrado en (a) [Adaptado de Talairach, pag. 15, 101]

Figura II.1. Esquema general de la metodologia propuesta para la segmentación híbrida de imágenes cerebrales multiespectrales de Resonancia Magnética (IMRM).

Figura II.2. Normalización de intensidades: (a) muestra de imágenes multiespectrales de los cuatro estudios simulados, (b) distribución de intensidades en estudios multiespectrales de RM. Se muestran vectores de materia gris, materia blanca y lcr. En negro el estudio de referencia, en gris claro un estudio de prueba.

Figura II.3. Distribución de intensidades normalizadas para las clases materia blanca (mb), fondo (f), materia gris (mg). liquido cefalorraquídeo (Icr), hueso (h) y piel-grasa (p) del estudio III.

Figura II.4. Estructura general de una Red con Funciones de Base Radial. En las funciones de la capa oculta a y b son parámetros predefinidos. El nodo de salida es un perceptrón.

Figura 11.5. Estructura final de la RFBRcc. $q 1, q 2, q 3$ : características de intensidad normalizada de la imagen multiespectral de RM, r y z: coordenadas cilíndricas del voxel; fi, i-ésima función de base radial; Sxx, perceptrón correspondiente (clases materia blanca, fondo, materia gris, líquido cefalorraquídeo, piel-grasa y hueso).

22

Figura II.6. Inicialización del modelo de contomos activos: (a) imagen binaria obtenida de la clasificación de materia blanca con la RFBRcc, (b) regiones separadas y etiquetadas, (c) contomo de las dos regiones mayores de (b), graficado sobre la imagen T2 original.

Figura II.7. Remuestreo de puntos: (a) conjunto original de puntos de control y contorno interpolado con espaciamiento regular, (b) muestra de puntos del contorno interpolado, (c) conjunto ordenado y reducido de puntos de control, (d) conjunto final ordenado e interpolado.

Figura II.8. Términos de $E_{\text {mmegen: }}(a)$ promedio de gradientes escalares, (b) gradiente multiespectral, (c) magnitud del Flujo del Vector Gradiente del término mostrado en (a)

Figura II.9. Término de Eimagen modificado: (a) Eimagen, (b) dirección del campo de fuerza asociado en paleta de colores inversa.

Figura II.10. Fuerza de restricción: (a) mapa discriminante de materia gris suavizado, (b) dirección del campo gradiente de fuerza asociado, en paleta de colores inversa.

Figura II.11. Ambigūedad de la RNFBRcc

Figura II.12. Esquema del acoplamiento dinámico entre la RFBRcc y el CASC

Figura II.13. Evaluación del desempeño del modelo: (a) imagen Binaria de Referencia (IBR) (b) imagen Binaria Diferencia (IBD=xor(IBR,IBC)) (c) imagen Binaria Calculada (IBC) 
Figura II.14. Relación lineal entre los indices de similitud más frecuentemente usado en la segmentación de imágenes cerebrales.

Figura III-1. Resultados del registro de cuatro volúmenes de imágenes reales. Primera columna muestra la imagen de referencia, la tercera columna muestra la imagen objetivo y en la segunda columna se muestra la imagen transformada.

42

Figura III-2. Espacio normalizado de intensidades. Se muestran vectores de materia gris, materia blanca y lcr. En negro el estudio de referencia (estudio I), en gris claro el estudio III.

42

Figura III.3. Imagen Segmentada del Estudio IV, para cuatro clases: materia blanca, materia gris, Icr y fondo: (a) sin normalización, clases fondo y materia blanca, (b) imagen multiespectral normalizada.

43

Figura III.4. Resultado de la pre-segmentación: (a) imágenes T1, T2 y DP, de izquierda a derecha, abajo imágenes en espacio de intensidades normalizado (b) mapas discriminantes: materia blanca, fondo y materia gris, en el segundo renglón: líquido cefalorraquideo, piellgrasa y hueso, (c) imagen segmentada considerando la máxima probabilidad posterior. en blanco se muestra la clase Icr, en gris claro se muestra la materia gris, en gris oscuro se muestra la clase fondo, y en negro se muestra la clase materia blanca.

46

Figura III.5. Vistas del volumen segmentado: (a) planos de corte (b) axial (c) coronal (d) sagital.47

Figura III.6. Representación volumétrica de algunas estructuras cerebrales segmentadas con la RFBRcc: (a) materia gris (b) materia blanca (c) ventrículos cerebrales

48

Figura III-7. Desempeño de la RFBRcc bajo diversas condiciones de ruido aditivo gaussiano. Matrices de confusión para: $(a, b)$ contaminación en intensidad $(c, d)$ contaminación en intensidad y coordenadas cilíndricas; (e-g) contaminación en coordenadas cilíndricas; (h) diferentes varianzas de ruido para intensidad y coordenadas cilíndricas.

Figura III.8. Imágenes T2 de prueba del Estudio II: (a) imágenes bajas (b) imágenes media-bajas (c) imágenes media-altas (d) imágenes superiores

Figura III.9. Contorno inicial: (a) imagen binaria dilatada de la clase materia blanca, en rojo se muestra el contomo inicial obtenido, (b) imagen T2 con contornos iniciales manual (verde) y semi-automático (rojo), (c) contomo semi-automático para cuatro regiones con área significativa.

Figura III.10. Combinación lineal de las magnitudes de los gradientes multiespectrales: (a) contorno resultante obtenido con el termino propuesto de $E_{\text {meon }}$, (b-d) magnitud del gradiente para las imágenes T1, T2 y DP respectivamente, (e) región de interés que muestra la naturaleza desordenada del campo de fuerza del término $E_{\text {immonen }}$. IT medio: $0.70 \pm 0.07$

Figura III.11. Gradiente multiespectral: (a) magnitud del gradiente multiespectral, (b) contomo resultante. IT medio: $0.70 \pm 0.07$

Figura III.12. Flujo del Vector Gradiente [54]: (a) contorno resultante, (b) logaritmo de la magnitud del Campo del Flujo del Vector Gradiente, paleta inversa de grises, (c) dirección del Campo del Flujo del Vector Gradiente para una región de interés. IT medio: $0.66 \pm 0.088$

Figura III.13. Efecto del umbral en el ordenamiento de puntos de control del contorno: (a) variación del indice de Tanimoto respecto a la variación en el umbral (b) efecto del umbral en la reducción de puntos de control, se muestra una relación porcentual respecto al número de puntos de la muestra original. 
Figura III.14. Efecto del umbral en el ordenamiento de puntos de control del contorno para una imagen de prueba, se muestra la banda $\mathrm{T} 1$ : (a) umbral $=0.25$ (b) umbral $=0.50$ (c) umbral $=$ 0.75 .

Figura III-15. Efecto del muestreo de puntos de control del contorno para una imagen de prueba, se muestra la banda T1: (a) muestreo regular (b) muestreo según curvatura del contomo 58

Figura III-16. Resultados en el esquema adaptable: (a) y (c) contornos resultantes (b) y (d) imegen binaria diferencia para los contorno de los modelos adaptable y sin adaptar.

Figura III-17. Resultados del modelo híbrido de segmentación: (a) contornos resultantes, en blanco el contomo del modelo sin adaptación, en negro el contorno del modelo adaptable (b) imagen binaria diferencia entre los contornos resultantes.

Figura III.18. Desempeño del modelo propuesto respecto a ruido gaussiano aditivo: (a) índice promedio de Tanimoto, b) razón promedio del índice de Tanimoto. En triángulo se muestra la serie de resultados del modelo sin adaptar, en diamante se muestra la serie de resultados del modelo adaptable c) ejemplo de imagen $\mathrm{T} 2$ con varianza de ruido de $\$ 2=0.10$, en blanco se muestra el resultado en un ambiente sin ruido, en negro se muestra el resultado del modelo adaptable con ruido.

61

Figura III.19. Segmentación de otras estructuras: (a) imagen multiespectral en vista sagital, de izquierda a derecha se muestra T1, T2 y DP, (b) mapas discriminantes para cuatro clases de interés, (c) imagen pre-segmentada, fusionando en la clase fondo, los voxeles de hueso y de piellgrasa.

Figura III.20. Contornos resultantes en imagen sagital: (a) contornos para materia blanca y ventrículo, (c) acercamiento a la región ventricular

Figura III.21. Regiones de muestreo de vectores característicos: (a) muestras 1-4, (b) distribución de características de las cuatro muestras y el conjunto completo, (c) distribución de características de las cuatro muestras y el conjunto completo para un volumen simulado (en azul, toda la muestra, en rojo región marcada en la muestra 1, en azul claro, región marcada en la muestra 2, en negro región marcada en muestra 3 y en verde región marcada en la muestra 4).

Figura III.22. Imágenes Simulada y Real Pre-segmentadas: (a) imagen simulada segmentada con la red original, (b) imagen simulada segmentada con la red re-entrenada para protocolo ICBM (c) imagen real segmentada con la red original, (d) imagen real segmentada con la red re-entrenada para protocolo ICBM

Figura Ill.23. Ejemplo de pre-segmentación de RII: (a) mapas discriminantes, (b) imagen etiquetada de acuerdo al máximo valor en discriminantes; las clases piel/grasa, hueso y fondo se fusionaron.

Figura III.24. Ejemplo de contomos inicial y resultantes: (a) contorno inicial (1223 puntos), (b) contomo inicial remuestreado (1067 puntos), IT=0.975 entre (a) y (b), (c) mapa de Energía de la imagen, (d) término de restricción, (e) contomo resultante de la RFBRcc-CASC estático, en rojo se muestra el contomo resultante y en verde se muestra el contomo inicial (f) Contomo resultante de la RFBRCc-CASC dinámico, en rojo se muestra el contorno resultante y en verde se muestra el contomo inicial, (g) IBD entre los resultados estáticos y dinámicos, se han superpuesto los contomos resultantes.

Figura III.25. Mapas de Indice de Tanimoto calculado en diferentes bloques: (a) bloques de 8x8, (b) bloques de $4 \times 4$, (c) punto a punto, (d) Imagen Binaria Diferencia 


\section{Índice de Tablas}

Tabla II-1. Parámetros para la generación de Volúmenes de Imágenes Multiespectrales do Resonancia Magnética según el simulador del Instituto de Neurología de McGill. 14

Tabla II-2. Parámetros de adquisición de estudios reales bajo el protocolo ICBM [ICBM] 15

Tabla II-3. Proporción de clases en el conjunto para entrenamiento y validación de la RFBRcc.22

Tabla III-1. Precisión de parámetros de la transformación global para registro de imágenes

Tabla III-2. Valores del loglikelihood para los estudios de prueba

Tabla III-3. Coeficientes de correlación entre las intensidades T1, T2 y DP del conjunto de vectores de entrenamiento.

Tabla III-4. Matriz de confusión para la RFBR mostrada en la Figura II-5. Los valores representan puntos porcentuales

Tabla III-5. Indices de Tanimoto obtenidos por diversos métodos en la segmentación de imágenes cerebrales

Tabla III-6. Indices de Tanimoto obtenidos por diferentes métodos en la segmentación de las imágenes de prueba, "indice después de eliminar manualmente espacio extra-meningeo 70 


\section{Apéndice A. Parámetros del Modelo Híbrido}

\section{A-l. Parámetros de la Red de Funciones de Base Radial Modificada}

\section{A-1.1. Capa oculta de la RFBRcc}

\begin{tabular}{|c|c|c|c|c|c|}
\hline nodo & $\mu$ & & & $\Sigma$ & \\
\hline 1 & {$\left[\begin{array}{ll}0.0271 & -0.0424\end{array}\right.$} & $-0.0004]$ & $\begin{array}{l}0.0262 \\
0.0014 \\
0.0001 \\
\end{array}$ & $\begin{array}{l}0.0014 \\
0.0028 \\
0.0000\end{array}$ & $\begin{array}{l}0.0001 \\
0.0000 \\
0.0021]\end{array}$ \\
\hline 2 & {$\left[\begin{array}{ll}-0.2919 & 0.0492\end{array}\right.$} & 0.00131 & $\begin{array}{r}0.0141 \\
-0.0017 \\
0.0000\end{array}$ & $\begin{array}{r}-0.0017 \\
0.0076 \\
0.0002\end{array}$ & $\begin{array}{l}0.0000 \\
0.0002 \\
0.0021]\end{array}$ \\
\hline 3 & {$\left[\begin{array}{lll}0.1907 & -0.0171\end{array}\right.$} & $0.0014]$ & {$\left[\begin{array}{l}0.0191 \\
0.0064 \\
0.0000\end{array}\right.$} & $\begin{array}{r}0.0064 \\
0.0040 \\
-0.0000\end{array}$ & $\begin{array}{c}0.0000 \\
-0.0000 \\
0.0022\end{array}$ \\
\hline 4 & {$\left[\begin{array}{ll}0.3862 & 0.0404\end{array}\right.$} & $-0.0006]$ & $\begin{array}{r}0.0026 \\
-0.0002 \\
0.0001\end{array}$ & $\begin{array}{l}-0.0002 \\
0.0023 \\
0.0000\end{array}$ & $\begin{array}{l}0.0001 \\
0.0000 \\
0.00211\end{array}$ \\
\hline 5 & $10.4086-0.0162$ & $-0.0016]$ & $\begin{array}{r}0.0125 \\
-0.0068 \\
0.0000\end{array}$ & $\begin{array}{l}-0.0088 \\
0.0092 \\
0.0001\end{array}$ & $\begin{array}{l}0.0000 \\
0.0001 \\
0.0021\end{array}$ \\
\hline 6 & $1-0.4553$ & $0.0081]$ & $\begin{array}{r}1.0 \mathrm{e}-003 \\
{[0.1529} \\
-0.2571 \\
-0.0052\end{array}$ & $\begin{array}{r}-0.2571 \\
0.4767 \\
0.0097\end{array}$ & $\begin{array}{c}-0.0052 \\
0.0097 \\
0.0080\end{array}$ \\
\hline 7 & {$\left[\begin{array}{ll}1-0.4144 & 1.3526\end{array}\right.$} & $0.0063]$ & 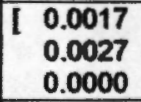 & $\begin{array}{l}0.0027 \\
0.0554 \\
0.0003\end{array}$ & $\begin{array}{l}0.0000 \\
0.0003 \\
0.0014]\end{array}$ \\
\hline 8 & {$\left[\begin{array}{ll}-0.4254 & 0.4222\end{array}\right.$} & $0.0024]$ & $\begin{array}{l}10.0026 \\
0.0047 \\
0.0001\end{array}$ & $\begin{array}{l}0.0047 \\
0.0756 \\
0.0003\end{array}$ & $\begin{array}{l}0.0001 \\
0.0003 \\
0.0021]\end{array}$ \\
\hline 9 & {$\left[\begin{array}{ll}-0.4225 & -0.0093\end{array}\right.$} & -0.00061 & 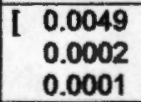 & $\begin{array}{r}0.0002 \\
0.0031 \\
-0.0001\end{array}$ & $\begin{array}{c}0.0001 \\
-0.0001 \\
0.0021\end{array}$ \\
\hline 10 & {$\left[\begin{array}{ll}0.0344 & 0.0441\end{array}\right.$} & $0.0003]$ & $\begin{array}{rr} & 0.0269 \\
0.0003 \\
-0.0000\end{array}$ & $\begin{array}{l}0.0003 \\
0.0083 \\
0.0000\end{array}$ & $\begin{array}{l}-0.0000 \\
0.0000 \\
0.0021]\end{array}$ \\
\hline 11 & {$[0.8461=0.4032$} & 0.00091 & $\begin{array}{r}0.0187 \\
-0.0141 \\
-0.0006\end{array}$ & $\begin{array}{r}-0.0141 \\
0.0145 \\
0.0005\end{array}$ & $\begin{array}{l}-0.0006 \\
0.0005 \\
0.0020\end{array}$ \\
\hline 12 & {$\left[\begin{array}{ll}0.0693 & 0.0367\end{array}\right.$} & $0.0002]$ & \begin{tabular}{|l|}
0.0196 \\
0.0009 \\
0.0000 \\
\end{tabular} & $\begin{array}{l}0.0009 \\
0.0084 \\
0.0000\end{array}$ & $\begin{array}{l}0.0000 \\
0.0000 \\
0.0021\end{array}$ \\
\hline 13 & {$\left[\begin{array}{ll}0.1530 & 0.0811\end{array}\right.$} & $0.0004]$ & $\begin{array}{r}0.0445 \\
-0.0120 \\
-0.0005\end{array}$ & $\begin{array}{r}-0.0120 \\
0.0097 \\
0.0002 \\
\end{array}$ & $\begin{array}{c}-0.0005 \\
0.0002 \\
0.0021]\end{array}$ \\
\hline
\end{tabular}

\section{A-1.2. Pesos de la Capa de Salida de la RFBRcc}

\begin{tabular}{|l|c|}
\hline nodo & Vector de pesos \\
\hline $\mathrm{mb}$ & {$[0.44,-0.36,0.25,1.18,-0.34,0.27,-0.24,-0.40,-0.35,0.15,-0.29,-1.96,1.41,0.13,-0.93,-0.38]$} \\
\hline $\mathrm{I}$ & {$[-0.09,-0.11,0.06,0.06,-0.10,1.41,0.96,-0.29,0.11,-0.17,-0.33,0.24,-0.19,0.17,0.76,-1.40]$} \\
\hline $\mathrm{mg}$ & {$[1.12,-0.36,0.46,0.05,0.18,-0.13,-0.54,-0.54,-0.27,-0.89,-0.62,2.91,-1.79,-0.002,-0.20,-0.58]$} \\
\hline $\mathrm{lcr}$ & {$[0.07,1.08,-0.29,-0.16,-0.26,0.06,-0.48,0.57,1.58,-0.02,-0.55,-0.52,-0.05,0.01,-0.61,-0.38]$} \\
\hline $\mathrm{h}$ & {$[-1.02,-0.52,0.21,-0.16,-0.02,-0.51,1.79,0.05,-0.60,-0.46,-0.89,0.93,-0.96,-0.12,-0.39,-0.26]$} \\
\hline $\mathrm{P}$ & {$[-0.67,0.54,-0.62,-0.10,-1.03,-0.46,-0.68,125,-0.44,2.48,3.21,-1.94,1.07,-0.08,0.53,-0.93]$} \\
\hline
\end{tabular}




\section{A-ll. Parámetros del Contorno Activo con Splines Cúbicos}

\begin{tabular}{|c|c|c|c|c|c|c|c|c|c|c|c|c|}
\hline Parámetro & $\alpha$ & $\boldsymbol{\beta}$ & $\boldsymbol{\gamma}$ & $\gamma_{\mathrm{mb}}$ & $\gamma_{\mathrm{f}}$ & $\gamma_{\mathrm{mg}}$ & $\gamma_{\mathrm{l}}$ & $\boldsymbol{\mu}$ & $\begin{array}{c}\text { No. de } \\
\text { iteraciones }\end{array}$ & $\begin{array}{c}\text { Umbral } \\
\text { de } \\
\text { curvatura }\end{array}$ & $\begin{array}{c}\text { Umbrales } \\
\text { de Intensidad } \\
\text { de bordes }\end{array}$ & $\boldsymbol{\eta}$ \\
\hline valor & 10 & 10 & 50 & 2 & 2 & 50 & 2 & 0.025 & 1500 & 0.15 & {$[0.035,0.075$} & $0.010-07$ \\
\hline
\end{tabular}




\section{Apéndice B. Publicaciones}

1. R. Valdes-Cristerna and O. Yañez-Suárez. Active Contours and Surfaces with Cubic Splines for Semiautomatic Tracheal Segmentation. Journal of Electronic Imaging. Vol. 12(1), pp. 81-96, Jan 2003.

2. O. Yanez-Suarez, R. Valdes, V. Medina and F. Barrios. RBF network with cylindrical coordinate features for Multispectral MRI segmentation. In Medical Imaging 2001: Image Processing, Milan Sonka, Kenneth Hanson, Editors. Proc. SPIE Vol. 4322(2001). pp. 1303-1310. 2001

3. R. Valdes, V. Medina and O. Yañez-Suarez. Adaptive RBF Network with Active Contour Coupling for Multispectral MRI Segmentation. Medical Imaging 2002: Image Processing, Milan Sonka, J. Michael Fitzpatrick, Editors, Proc. SPIE Vol 4684(2002). pp. 1610-1621. 2002.

4. R. Valdes, V. Medina and O. Yañez-Suarez. Coupling of Radial Basis Network and Active Contour Model for Multiespectral Brain MRI Segmentation. IEEE Transactions on Biomedical Engineering. Aceptado para publicación.

5. R. Valdes, V. Medina and O. Yañez-Suarez. Eigenspace Normalization of Multi-spectral Magnetic Resonance Images. $25^{\text {th }}$ Annual Int. Conference of the IEEE EMBS, Cancun, September 17-21, 2003. 